University of Rhode Island

DigitalCommons@URI

Open Access Master's Theses

1996

\title{
Community-Based Economic Impact Planning for a Low-Level Radioactive Waste Disposal Facility
}

David Patton Gilmour

University of Rhode Island

Follow this and additional works at: https://digitalcommons.uri.edu/theses

\section{Recommended Citation}

Gilmour, David Patton, "Community-Based Economic Impact Planning for a Low-Level Radioactive Waste Disposal Facility" (1996). Open Access Master's Theses. Paper 711.

https://digitalcommons.uri.edu/theses/711

This Thesis is brought to you for free and open access by DigitalCommons@URI. It has been accepted for inclusion in Open Access Master's Theses by an authorized administrator of DigitalCommons@URI. For more information, please contact digitalcommons-group@uri.edu. 


\section{Community-Based Economic Impact Planning for a Low-Level Radioactive Waste Disposal Facility}

By

David Patton Gilmour

A Research Project Submitted in

Partial Fulfillment of the Requirements

for the Degree and Master of

Community Planning

University of Rhode Island

1996 


\section{Master of Community Planning \\ Research Project \\ of \\ David P. Gilmour}

Approved:

Major Professor

Dr. Howard H. Foster, Jr.

Acknowledged:

Director

Dr. Farhad Attash 


\section{Abstract}

This monograph discusses the assessment of social and economic impacts for a Low-Level Radioactive Waste (LLRW) disposal facility siting. It examines how to maximize the possibility of locating a host site by actively involving stakeholders to obtain their input on site design. To realize a siting stakeholders may require extensive information sharing and education about the proposed land use. Negotiation and use of incentive can also be useful for developing optimal policy and generating opinion in favor of a siting.

LLRW is relatively benign nuclear refuse produced in power generation, medicine, high-tech industry, and research. Compared with high-level radioactive waste that consists of large concentrations of hazardous isotopes with long half-lives, LLRW usually consists of low concentrations of short half-life isotopes (100 years or less). Federal health and safety policy mandates that states must develop facilities to dispose of LLRW. Massachusetts has established grants for municipalities to voluntarily evaluate whether this type of land use will convey positive economic impacts. If a majority of residents vote in favor of a siting, and the required approvals are received, many incentives and subsidies will be awarded to compensate a community for hosting a LLRW facility.

With limited resources, how should a community structure a process to assess potential economic impacts from a LLRW disposal facility? To establish evaluation criteria it is important to examine relationships between social and economic impacts. The two are related and there may be a tendency to inadequately consider the former.

Community-based economic impact deliberations promote familiarity with nuclear science and the avoidance of potential problems. Such evaluations can also be useful for addressing fears and building popular management policy. Residents can provide valuable insights on defining 
impacts, planning policy, conducting oversight, and implementing policy. Residents can also aid outside experts by identifying critical uncertainties in existing plans. Community residents have a good sense of how a specific land use could effect local culture.

A matrix is presented showing economic impacts that residents could consider when deciding whether to host a facility. Discussion covers short-term impacts that occur at the commencement of the siting; it also examines more intangible impacts, such as ones that have a remote probability of occurring, or which are long-range in nature, but which should be considered because the effects are uncertain, could occur over a large area, or with a significant degree of risk.

Cases are reviewed to show how socio-political factors relate to the structure and content of similar dialogues. Finally, suggestions are provided on how a Community Supervisory Committee (CSC) could successfully design a process to comprehensively evaluate the economic impacts that may arise from hosting a LLRW disposal facility. The process is in many ways a capacity building exercise involving two-way knowledge transfer. Success in this case is defined as the ability to predict and mitigate against adverse impacts, especially to groups traditionally excluded or underserved. Success is also defined by the ability to spur positive impacts and enable development of a necessary regional facility, by establishing financing mechanisms and management plans that are widely accepted as legitimate. 


\section{Dedication}

At U.R.I. CPAD gracious thanks go to the readers who assisted with this manuscript:

$\begin{array}{ll} & \text { Dr. Howard H. Foster, Jr. } \\ \text { David Westcott } \\ \text { Denise DeSautels }\end{array}$

I appreciate your expertise and commitment to the field. Your thoughts in, and from, the margins were insightful. Thanks also to Dr. Feldman, Dr. Feld and Dr. Atash. Dr. Cynthia Hamilton's influence regarding urban issues and diaspora must also be prominently noted.

The continued interest of family and friends has also been noteworthy. I especially appreciate the compassion and support from my truest love Liz. Thank you for putting up with the marathon push to finalize this monster!

To set the tone, I use Havel's (1991: 362) comments regarding Farce, Reformability and the Future of the World:

The way I see it, the only possible alternative for us is not to worry about ideological nonissues, but instead to make practical efforts - here and now, whatever we are doing, and wherever we are - to change things for the better, to try to win more freedom, more respect for human dignity, to work for an economy that functions better, less destruction of the earth, government by more sensible politicians, the right to speak the truth - and finally, to ensure that people do not lose hope when confronted by the truth, but instead try to draw the practical lessons from it. 


\section{Table of Contents}

\section{Community-Based Economic Impact Planning for a Low-Level Radioactive Waste Disposal Facility}

1. Introduction and Overview 1

$\begin{array}{lr}\text { Subject To Be Addressed } & 1\end{array}$

$\begin{array}{lr}\text { Problem Delineation } & 4\end{array}$

$\begin{array}{lr}\text { Objectives of the Study } & 7\end{array}$

Significance of the Subject 9

Major Questions, Policy Issues, and Hypothesis to be Addressed in the Project

Procedures and Methods of Anahsis Employed in Carrying Out 16 the Project

Specifications of the Data or Information to be Used in Analysis 17

$\begin{array}{lr}\text { Conclusion } & 18\end{array}$

2. Administration of the Low-Level Radioactive Waste Management Act

$\begin{array}{ll}\text { Description of the Existing Environment } & 20\end{array}$

$\begin{array}{ll}\text { Six Phases of the LLRW Management Act } & 27\end{array}$

Siting a LLRW Facility In Massachusetts $\quad 36$

$\begin{array}{ll}\text { Volunteered Site Program } & 38\end{array}$

$\begin{array}{lll}\text { Conclusion } & 41\end{array}$ 
3. Characteristics of LLRW Production and

Disposal

Defining Radiation and Characterizing LLRW

How Radiation Affects Living Systems / Humans

Characterizing LLRW and Production Levels

Patterns / Trends in LLRW Production and Management

Social and Economic Benefits Derived in LLRW Production

Conclusion

Policy Making Criteria: Potential Economic

Impacts of a LLRW Facility

Introduction: Economic Impact Criteria Definition

Economic Impact Assessment Methods and Tools

Categories / Typologies of Impacts: Timeframe and Physical vs. Social Effect

Long-Range Economic Impacts and Short-Range Economic Impacts

Physical and Social Economic Impacts

85

Long Range Social Economic Impacts

Examples of Potential Long-Range Physical' Economic Impacts of a

LLRW Facility

Short and Medium Range Impacts

Short Range Social Impacts

Short Range Physical Impacts 
Introduction

Barnwell, South Carolina -South Carolina -South Carolina - The C

hem-Nuclear, Inc. LLRW Disposal Facility

Baldwin, Florida - The Yellow Water Road Incinerator

Yucca Mountain, Nevada - A High Level Radioactive Waste Disposal

Facility Süting Dilemma

Clive, Utah - The Envirocare, Inc. LLRW Disposal Facility

Manitoba, (Canada) Hazardous Waste Treatment Facility - A Success

Conclusion

6. Recommendations Public Discourse of Economic Impacts from a LLRW Facility

Introduction

Presentation of Factors that Influence Economic Impact Planning

General Discussion of Issues, Analytical Techniques, and Paradigms

Addressing Equity Issues in LLRW Management

Modifications to Public Administration and Policy to encourage

Successful Sitings

Conclusion

References

\section{List of Tables}

Categories and Volumes of Waste in Massachusetts (1994)

Massachusetts Low-Level Radioactive Waste Stream (1994) Description: Radionuclides With Half-lives Greater Than 5 years \& All Radionuclides

Matrix of Types of Potential Economic Impacts Resulting from a LLRW Facility Development 


\section{List of Figures}

Factors Influencing Successful Sitings and Planned Impacts 


\section{Chapter I:}

\section{Introduction \& Overview}

\section{Subject To Be Addressed}

If community residents initiate an analysis of the potential fiscal impacts of the local siting of a State facility to undertake the long-term storage of low-level radioactive waste (subsequently referred to herein as LLRW), then a substantial dialogue is required to determine the structure of analysis, define the cultural values in which to frame debate, and to evaluate alternatives in detail. In Massachusetts, in the early stages of such a site selection process, municipalities have an opportunity to undertake a planned process to evaluate what economic impacts might occur from site development. A State grant program has been developed for communities to consider the economic impacts of siting a disposal facility and to encourage familiarity of issues in nuclear waste site management (Low-Level Radioactive Waste Management Board, 1995). This topic concerns the appropriate use of such grants.

The complexity of nuclear materials management makes it difficult for a planner to provide advice to stakeholders undertaking such analysis. Factors to consider are:

- How will uncertainty be dealt with?

- What attributes of community social structure and economy should be considered and monitored?

- How will value be assigned to different factors?

- Do local factors influence development of a program designed to conduct analysis?

- What planning tools are useful to characterize and forecast economic impacts? 
In other words, how should the process of undertaking such economic development dialogue be strategically structured and implemented? One key aspect of planning for land use decisions involving radioactive materials is the time frame because operation and management of an approved site will occur for hundreds of years into the future.

\section{Obligation of the Commonwealth to Manage LLRW Waste Produced Within the State} This question faces the Massachusetts executive branch, and the municipalities of the state, as a result of the federal 1980 Low-Level Radioactive Waste Policy Act (and 1985 amendment). Under this federal law, states are required to assume responsibility for LLRW generated within local jurisdictions. In Massachusetts the Low-Level Radioactive Waste Management Board (hereafter LLRWMB or Board) is charged with this responsibility

As a result of the Act, Commonwealth officials resolved to follow a comprehensive framework to manage LLRW produced locally (LLRWMB, 1994, 1-13). A major objective of the Massachusetts Low Level Radioactive Waste Management Act (Department of Public Health, December, 1987) is that planning should occur for the development of an in-state LLRW disposal facility (LLRWMB, January 1994). To ensure that a facility siting is acceptable to residents of areas adjacent to the land use, process was developed to ensure that they have access, and a role, in decision making regarding site development from an early stage (Site Selection, April 12, 1995). 


\section{Volunteered Site Program}

The Volunteered Sites Program "...will include grants for communities wishing to evaluate the economic impacts of [hosting] an LLRW facility" (Ibid). Grants will be awarded by the Commonwealth, through the Massachusetts Low-Level Radioactive Waste Management Board (referred to hereafter as LLRWMB and Board), to allow residents to evaluate the economic pros and cons of hosting a facility (Ibid). It is noted that municipalities will be encouraged to offer suitable sites in exchange for controls over the facility, such as hiring preferences, revenue sharing, and other compensation.

As LLRWMB Executive Director Carrol Amick explains (October, 1995), the Board developed a voluntary evaluation process to help communities assess the economic pros and cons of hosting a site in order to develop support (and involvement) at the local level rather than impose decisions onto localities. A common theme in the literature (Castle, 1993; Covello and Slovic, 1988; Selig, 1995) is that when efforts to build greater understanding and familiarity of potentially hazardous activities and its management occur, that opposition due to fear or misunderstanding can be reduced. Risk communication is a process of defining and quantifying risks, as well as educating people about how factors interrelate to convey risk. Information exchange and education of participants seem to lead to more sophisticated levels of dialogue (Susskind and Cruikshank, 1987; Innes, 1990). 


\section{Problem Delineation}

A problem in undertaking this analysis is that it is not apparent what will be an adequate definition of the "...full range of economic impacts that will occur from hosting a site..." (LLRWMB, 1995)? Depending on the dominant paradigms and the research methods used, there can be great differences in how experts predict social and economic impacts to occur (Pinel, 1994; Finsterbusch, 1977). For example, how will long-range and uncertain effects be accounted for and evaluated in models and forecasts? How accurately can financial costs be assigned to potential social and ecological impacts?

Risk communication and hazardous facilities siting literature (Covello and Stovic, 1988; Hance, et al, 1990; Kasperson and Stallen, 1991) touches on a common cord -- how will scientific knowledge be exchanged by stakeholders to promote consensus on viable alternatives? A planner is also concerned with fair evaluation processes and an equitable distribution of project impacts (Rawls, 1971; Forrester, 1989; Krumholtz and Forrester,1990).

A focus in this project is how stakeholders exchange empirical-based information, as well as beliefs about how the future economy and social fabric may be effected by development. How do stakeholders deal with discrepancies to attain consensus, such as when lay persons and experts have different conceptions about expected impacts? How does a planner help promote review of competing paradigms so that meaningful alternatives are designed? 
In discussing the process of siting of large scale projects in rural areas of the U.S., Tauxe (1995) notes that a legalistic and bureaucratic form of rational planning muted local norms, forms of expression, and community culture. In discussing 'social impact assessment', Gramling and Freudenberg (1992) note that the field has been traditionally narrow in focus. They assert that traditional social impact analysis fails to adequately define impacts on a community from new major projects or land use changes. Speaking about impacts of oil field development on indigenous cultures the authors note:

....(I)t has become increasingly clear that a number of predictable, significant impacts take place before and after the period of most intense activity; these impacts are missed by social impact assessment approaches that are excessively narrow in focus (ibid, 216).

Assessing Gulf War health impacts a year after hostility ended, Kuwaiti environmental and public health officials were concerned that social and psychological impacts on the population from the war had not been considered (Harvard University, 1992). So how can economic and social planning be used to more precisely evaluate potential impacts? How can it be used to design development that positively impacts a majority of people? And how is assessment different from environmental impact assessment required in NEPA or MEPA review?

Critics may question to what level should social impacts be controlled? What degree of influence, compensation, and safeguards is adequate rewards for a community to voluntarily host a disposal facility? After all, there seem to be numerous safeguards already built into 
LLRW management regulations. Can a community be overcompensated? Is it possible that major regional projects that present slight degrees of risk can not succeed because local groups have too much influence on decision making?

To summarize, the problem focus is how should a planning dialogue for the siting of a LLRW facility be structured to evaluate different social and economic philosophies so that the process is inclusive, but not so bureaucratic that impasse is never overcome? In particular, how can the focus of scientists be merged with the potentially opposed, focus of local stakeholders, to attain a consensus on what is an appropriate siting method and appropriate amount of economic impact? 


\section{Objectives of the Study}

This study will review types of impacts, risks, and methods used to forecast economic costs and benefits that a major land use may convey on the long-range fiscal condition of a community. Analysis will provide suggestions on ways to structure local policies to ensure that a 'fair' level of impact mitigation is achieved and a successful siting occurs.

\section{Methods for Conducting Fiscal Impacts Analysis}

Methods for estimating benefits and costs to a community from hosting a land use are discussed. This is intended to help identify examples of criteria to consider. Discussed are:

- Social Impact Assessment (SIA);

- Environmental Impact Analysis (EIA) and natural resources valuation;

- Cost-Benefit Analysis (CBA);

- Use of financial incentive to stimulate development of a public facility; and

- Probability and risk assessment.

Review of difficult siting processes of Locally Unwanted Land Uses (LULUs) such as landfills and incinerators demonstrates the structure and substance of public discourse in similar cases. This is intended to show successes and failures. A focus is how people communicate and use power and influence in such processes (Schon, 1983; Tauxe, 1995). 
A main objective is to identify, describe, and compare issues in economic impact planning. Examining how science, creativity, and politics are used to define optimal situations regarding the use and protection of cultural and natural resources will help avoid common pitfalls. It will review how popular land use decisions have been attained and structured -- particularly how other radioactive waste storage sitings have been handled. This should help identify what forms of decision making are more likely to succeed. 


\section{Significance of the Subject}

Our society is divided over the safety of nuclear technology. Segments of the public, especially people not familiar with aspects of radioactive technology, fear uses such as nuclear power plants. This is so even though other sources of exposure (sunlight, $x$-rays) are commonly accepted. Extensive contamination of defense facilities (World Watch Institute, 1992) is an example of justified fears.

Whether benefits of producing LLRW outweigh potential adverse impacts of radioactive energy released to the environment cannot be answered with certainty. Therefore, it is typical for public health practitioners to use conservative methods to manage waste. This project examines attainment of adequate safety standards versus development of standards that could be difficult (costly) to effectuate or which are unenforceable as policy. It concerns attaining an accurate and equitable assessment of economic impacts that is perceived as legitimate so that there is a better chance of success.

\section{Does LLRW Processing Capacity Influence Demand for Radioactive Material and Is}

\section{This a Necessary Public Investment?}

A LLRW facility siting is important because the supply of disposal could affect future use and management of nuclear material. For example, during part of 1995 Barnwell, North Carolina was the only facility certified in the U.S. to accept all forms of LLRW (Mckelway, 1996; LLRWMB, Fall 1995). Decisions by officials in that state to not accept waste (with closure 
for a period) impacted the price of disposal throughout the nation (Helminski, 1995; LLRWMB, 1996). It also affected management practices used in Massachusetts (Keith Kidd, 1995; LLRWMB, 1996).

When limited disposal options are available, regulation seemed to be less stringent and applicable management practices were less likely to be followed by personnel managing waste. During Barnwell closure, waste accumulated on site and best management practices were ignored (Emaleh, 1995). One advantage of an oversupply of disposal capacity may be that industry pursues legal disposal/ management options rather than illegally discharging byproducts. It can also promote avoidance of storage in less than ideal conditions.

A phased siting process that pre-screens potential sites could help to identify potential mitigating factors early on. This promotes sensible use of public expenditures by encouraging development of sites that are more highly valued by the public as appropriate for such a use. It helps avoid the strain of pushing through an unpopular site and facing extensive costs and delay due to opposition and legal actions to prevent a siting.

\section{Comprehensive and Practical Long-Term Management Systems are Required}

It is important that effective and appropriate capacity be developed to manage radioactive waste. The pace of technological change is rapid. Third world economies may face similar disposal problems. There is no complete consensus in the literature as to whether demand 
for radioactive waste management capacity in the United States will increase or decrease. For one, forecasts in the U.S. seem uncertain because the definition of LLRW is in many ways arbitrary, based less by scientific classification than by the source of the waste.

Since projections of LLRW facility periods of operation are long range in nature (quarter century estimated of waste collection; 100 years of post collection control; and up to 500 years institutional control), there is uncertainty in how society will change in the period. In an analysis of all radioactive waste production in the U.S., the EPA (1994: 8) predicts that volumes will double over the next quarter century. Alternatively, in Massachusetts the volume of waste shipped for disposal over the last decade demonstrates consistent declines in shipment levels (LLRWMB, 1994: 70; LLRWMB, 1996: 34) due to source reduction practices such as recycling, compacting, and elimination of uncompetitive practices. It is difficult to estimate demand for disposal outlets because there will be changes in the economic base and technology, but it does seem that well planned and well-built infrastructure will have utility and be used by society.

\section{Management of LLRW Must Demonstrate Appropriate Safeguards}

It is important to safely manage LLRW because, depending on the half-life of the isotopes involved, if accidental release occurs, the pollution could remain for long periods. Too often in the past environmental contamination has been manifested as a market externality where clean-up costs are carried by the public rather than the parties that initially caused the 
problem. Whether ecosystems contaminated by anthropogenic substances can be returned to pristine condition after a clean-up is questionable.

\section{Promoting the Elimination of Unsafe Practices}

There is a limited supply of facilities permitted to store LLRW according to stringent health codes. Facilities have closed because capacity has been reached, while others have closed because of materials improper encapsulation and contamination. In the case of Barnwell, the only site permitted to accept LLRW (National Public Radio; March, 1996), the locality remains open although the facility may be surpassing design capacity.

Potentially unsafe practices may be occurring within current waste management. For example, in Massachusetts there are cases where spent LLRW is being stored in less than optimal conditions at the point of production (Wabba, 1995; Emelah, 1994). Regulations permit the storage of LLRW materials for up to two years on-site, however, this does not seem optimal for safeguarding public health. Dangers of on-site storage is demonstrated at a hospital that stores a portion of its waste in a method known as storage for decay (Emaleh, 1994). With storage occurring in cardboard boxes below ground in conditions that are susceptible to flooding and fire, the method appears less than optimal (Ibid). Sitings carried out with extensive planning result in practices more likely to protect public safety and welfare. 


\section{Clarifying Myths and Misunderstanding of Radioactivity}

There is no absolute certainty about safe levels of radiation exposure and safe volumes of material that can be released to the environment. However, many of the discrepancies that arise are between scientists familiar with extensive scientific debates and publics that are less familiar with the issues and who do not implicitly trust experts. While many regulatory standards have high margins of safety, there may be situations where technological restrictions, or the high costs to manage waste, result in material being discharged to the environment. For example, at a LLRWMB meeting in April 1995, Board members debated whether permissible regulatory limits for emissions to air and sewers actually safeguarded public health. Studying the economic impacts of siting should result in better radioactive materials management.

Similarly, it is uncertain what are the trade-offs involved in using radioactive waste in society? Use of radioactive materials occurs in many sectors of the economy. In some cases, alternative technologies are not available to substitute for ones that use radioactive isotopes. For example, biomedical research, medicine, agriculture, and educational institutions use different forms of radioactive material (Nuclear Energy Institute, 1995). Developing sites to manage radwaste fosters an understanding of the externalities in the marketplace, understanding of social problems posed by development, and encourages the appropriate placement of responsibility for problem correction. 
Finally, this study will promote an understanding of the social and fiscal impacts from developing new sites. Often plans to develop heavy industry in communities are opposed by residents who sense a lack of control, inadequate accountability, or poor public oversight. There are cases where problems to arise to impact the community in adverse ways or the positive economic impacts expected do not materialize. This study will examine how to obtain resident input on the hypothesized effects of development and how to formulate acceptable and legitimate alternatives. 


\section{Major Questions, Policy Issues, or Hypothesis to be Addressed in the Project}

The major question is how should a community organize a process in order to define economic goals and objectives and forecast potential economic impacts that may occur if a Low-Level Radioactive Waste (LLRW) storage facility is sited in the municipality? Do different perspectives on what is the appropriate use and handling of radioactive material create different opinions on the types of economic impacts that could occur in a community?

Such processes are inherently difficult because the types of impacts that the community is to review could occur over an expansive time period. Key questions are:

- How can medium and long-range impacts be examined when there is uncertainty about key factors and probabilities?

- How will economic impacts be defined and ranked?

- How can findings be synthesized and analysis occur to determine if community residents do want to host such a land use?

- How should economic analysis and economic debate be structured?;

- Is it legitimate to be concerned with a broad socially-oriented definition of economic impact and the fiscal implications associated with them?; And

- What tools of communication, learning, and negotiation should be used to build consensus about potential impacts? 


\section{Procedures and Methods of Analysis to be Employed in Carrying Out the Project}

Review of literature and case examples for sitings will be used to identify ways to evaluate the economic impacts of hosting a LLRW site. Information will be used to formulate definitions and show planning and research tools that are typically used. This will provide insight into competing paradigms as well as pitfalls experienced in sitings. By identifying problems that have occurred, an objective is to identify and recommend ways to avoid them through modifications in the structure of analysis, policy development, or program implementation.

The two main types of literature relevant to this problem are:

1. Methods for conducting social and fiscal impacts analysis, particularly for sitings involving hazardous facilities, and radiogenic materials in particular; and

2. Methods for engaging in public land use disputes where management of hazardous materials is involved. 


\section{Specifications of the Data or Information to Be Used in Analysis}

Most information and data will be derived from the public documents produced by the LLRW Management Board. In addition, case examples will be obtained from descriptions of other hazardous facility sitings as well as literature of planning, sociology, economics, public health and engineering. Since there is a great deal of literature developed on this subject of LLRW management for Massachusetts, this material will be reapplied to the particular problem at hand. Research and planning used in other areas of nuclear science and nuclear materials management, such as in the weapons industry and the power industry, also provide additional data and examples. Finally, to interpret the history and effect of LLRW management, players identified to be important to such a process, as well as experts in the field, are interviewed. 


\section{Conclusion}

This research monograph considers the assessment of economic impacts for a LLRW facility and presents types of potential impacts. For a community deciding how to formulate evaluation criteria and use assessment tools, it is expected that socio-political issues will influence decision making. For example, finding a way to reconcile the positions of scientists/ experts on one hand, with those of community residents and lay persons, may be required. Both paradigms have validity, so how can these be merged to formulate management plans that are proactive and comprehensive in efforts to stimulate positive economic impacts while minimizing adverse economic impacts? 


\section{Chapter II:}

\section{Administration of the Low Level Radioactive Waste Management Act}

This chapter describes Massachusetts laws and policies, as well as those of other states, municipalities and the federal government, which are relevant to siting and managing facilities to process and store LLRW. It also identifies stakeholders involved in enacting the program. The purpose of this chapter is to provide context to evaluate how to forecast economic impacts of a siting, and ultimately to promote sound alternatives to manage LLRW. Key points in the history of LLRW regulation and site development also provide background.

Examining the structure of government programs is intended to show the framework in which a community would analyze potential economic impacts by reviewing:

- How are policies used to guard against adverse effects that a land use decision may have on the economy of a community or region?

- How do current policies and regulations of the state government potentially influence debate about site development?

- How is interaction among stakeholders facilitated?

- What information or values are emphasized as central to decisions about whether and how a potential siting should proceed?

- What is the role of incentive in site selection? And

- What policies ensure that economic impacts are distributed in a fair and equitable way? 


\section{Description of the Existing Environment}

Many stakeholders claim roles in initiatives to promote local economic development. In such policy debates there seems to be two main paradigms. One is optimism that public spending to spur development will result in opportunities to build the tax base, create jobs and provide infrastructure to support a higher order economy, regardless of the nature of the development. Contrasting with this is a notion that development is often not sustainable because total life cycle costs of development are not considered, such as the cost of environmental degradation. It advocates for considering development in relation to the intended long-range characteristics of community. This position asserts that without detailed fiscal analysis and planning, potential could exist for adverse effects to arise from new development and a compromised financial status of a local government.

It seems that the propensity for communities to try to locally influence economic development and compete rigorously for federal subsidies will become more pronounced if the federal government continues to reduce spending. Are communities more likely to consider hosting a potentially unpopular land use to obtain relatively scarce subsidies for city administration? Is it sensible to spur new development as a tactic to reduce current fiscal stress?

Another influence on the success of regional facility sitings seems to be citizens' demands to protect local natural resources. Developing a low-level radioactive waste storage facility in Massachusetts seems to be a dialectic between people concerned about creating jobs versus 
those advocating for complex controls to protect against degradation of local resources, both ecological and cultural.

\section{Ecological Protection -- The Traditional Forum for Impact Assessment}

One legacy of high-tech industry is contamination of sites with by-products of production. The Environmental Protection Agency (EPA), boards of health, planning departments, the U.S. Department of Energy (DOE) and state environmental protection agencies are examples of government units that promote public environmental health and natural resources protection. The DOE now has in its mission the objective of preventing natural resources harm, encouraging contaminated sites clean-up, and promoting the adoption of technology that is less likely to convey adverse impacts (Office of Environmental Management, 1994).

Promoting clean-up of contaminated sites, and ensuring that new facilities comply with detailed development standards is a legalistic process. Superfund programs (the Comprehensive Environmental Response, Compensation, and Liability Act of 1980 and the Superfund Amendments and Reauthorization Act of 1986) are examples of policies which are commonly asserted to involve large sums spent litigating claims of responsibility for clean-up, with only small sums spent on actual remediation. When site clean-ups occur, it often seems that government covers large portions of the costs, as a result of findings of limited liability of private corporations, or due to the bankruptcy of firms responsible for contamination. 
Determining what restrictions to place on a potentially hazardous land use can be: bureaucratic, legalistic, contentious, and political.

Traditionally, industry has been taxed to pay for government to react to externalities that may result from development. Facilities where hazardous activities occur must institute practices that: prevent occupational exposure to hazards; restrict release of harmful levels of waste to the air, water, and surrounding land; and attain engineered designs that protect adjacent neighbors from harm in case of sudden accidents and nuisance. For federal facilities the range of environmental impacts that development could convey to an area must also be considered. Science and engineering professions seem to view the practices and policies as sufficient to protect the environment. Technological optimism often prevails leading to the belief that physical solutions can be engineered to overcome potential development obstacles.

Public involvement in processes to regulate contaminated site clean-up insures that adjacent communities are informed about new developments and the type of activity to be performed at a site. It also provides a way to influence what activities occur at a site (Office of Emergency and Remedial Response, January, 1992). Public participation requirements are also applicable whenever a major new facility is proposed through regulations such as the Massachusetts Environmental Policy Act. Local community review is also required in the hearings of Planning Boards and Boards of Health. At the Federal level it is also required by the Emergency Planning and Community Right to Know Act (EPCRA). Based on public 
response, facilities may be required to implement additional measures to ensure compliance with health and safety standards.

Critics of the environmental protection bureaucracy argue that public processes are redundant and create burdensome requirements on industry. For example, for radiogenic materials transport, there are complex packaging and handling requirements, and complex management and planning systems that must be followed to protect the public from accidents. Critics argue that developing safeguards beyond what is already mandated means duplication and unnecessary bureaucracy. There seem to be different opinions about the appropriate role of government to influence facilities development involving dangerous materials. The locus of criticism of a 'protection philosophy' is regulated industry. Corporations prefer to work with less information exchange in order to be efficient. Corporate officers assert that organizations they represent will ensure safety by utilizing technology and responsibility to the community.

\section{Background on Federal Programs that Involve LLRW Management}

Major Federal nuclear and solid waste management policy was enacted in the 1980s for commercial nuclear waste transport and storage. It addressed concerns that poorly managed waste posed a risk to the public and surrounding environment. The Low-Level Radioactive Waste Policy Act (1980) delegated responsibility for LLRW planning to states and provided capacity for them to enter waste management compacts. It mandated that states undertake planning for how low-level radioactive waste produced in a state is stored, treated, and 
managed during the period that it remains radioactive, which could be into the period of disposal. The Low-Level Radioactive Waste Policy Act Amendments (1985) established new procedures and milestones for the development of disposal facilities (LLRWMB 1994, xxv).

Many deadlines have been missed, and there has been extensive political maneuvering by officials in the states to avoid having the first facility -- and possibly responsibility for wastes from other states (Lewis, 1988). However, extensive planning has occurred in every state, concerning management and disposal of LLRW. States are required to develop plans that clearly describe how LLRW will be managed and eventually disposed of in the state, or if alternatively decided, safely managed by a compact of states (Ibid). Since there is a diversity of opinion as to benefits and risks associated with utilizing radioactive materials, the laws provide for extensive consensus building and public participation during the planning for radwaste storage and disposal.

\section{Massachusetts Low-Level Radioactive Waste Management Act}

The federal program objectives have been incorporated into the state code in Massachusetts General Law c. $11 \mathrm{H}$, the Low-Level Radioactive Waste Management Act. Policy is further defined and effectuated in the Low-Level Radioactive Waste Management Plan (345 CMR 1.00) Regulations and the Massachusetts Low-Level Radioactive Waste Management Plan. Volumes I \& II (LLRWMB, January, 1994). 
Policy continues to develop as the Low-Level Radioactive Waste Management Board implements the Plan and further develops policies on its implementation. The Board is incrementally dealing with the plan objectives. Examples of policies developed recently are Proposed Additional Revisions to 345 CMR 1.00 (LLRWMB; April 4, 1995) and Staff Discussion Draft: Options to Consider in Reviewing The Level of Management Board Siting Activities (Amick: March 27, 1996). Other major administrative agencies besides the Board are the Departments of Public Health and of Environmental Protection.

\section{The Low Level Radioactive Waste Management Board}

The Board is responsible for planning and effecting management of LLRW in the Commonwealth. It is an independent agency with the mission to guide development and enactment of the LLRW management plan with a primary consideration to protect public health, safety, and the environment (M.G.L. c111H, 1987). The board selected two main objectives to manage LLRW.

Its two track approach involves (1) on-going discussions with other states and regional compacts to identify a long-term, out-of-state disposal solution, and (2) taking slow, deliberative steps to identify a suitable disposal facility site within Massachusetts, if an out-of-state disposal solution is unobtainable. The Board's preference is for an out-of-state solution (LLRWMB, February 16, 1994).

The board consists of nine persons including: public health officials, environmental protection experts, experts in radiological science and health, a designee of the Executive Office of Human Services, a professional engineer, and citizens appointed to act in the public interest 
(M.G.L. c111H, 1987 ss2). Board members are appointed by the Governor. The Board conducts monthly meetings as well as routine public information meetings and public hearings on issues throughout the State. This body has a support staff of eight persons.

A recent example of an issue affecting the Board is a reorganization and downsizing of State Government proposed by Governor Weld (Struhs, 1996). Under a recent arrangement, due to federal requirements to quickly meet LLRW management objectives, the Board will retain its purpose and structure as an independent board affiliated with the Department of Environmental Protection, with the purpose of effectuating LLRW management. However, recent votes by the Board (LLRWMB, March 27, 1996) have significantly slowed the pace and type of planning that will be conducted to develop an in-state facility to manage radioactive materials storage. In some cases, siting objectives have been put on hold. 


\section{The Six Phases of the Massachusetts LLRW Management Act}

Approved in 1987, the Act is a comprehensive regulation that provides a framework to guide how the Commonwealth will implement a regulated process to manage LLRW disposal (LLRWMB, 1994: C-7). As passed, the Act did not provide all policy details as to how management will occur, rather six phases of a management process are identified. In 'Phase I: Planning', most policies and regulations are developed (Ibid: C-5). A determination in Phase I was whether in-state siting processes would occur at all. Later phases involve steps to select an actual host site. To summarize, the Chapter $111 \mathrm{H}$ stages are:

\section{Phase I: $\quad$ Planning}

Phase II: $\quad$ Site Selection

Phase III: Operator/Technology Selection

Phase IV: $\quad$ Facility Approval and Licensing

Phase V: $\quad$ Facility Development, Operation, Closure, and Post-

\section{Closure Observation and Maintenance}

Phase VI: Institutional Control

Looking at all phases, it is evident that there are redundant features designed into the program. In its entirety, the LLRW storage facility selection process is bureaucratic with many iterations. The purpose is to promote selection that is comprehensive and attempts to eliminate unforeseen externalities in what will be a long duration (at least three hundred year) 
operation from the point the facility is constructed to the point the site is expected to no longer require monitoring. The phases are explained briefly below.

\section{The Planning Phase}

The planning phase involved undertaking research on radiogenic use levels, defining LLRW management nationwide, and initiating research and development of a detailed plan regarding how to carry out and implement the Management Act. Designing detailed policy on how radioactive waste would be regulated and how site selection would occur were major objectives in this first phase.

The final determination of phase one states (LLRWMB, December, 1993; March, 27 1996):

While the Board would first and foremost advocate for Massachusetts to join a compact with other state(s) to develop adequate storage space in a facility located out of state, that the political climate that would enable an out of state facility was uncertain, and therefore Massachusetts would also initiate process to site a facility within the Commonwealth.

This triggered subsequent phases. Currently, the LLRWMB is in Phase II: Site Selection.

\section{Site Selection}

The Board is currently involved in completing detailed procedures to select potential sites (procedures could not be developed in Phase I because it was not determined whether in-state 
siting would occur) and implementing procedures to screen potential sites and prepare for a site development process. Some objectives are:

- Establishing detailed regulations and policies for site selection;

- Designing an administrative system to enact policy and deliberate on siting;

- Providing for public deliberation on site selection, including empowering communities located in a potential host community and adjacent areas to become involved at an early stage in the site selection process;

- Undertaking actual scientific analysis to identify broad geographic regions that could host potential sites (a first screening to define broad areas that pass basic criteria such as wetlands, soil type, demography, etc.);

- Identifying candidate sites; and

- Performing detailed investigation and reports on candidate sites.

In Phase II the process to consider impacts of development on a community starts as do procedures to ensure the long range financial viability of a site. Rules on how to assess economic impacts to a community are incomplete. Lawmakers intended procedures to be designed in an ad-hoc fashion to encourage stakeholder involvement in analytical methods design. The tactic also seems intended to ensure that the process is perceived as legitimate. 


\section{Other Phases of Implementation}

Phases overlap. This report focuses on regulations and procedures developed in phase II. Descriptions of the latter phases are provided to promote a understanding of the whole selection process. The many redundant processes and safeguards, such as extensive insurance requirements, seem to show that policy makers wanted a facility to be extensively supported by the State. This approach is similar to that of Connecticut and New Jersey, among others; however, even with all the fail-safes and incentive developed, seldom do U.S. municipalities volunteer a site or demonstrate substantial public support for LLRW disposal facilities.

Phase III: Operator / Technology Selection (Ibid: 2-8) is the process of reviewing firms to certify that designs are sound and conform to acceptable science and engineering. Operators must also be certified to meet all legal and financial requirements to be a principal to operation. Examples are demonstrating: proof of insurance; relevant professional experience; sufficient operating resources; and adequate bonding.

Phase IV (Ibid: 2-9) is review of a final application of an operator of a potential site that may result in approval of a facility operating license for an entity. It includes demonstrating compliance with environmental impact reporting and complying with public demands articulated through the Community Supervisory Committee and public forums. 
Phases V and VI (Ibid: 2-9 to 2-10) involve site construction; facility start-up; operation; preparation to shut-down at the point it has reached capacity or time operating limits; and transfer to Institutional Control for a decommissioning period of State management.

\section{Federal and State Regulations Affecting LLRW Facility Development}

The Massachusetts Department of Environmental Protection and Department of Public Health, and Federal counterparts such as the Nuclear Regulatory Commission (NRC), EPA, and Department of Transportation (DOT) also influence management policy. It is noted (LLRWMB, 1994: 2-18 to 20) that regulations are complex and it is difficult to maintain clarity and consistency across regulations promoting safe waste management. The Low-Level Radioactive Waste Management Plan, Volume I and II (LLRWMB, January 1994) provides background on regulations affecting facility development.

Parts of the Act that Concern Site Financial Viability and Mitigation of Impacts on Communities and Adjacent Land-Owners

As a comprehensive approach to management of radioactive waste, the LLRW Management Act and Plan contain numerous provisions to ensure that sufficient resources are allocated so that site management does not cease before all required activities are complete. For example, contractors must have extensive certificates of insurance and be bonded. There are also mechanisms to protect communities and adjacent land owners from adverse fiscal impacts on property values as a result of a facility being constructed in a locality. Finally, incentives are 
provided for a community to assume risks that are inherent in a facility siting. Provided below is a list of ways that entities that dispose of waste at a facility will be regulated as well as important aspects of the facility management entity:

- LLRW Licenses, with a Management Fund and Assessment Fees to users;

- Enforcement, Penalties, Liability, Damages, and Grievance Mechanisms;

- Environmental Impact Report requirements;

- Community Compensation; and

- Contingent Liability Account, Institutional Control Account, and the LLRW Trust Fund (LLRWMB, 1994:).

\section{LLRW Licenses, the Management Fund, and Assessments}

To initiate a process to develop a LLRW disposal facility a license application must be approved. The application provides information on the type of technology at the application site and projections on the types of radioactive material to be processed. A developer must also complete an Environmental Impact Report. During an Application Period a Public Participation Coordinator receives public comment and input regarding development and issuance of a license. A draft license released for public comment will contain the facility design and performance specifications (MA DPH $1988 \mathrm{Ch} .11 \mathrm{lh}$ ss 31 ).

The LLRW Management Fund is a separate fund to support implementation of the LLRW Management Plan (MA DPH $1988 \mathrm{Ch} .111$ h ss 31 ). The fund is supported by annual 
assessments to each entity licensed to handle radioactive waste in Massachusetts. One noteworthy and potential problem is that the total amount assessed in one year may not exceed $\$ 500,000$. Funds are to be used to cover operating costs of a facility. This seems like an arbitrary figure, there is no relationship between the total fees collected and the waste produced. Nor is the law based on how many licenses are required. However, based on the classification schemes developed in the Management Plan, schedules of surcharges may be developed (Ibid). State bonds have also been authorized to fund development, financing for which will be covered by producers.

Enforcement, Penalties, Liability, Damages, and Grievance Mechanisms

If the Management Board finds that licensees are not complying with license requirements, whether or not a violation is willful, it may levy civil penalties (MA DPH $1988 \mathrm{Ch} .111 \mathrm{~h}$ ss 4B). One objective for the state is to ensure that instances of non-compliance are more expensive than compliance so that noncompliance is deterred (Ibid). One common trend in enforcement of environmental regulations is to require that fines levied occur in the form of supplemental environmental projects. If fines are levied, will the revenues be used to support a local initiative designed to improve the local environment?

\section{Environmental Impact Report}

In order to obtain a facility license, extensive development plans and operating procedures must be approved. To paraphrase the regulations (MA DPH $1988 \mathrm{Ch} .111 \mathrm{~h}$ ss 30) an 
Environmental Impact Report (EIR) is required for the proposed development, operation, closure, post-closure observation and maintenance and institutional control period. The EIRs will identify each community expected to experience significant impacts as the result of the facility location, development, operation, closure, and post-closure. Citizen's Supervisory Committees (CSC) will establish specific procedures to evaluate and review environmental impacts of the project. This process would be focused on mitigating adverse impacts and finding ways to promote desirable ones.

\section{Community Compensation}

Communities will be compensated for accommodating potential project impacts. Mechanisms are created to negotiate a comprehensive operating contract and compensation would occur according to established formulas and negotiated agreements. The CSC is a primary advocate for the rights of residents. It facilitates participation of a community in which a candidate site is located (MA DPH $1988 \mathrm{Ch} .11 \mathrm{~h}$ ss 1 and 34).

In the case of accidental release, it will be the responsibility of the operator to clean-up waste released. An operator must have sufficient funds set aside for such an eventuality. The 'Institutional Control Account' of the 'LLRW Trust Fund' will also be used for this purpose when the facility is in the process of being decommissioned (MA DPH $1988 \mathrm{Ch} .11 \mathrm{lh}$ ss 9). Should such funding run out, the Commonwealth would be responsible for 'the reasonable costs of clean-up and stabilization of a facility' (Ibid). An 'institutional control account' and 
a 'contingent liability account' are funded from surcharges on waste producers (MA DPH $1988 \mathrm{Ch} .11 \mathrm{lh}$ ss 41 ). The latter is to be used to compensate victims of injuries or property damage according to a principle of strict liability (ibid). The money in trust funds is also to be used to purchase insurance during the period of institutional control when a facility is under state control for decommissioning.

As the examples demonstrate, there are many pre-established programs and procedures intended to ensure that the facility is operated safely and with adequate financial resources. In addition, extensive strategies are developed to ensure that the site is viable in the long range and is accepted by stakeholders. The next section further explains the early stages of site selection and demonstrates how residents can evaluate the potential impacts of a facility and establish policies to plan for desired impacts. 


\section{Siting a LLRW Facility in Massachusetts}

As described in Site Selection (LLRWMB, 1995) selecting potential sites involves:

1. Development of a site selection process and development of state wide site selection criteria;

2. Application of the site selection criteria through mapping and screening of all land in the State to identify locations that might be feasible (current focus);

3. Publishing a Possible Locations report;

4. Seeking volunteers (host communities). This is the point where local stakeholders can evaluate economic impacts of hosting a site;

5. Naming candidate sites;

6. Studying potential sites in detail;

7. Selecting a site; and

8. Involving the community in the design and development of such a site.

Preliminary site selection and evaluation of local opinion regarding a siting is the focus of the CSC. The CSCs will evaluate economic impacts ("...the pluses and minuses to a facility...") to a community from the local siting of LLRW disposal facility (Ibid). Becoming involved in the process does not obligate a community to participate in later stages of site selection.

As of the fall of 1995, the LLRW Management Board awarded contracts to begin a preliminary state wide assessment process that will utilize pre-determined evaluation criteria 
to identify land areas that are suitable for a LLRW Storage facility (LLRWMB; Winter, 1996). The selection criteria in this phase covers a range of physical as well as demographic factors and the process is expected to take two years (lbid). 


\section{Volunteered Site Program}

The fourth component of the overall site selection program is the 'Volunteered Sites Program'. The Volunteered Sites program "...will include grants for communities wishing to evaluate the economic impacts of an LLRW facility" (Ibid). This program will be entered into by a community through its Chief Elected Official. Money (up to $\$ 50,000$ in one grant, with possibility for numerous grants) will be granted by the Commission to evaluate the economic pros and cons of hosting a facility (Amick, 1994). In Site Selection (1995) it is noted that municipalities will be encouraged to offer suitable sites in exchange for controls over the facility, hiring, and other forms of compensation.

In this phase, scheduled to begin in late 1996 for communities with regions that pass preliminary screening criteria in \#3 above, there will be a program developed whereby grants will be allocated to foster research and planning for the economic impacts of a local siting (Beverly Johnson, June 1995). The research will allow residents to build a consensus as to whether a local siting is of interest to the community. The grants sponsor investigation "....of the advantages and disadvantages of an LLRW facility" (LLRW Management Board, 1995:3). The objectives are to provide for independent evaluation, provide a community with decision making power, and establish a mechanism for local approval (Ibid).

Nowhere in the documentation has the author discovered substantial discussion or definitions of what constitutes an environmental impact, nor is there direct discussion of potential for 
differential impacts on social groups. As previously noted, this may be because lawmakers intended participants to formulate such definition in subsequent stages. As Pinel (1994) notes in discussion of social impact assessment, the definition of 'social impact' is not concrete. What constitutes social impacts varies by profession and subject under review. Sometimes it seems to relate to environmental (ecological) impact planning or fiscal relationships that emanate from social behavior.

A problem with not providing any guidance on how to define and analyze impacts is that opportunity is presented for simplistic definitions and analysis. It seems that a community planner employing professional norms would focus on social impacts rather than more discrete financial economic impacts. The former is more concerned with spatial characteristics of social equity and a focus on unique local culture and characteristics. It also considers a more holistic definition of cost that internalizes externalities and spinoffs. Thus the econometric models of planners would contain more uncertainty than more explicit quantitative analysis are the tradition in urban economics.

The site selected for development will receive grants and impact fees for hosting the facility. Included will be:

- A four percent portion of gross revenues (slightly less for a non-voluntary site);

- One time impact fees;

- Payments in lieu of property taxes; 
- Technical assistance and administrative support financing;

- $\$ 150,000$ per year, until five years after the site license; and

- The state will provide support including facility permitting oversight, continuous health monitoring, and responsibility for managing the site for a century after it stops accepting waste (LLRWMB, 1994).

Consultation is intended to encourage debate and planning beforehand so that conflict may be avoided at a later stage when a great deal more resources have been invested in developing a particular site (LLRWMB, 1995; LLRWMB, April, 1995).

\section{Public Comments on the Site Selection Process}

A review of public comments (LLRWMB, March 19, 1996) and discussions with LLRWMB officials (September, 1995) show two main criticisms of the Voluntary Siting Program. One was that there was not enough money allocated to communities that seek to analyze the economic pros and cons of potentially hosting a facility. It was felt that sufficient research and forecasting could not be undertaken with $\$ 50,000$ in technical assistance grants that communities are eligible to receive (LLRWMB Public Participation Coordinator Interview, 9 September 1995). Another comment was that the grants amounted to bribes to communities to host a LLRW disposal site (Ibid). 


\section{Conclusion}

Judging from attendance at public meetings, stakeholders participating in the process include State officials, concerned citizens, environmental protection advocates, LLRW generator representatives, contractors, academicians and federal officials. Most people currently involved with the process are familiar with the extensive plans and procedures developed to date. Board members have the most power in the process. Major influences on the Board and staff seem to be Federal directives, executive dictates, legal decisions and issues in the disposal marketplace. For example, when disposal outlets were recently closed, the body seemed to push to fully develop the siting procedures. When the disposal option was regained, it subsided.

From research conducted for this project, it is apparent that not a lot of effort has been taken to define what is an economic impact. The terms 'social' and 'economic' impact are used interchangeably. For the process to succeed it is advisable to further formulate definitions, or substantiate why they are not fully developed. If the intent of policy is not made explicit, issues could arise because of misperceptions. There should also be explicit explanations of intent to avoid inequitable policy impacts. Perhaps because waste management has been the domain of engineering science and public works, physical impacts have been the major focus rather than a balanced approach that also considers potential socio-economic impacts. 
Among the stakeholders there seems to be a lot of posturing, lobbying, and negotiation as the LLRWMB proceeds with completing the siting guidelines -- it is a very political process. The main competing viewpoints of stakeholders are:

1. Distrust and fear of a facility with advocacy for more sustainable technological and natural resource use practices -- such as those that do not contribute to global ecological problems, and

2. Belief that limited oversight of science and engineering, combined with less taxation, will result in responsible management.

The focus by stakeholders such as Greenpeace and EarthFirst representatives on further preventing adverse environmental impacts may be surprising given the many environmental protections built into policy. But these groups may have to resort to sensational means to obtain political power because they do not have real influence within the administrative process. Diverse opinions do have opportunity in the given political structure to prominently present objections to policy and promote review of alternatives. Given further access to policy negotiations, their creativity and experience could be useful for obtaining more effective management and siting policy.

A regulatory approach characterized as mild, or laizez faire, appears to be demonstrated by State agencies, such as the Department of Environmental Protection, in oversight of LLRW processors. This is also evident in federal level oversight. Thus, while there are many codes 
developed to protect public health and safety, and there innumerable bureaucrats, the end result is inefficient government and unenforced regulations. A problem with a protracted policy development process and vacillation in policy at the State level, is that relationships have not been fostered between the LLRWMB and host communities. Policy is undefined and uncertain. Finalizing policy on site selection will enable the current period to be used to promote effective partnerships between stakeholders and build networks that are necessary to obtain consensus on popular siting alternatives.

Pervading the process is a social contract, that appears to work, that citizens will have the opportunity to add to the public record at virtually any time. More difficult to discern is whether a stronger and more effective political network is manifested behind the scenes. Votes by the Board may be decided before hand along party lines where a majority votes support free market rule and postponing facility development, if at all legally feasible, because it involves public obligations.

In summer 1995 the Board conducted three meetings in different regions to provide the public with explanations about the Draft Siting Plan, the Volunteered Sites Program Plan and to obtain public input on site selection. The focus was early stages of site screening, such as identifying voluntary host sites and regions (LLRWMB, February, 1995). With extensive plans and policies formulated to date, and more policy development required at the State level before a siting could proceed, even with specific efforts by the LLRWMB to clearly 
communicate to the public how the siting process should work, it appears that it will take a long time for a new participants to learn about and understand the mechanisms developed. An effort is required to disseminate the information processed to date in a clear, coherent and consistent fashion. Short and concise policy statements should be adopted. For example, there should be a clear commitment to obtaining a site and the State should show how oversight, underwriting, and incentive will enable effective site development.

With so much procedure, a new participant may feel that it is difficult to influence policy. The bureaucracy and formality that the Board approaches policy development contrastswith the virtually free-form way that a community will be allowed to define how it will assess potential economic impacts. Although the Board wants to foster local autonomy and build a sense of involvement in a site so that the siting process is not viewed as illegitimate, there may be a need for a strong facilitator, such as between the State and municipalities. If this role can not be better assumed by the Board, an independent facilitator or ombudsman could be appointed now to help manage the whole siting process.

Attendance at recent public meetings averaged approximately 35 persons (Mckelway, September 1995). At one meeting (LLRWMB, May 10, 1996) there was a diverse set of stakeholders and it was apparent how difficult it is for the Board to build consensus among the participants. No one seems to support siting because it is perceived as too dangerous or too costly to site a facility. Much of the citizen and advocacy group opposition to siting 
appears based in Western Massachusetts. It does not appear that federal officials are pushing for action, which appears to sit well with an anti-development Board. Overall, there is a great deal of information for participants to process. It will be difficult to formulate a coherent policy that can be practically implemented and meet all of the established legal requirements. The planning process also appears confounded by reorganization in the State administrative structure, in particular efforts to downsize and eliminate spending. 


\section{Chapter III}

\section{Characteristics of LLRW Production and Disposal}

This chapter defines LLRW, describes how it is toxic, explains production and handling, and presents factors that influence its management and regulation. It shows how people classify waste and employ physical controls and management to control LLRW. The purpose is to present subjects opponents are likely to focus on regarding how LLRW disposal occurs, and how a community may be impacted, especially through potential for physical harm from LLRW. The next chapter provides a matrix of physical and social impacts that a siting could convey to a community. Together the these next two chapters provide a basis to define how humans can help effect LLRW management to minimize unwanted economic impacts.

To aid conceptualization, this chapter will:

1. Define radiation;

2. Review how radiation can adversely affect the natural environment and/or physical health of humans;

3. Characterize low-level radioactive waste and ways that it is produced, including characterizing prominent forms and material streams generated in Massachusetts (and the nation);

4. Examine how LLRW production is changing and predicted to change; and

5. Show the economic and social benefits derived by society in the course of consuming materials that produce LLRW (with more descriptions in Chapter 4). 


\section{Defining Radiation and Characterizing LLRW}

Definitions of radioactivity and the forms and quantities it is commonly demonstrated in Low Level Radioactive Waste is provided to aid conceptualization. Definitions are intended to provide a core from which to address uncertainty and identify issues that require additional research or debate.

\section{What is Radioactivity and Radioisotopes?}

An isotope is the 'mass number' of an element. It defines the weight of an atom based on the number of neutrons (neutral particles with no charge) and protons (positively charged particles) in its core. There can be different numbers of neutrons in the core of an atom. To paraphrase Miller (1985), nuclei of isotopes of an element can be either stable (nonradioactive with the same number of neutrons and protons) or unstable (radioactive with more neutrons than protons).

Radioactivity is energy released to the environment as different parts of the nucleus of an atom affect one another, seeking a physical balance. Radioisotopes are radioactive isotopes with nuclei that emit high energy radiation. The type of radiant energy associated with radioactive materials is ionizing radiation (LLRWMB, 1994). This radiation may be in the form or particulate or electromagnetic radiation. Ionizing radiation (Miller, 1985) is high energy radiation in alpha, beta, or gamma forms that, when passing through stable (or nonradioactive matter), can physically alter the other atoms (irradiate it) to produce reactive 
charged particles called ions. The process of irradiating something imparts an electrical charge on the stable atom. A way to conceptualize these three forms of radiation is the amount of material that each one passes through before that particle is halted. Alpha radiation may be stopped by a thin sheet of paper; gamma radiation could pass though lead or a thick wall before it is stopped.

\section{Half-Life}

Half-life is a commonly used method for classifying the nuclear content of radiogenic material. Miller (Ibid) defines half life as:

...the length of time it takes for half the nuclei in a sample to decay by emitting one or more types of radiation and, in the process, to change into another non-radioactive or radioactive isotope.

For example, a radionuclide such as Hydrogen-3, the most commonly processed LLRW byproduct present in wastestreams of commercial producers in Massachusetts in 1993 (LLRWMB, 1994), has a 12.3 year half-life. Starting with a 55 gallon drum of Hydrogen-3 waste, after 6 half-lives, or nearly 75 years, with the exponential decay rate, less than a gallon (about 1.5 percent) would remain radioactive in the form of Hydrogen-3. 


\section{Common Units of Radioactive Decay}

The Curie ( $\mathrm{Ci})$ and Becquerel $(\mathrm{Bq})$ are units of radioactivity that define the number of disintegrations per unit of time (LLRWMB, 1994). The Curie is the amount of radioactive material to decay in a second. Similar calculations are used to define the Becquerel, an international unit that represents the quantity of any radionuclide that undergoes 37 billion disintegrations per second (Ibid). Based on informal discussion with a Chemical Engineer and Chemist that are experts in hazardous materials treatment and environmental management, one Curie concentrated in a quantity of material such as would occupy a train car full of soil or 10,000 gallons of material requires elaborate handling because of hazardous potential it possess. 


\section{How Radiation Levels Affect Living Systems / Humans}

In the hand-out Questions and Answers About Low-Level Radioactive Waste

(LLRWMB, 1995) discussing whether LLRW is dangerous it is noted:

... [LLRW] can pose a hazard to human health if misused. However, very few people besides certain employees of the companies and institutions that use radioactive materials, and workers at the treatment and disposal facilities where the wastes are managed, are ever in a position to receive any radiation from LLRW. Properly controlled transportation, use of special handling and disposal techniques, and site monitoring for radionuclide migration should isolate LLRW from the public. No health effects have been documented in people residing near a radioactive waste disposal facility. While scientists disagree on the amount of radiation that is harmful, all agree with the policy of isolating radioactive material and low-level radioactive waste to ensure safety.

\section{Units of Dose and Exposure}

Decay rates do not present a standard that defines potential for an organism to be affected by radiation. Common terms for absorbed amounts (doses) of radiation include: rad, rem, and Sievert (sv). A rad is 'radiation absorbed dose' that represents the amount of energy per unit of living material (Ibid). The rem is a standardized unit that attempts to define a 'dose equivalent'. A rem provides a qualitative index of the degree of biological reaction based on the type of radiation and other factors (Ibid).

Based on literature research conducted during the course of this project, it is the opinion of the author that experts and lay people seldom communicate terminology of dose and 
exposure. One exception is that surface radiation levels of LLRW materials shipped in Massachusetts each year are summarized in the unit millirem per hour. In the example, of approximately 90,000 containers shipped in 1994 , less than one half of one percent demonstrated radiation emissions greater than one times normal background levels of radiation in millirem/hour (LLRWMB, 1996: 24), an amount that would still constitute only a small portion of all annual exposure.

\section{Radiation and Ecosystems}

Just as compounds such as PCBs or DDTs can bioaccumulate in higher-order organisms through biological magnification, so can some radionuclides demonstrated in LLRW. Miller (1985) notes that particularly dangerous LLRW radioisotopes are:

- Iodine-131 (8 day half-life) periodical table notation - I;

- Cesium-131 (27 years) periodical table notation - Cs; and

- Strontium-90 (28 years) periodical table notation - Sr.

Such materials are not diluted or broken down passing through the food chain and thus, can bioaccumulate in tissues, moving-up the food chain.

\section{How Radiation Physically Afrects Material and Living Tissue}

Depending on the circumstances, if radiation ionizes living material it may cause a chemical change in living tissue (LLRWMB, 1994). One reason that exposure to radioactivity, in 
amounts greater than background levels, and especially in concentrated amounts is dangerous is because radioactivity can alter genetic materials (Lippman, 1979). Miller (1985) notes that exposure to radioactivity can cause genetic damage (mutagenesis) or somatic damage (cellular morbidity also referred to as injury).

Mutagenesis represents physical damage (mutation) that is passed on to progeny. Examples of morbidity are: burns, leukemia, cataracts, miscarriages, and cancers of the bone, thyroid, lungs or breasts. Tissues with cells that divide and reproduce rapidly are especially sensitive to radiation (Ibid). Embryos are extremely sensitive and pregnant women should avoid exposure to radioactivity (lbid). Examples of target organisms besides reproductive organs are bone marrow and the digestive tract. Contamination that occurred due the atomic bombing of Japan in World War II demonstrates how radwaste exposure can adversely affect humans and the environment (Shimizu, et al, 1990).

\section{Exposure Pathway}

The route of exposure is an important factor that affects whether radiation may cause harm. For example, alpha or gamma radiation that is normally not strong enough to penetrate human skin, can cause harm if the material enters the body through a medium such as through the air, food or water. Such material can remain in the body until the full amount has decayed, or the material is passed out of the body (Miller, 1985). 


\section{Human Exposure to Radiation}

Radioactivity is naturally occurring, and readily present in environments we live in -- in many forms it is ubiquitous. Typically, the most radiation that people are exposed to in a lifetime occurs from common 'background' sources. Examples of common background sources are:

- Sunlight, and

- Radon (bedrock).

The National Council on Radiation Protection and Measurements (cited in LLRWMB, 1994) estimates that natural radiation consists of over 80 percent of all radiation exposure. Generally speaking, important factors that influence exposure to radiation include where one lives; what one breathes, eats, and drinks; living habits, and where one works. For example living at an elevation above 5,000 feet or frequent plane travel would increase one's exposure. Yet, according to one U.S. EPA/DOE study (cited in LLRWMB, 1994), living habits that we can personally influence, such as the technology we use, contribute only a small portion (less than 20 percent) of all of the radiation we are exposed to.

\section{Dose and Exposure Versus Estimates of Risk and Potential Effects}

Estimates of the effects of a hazard upon organisms are based on calculated dose-response relationships and predictions of exposure (Henekens and Buring, 1987). Together the two define risk assessment. Exposure is how differences in movement and time (activity) allows 
a dose of radiation to affect a target (organism or physical material). Dose represents the toxic potential of a unit of a hazard. Activity can be highly variable and uncertain -- it is difficult to calculate the movement and exposure of one person with precision. Therefore, models and standards are developed that present typical and likely cases of exposure. These use mathematical probabilities.

For a community hosting a disposal facility, a key question is what types of patterns are present that may create a significant potential for exposure to an unhealthy dose of radiation, that is greater than if the facility was not located there? There are many safety procedures and physical controls developed to attain radioactive materials management. Many techniques are proven, such as in other applications of hazardous waste management. Some techniques are not tested in the field because these represent new innovations spurred by initiatives to modernize potentially hazardous materials management.

Noteworthy is that the EPA and the public perceive and value risks somewhat differently. For example, while the public ranks location next to a hazardous waste site as highly problematic and dangerous, the EPA considers other factors to be more dangerous to public health, such as general urban ambient air quality and exposure to dangerous levels of radon in homes (Lea, et al, 1996). 
A reason cited for this discrepency is that the public perceives risk differently. Citizens may be concerned with the degree of control over a potential exposure -- the amount to which exposure is voluntary. For instance, a person living next to a hazardous waste clean-up or a potentially hazardous facility may feel that they have little control over, or relationship to, activities occuring at the site and consequently have no control over exposure.

As is the case in many situations that involve predicting how to minimize risks from hazards, models of radiation exposure contain assumptions since calculations attempt to simplify complex situations into patterns that can be evaluated. A key topic in risk assessment is how to perfect methods of modeling so that error does not arise, and also so that error is not transferred through mathematical models of risk to the extent that the models are of questionable accuracy or precision.

Models built-out of assumptions are used to define what is reasonable risk. Such models are also analyzed to decide what aspects of a system can be managed cost-effectively to produce the greatest reduction in risk. Studies not only attempt to perfect risk analysis, but also to improve predictions of the types of costs society may encounter as a result of engaging in hazardous activities, and resulting attempts to manage them. The studies attempt to improve predictions about where spening on health protection are best allocated. 


\section{What Role for Experts?}

Developing consensus on model designs for forecasting alternatives in a community is essential. Scientists and lay people typically get involved, especially in democratic processes that involve 'public' decision making. In hazard assessment, such as during the siting of a LLRW facility, there is a debate as to how the different factors should be assigned probabilities. Risk communication represents a process of collectively defining risks and educating and communicating to others how risks have been assessed and defined (Department of Public Health, 1995; Covello and Slovic, 1988; Office of Emergency and Remedial Response, 1992). 


\section{Characterizing LLRW and Production Levels}

\section{Federal and State Definition of LLRW}

LLRW is officially defined as radioactively contaminated industrial or research waste such as paper, rags, plastic bags, protective clothing, cardboard, packaging materials, organic fluids, and water treatment residues (EPA, 1994: 8).

It is produced in industrial sectors not directly related to power production or arms production, typically, though not always, characterized by isotopes that consist of short and medium length half-lives. LLRW is often defined by what it is not: spent nuclear fuel and high level radioactive waste, transuranic waste, uranium mill tailings, or naturally occurring and accelerator produced radioactive materials (Ibid).

Massachusetts (LLRWB, 1994) defines LLRW waste as:

'....radioactive material that (1) is neither high-level radioactive waste, nor spent fuel, nor uranium mill tailings, and (2) is classified by the Nuclear Regulatory Committee as LLRW. It does not include waste which remains a federal responsibility, such as that owned or generated by the U.S. Department of Energy, the U.S. Navy as a result of decommissioning vessels, or by the federal government as a result of any research, development, testing or production of any atomic weapon. "Other" radioactive wastes have a radioactive characteristic, but are not included in the legal definition of LLRW because various management methods authorized by the NRC, such as controlled air emissions and sewage releases, obviates their need to be shipped to disposal facilities.

Based on these definitions, it is apparent that management policy for LLRW is not based exclusively on the radioactive characteristics of the material, or the estimated potential to 
impact health. Rather, other major factors influencing how waste is managed in the sector of the economy that it is produced in, political responsibility for material, and the reason it is produced. Another important factor is what government body (such as DOE, NRC or EPA) has jurisdiction over the industry or sector. Generally LLRW is considered less dangerous than 'hotter' material that is classified as high-level radioactive waste. Thus, while the definitions have useful purposes, to some extent the definitions cause the management process to be fragmented, not integrated and comprehensive.

\section{Classification of LLRW in the U.S.}

The Nuclear Regulatory Committee (NRC) uses three categories to classify LLRW based on the radiological hazards, particularly the half-life, concentration, and toxicity of the different radioisotopes in a volume of waste (LLRW, 1994). Generally, most LLRW should not be acutely toxic after 500 years. To paraphrase the LLRWMB definitions (1994: xvixvii) the main categories are:

- More benign 'Class A' wastes (a majority of the Massachusetts stream) that contain low concentrations or longer half-life materials;

- 'Class B' containing up to 40 times more longer period isotopes, with concentration limits by isotope, and container performance requirements of 300 years;

- 'Class $\mathrm{C}^{\prime}$ wastes which due to greater concentrations of radionuclides, must meet extremely stringent packaging requirements to remain durable for very long periods 
(at least 500 years) because waste would contain active concentrations of nuclides above established safety standards for over 500 years.

- In addition, an $\mathrm{AH} \& \mathrm{BH}$ category is defined under Massachusetts regulations to represent materials that also present other hazardous characteristics (such as mixing with other toxic, corrosive, or flammable chemicals).

While classification of LLRW is not based solely on the half-life of material, generally speaking, the half-life of most LLRW is typically less than five years (LLRWMB, 1994). Some radionuclides that violate this exception are:

- Carbon-14 (5,730 year half-life),

- Nickel 63 (100 year half-life),

- Radium- 226 (1,600 year half-life) and

- Uranium-238 (5 billion year half-life).

To summarize, it is no surprise that Lippman (1985) defines low-level waste as 'not very reactive matelials', compared with byproducts of nuclear power production, a principle constituent of which is very high concentration of Uranium-238 that has a half-life of nearly five billion years. For such highly concentrated waste the method of disposal being pursued at the national level is deep underground disposal (LLRWMB, 1996). 


\section{Common Sources of Radiation}

There are three primary sources of anthropogenic (human produced) radioactive materials; however, as explained above, federal regulations (NRC) exclude much of the material from being defined as LLRW due to the concentration of the by-product and the source activity (Lippman, 1985). The main sources of all radioactive material are:

1) Nuclear weapons production and testing;

2) Use of nuclear energy for electric power generation; and

3) Industrial and medical use of radionuclides.

Lippman (Ibid) notes that to date the use of nuclear power has contributed a smaller increment of the release of nuclear contamination than nuclear armaments, and industrial and medical applications have produced still smaller amounts. Lippman (Ibid) estimates that radioactive materials from industrial and medical applications are a small percentage of the radioactive energy managed by humans.

\section{Production of LLRW}

The Air and Radiation Division of the U.S. Environmental Protection Agency (1994: 9) estimates that the production of LLRW, by industry type are:

- 56.3 percent electric utilities;

- 31.2 percent academic and medical institutions;

- 6.3 percent government; and 
- $\quad 6.2$ percent industrial.

\section{Production of LLRW Among the States}

Massachusetts produced the 11 th highest volume of low level radioactive waste in the U.S. in 1993 at approximately 25,000 cubic feet $\left(\mathrm{ft}^{3}\right)$ and 18,000 Curies (LLRWMB, 1994). A rough calculation shows that this material would cover a football field with a volume of waste about one foot deep. At that time, the average volume produced for the states was $10,000 \mathrm{ft}^{3}$. The activity of the Massachusetts waste stream in curries ranked eighth. Using 1993 shipping statistics (Ibid), Georgia processed a volume of waste (over 218,000 curies) three times more active than the next highest state.

\section{Categories of LLRW by Economic Sector}

In Massachusetts sources are classified in the following groups of generator categories:

- Commercial,

- Academic,

- Health Care,

- Utility,

- Government, and the

- Federal government (LLRWMB, 1996). 
In Massachusetts in 1993 (LLRWMB, 1994) more than 600 hospitals, government agencies, and firms were licensed by the NRC or the Department of Labor and Industries (DLI) to use or possess radioactive materials (ibid). Of this set, 261 produced LLRW that required disposal in a federally approved repository and approximately 85 of these entities actually moved waste in Massachusetts (Ibid) to disposal as LLRW. Generally, most of the waste comes from electric utilities.

Two Main Components of the Massachusetts Stream: Remediation and Production There are two main parts to the Massachusetts waste stream. One is materials produced in site clean-up of contaminated soil. The other is material produced in routine processes. Generally, based on 1993 and 1994 statistics, routine production of LLRW is centered in a very small number of licensed entities that have produced a majority of the volume and activity in the whole LLRW load (Ibid: 25 ). The primary routine sources in the State are the nuclear power plants and a medical device manufacturing plant. Similarly, non-routine waste has been produced at a few major routine producers and at a few large scale cleanups (Ibid). In 1994 (Ibid: 2) decommissioning and remediation accounted for 99 percent of the LLRW volume and 94 percent of the radioactivity.

\section{What Might a LLRW Stream Look Like?}

Waste streams have many different characteristics. The sources, types and volumes of waste are highly varied. Table 1 - shows categories of waste and the volumes exhibited in 1993. 
Table 1

Categories and Volumes of Waste in Massachusetts (1994)

\begin{tabular}{lrr|rr}
\multicolumn{1}{c}{ Waste Category } & Volume & Total & Activity & Total \\
& \multicolumn{1}{c}{$\left.\mathbf{F t}^{\mathbf{3}}\right)$} & $\boldsymbol{( \% )}$ & (curies) & $\mathbf{( \% )}$ \\
\hline Irradiated Reactor Components & 383 & 0.0 & 130,546 & 92.6 \\
Absorbed Liquids & 139 & 0.0 & 6636 & 4.7 \\
cartridge Filters & 515 & 0.0 & 1,379 & 1.0 \\
Solidified Filter Media & 156 & 0.0 & 919 & 0.7 \\
Sealed Sources & 147 & 0.0 & 442 & 0.3 \\
Solidified liquids & 334 & 0.0 & 320 & 0.2 \\
Dewatered Ion Exchange Media & 2,308 & 0.2 & 203 & 0.1 \\
Dry Activated Waste - Uncompacted solids & 12,233 & 1.1 & 192 & 0.1 \\
DAW - Uncompacted Bulk Material & 3,262 & 0.3 & 185 & 0.1 \\
DAW - Compacted Bulk Material & 3,497 & 0.3 & 47 & 0.0 \\
Dewatered Filter Media & 614 & 0.1 & 40 & 0.0 \\
Contaminated Large Metal Objects & 367 & 0.0 & 21 & 0.0 \\
Incinerator Ash & 1,354 & 0.1 & 3 & 0.0 \\
Other Dewatered Sludge & 483 & 0.0 & 1 & 0.0 \\
DAW - Soils/ Building Rubble & $1,055,214$ & 97.5 & $<1$ & 0.0 \\
Other Solidified Sludge & 988 & 0.1 & $<1$ & 0.0 \\
All Other (4) Categories & 179 & 0.0 & $<1$ & 0.0 \\
\hline Total & $1,082,173$ & 99.7 & 140,935 & 99.8
\end{tabular}

Source: Table D-4. LLRWMB. January, 1996. 1994 Massachusetts Low-Level Radioactive Waste Survey Report

Excluding highly active reactor components (which the State calls 'non-routine') and remediation soils that are bulky, but low in radioactive concentration, dry active wastes (DAW) make up the main source bulk. DAW includes ingredients such as: paper, clothing, glassware, plastic, metal concrete, wood and hardware which are present in the waste streams of all generator categories and are produced across almost all activities that involve 
radiogenic material. Typically such waste is centrally collected at organizations that produce waste. Occasionally, such material is separated for storage decay or recycling or resource recovery at a later date (Emaleh Interview, 1995). It is unclear to what extent different isotopes and different characteristics of waste are intermingled.

Another major source of radioactivity is in filter media and liquids. A filter might be placed after a pump to isolate radioactive particles from a water cooling line. Alternatively, absorbed liquids may be coolants or research liquids.

\section{Common Radionuclides in Massachusetts LLRW}

Over 50 radionuclides processed in different sectors of the Massachusetts economy contribute to the low level radioactive material waste stream (LLRWMB, 1996). Table 2 presents the total level of radioactivity (in curies) for the refuse materials produced in the State in 1994, highlighting the portion of the annual waste contribution from one year that would remain active radiologically one hundred years in the future. 
Table 2

Massachusetts Low-level Radioactive Waste Stream (1994) Description: Radionuclides With Half-life Greater Than 5 years \& All Radionuclides

\begin{tabular}{|c|c|c|c|c|c|}
\hline $\begin{array}{l}\text { Atomic } \\
\text { Symbol }\end{array}$ & Half-Life & $\begin{array}{c}A \& A H \\
\text { Categ. Waste }\end{array}$ & $\begin{array}{c}\text { All Waste } \\
\text { Categories(1) }\end{array}$ & $\begin{array}{c}\text { Portion of } \\
\text { Total }\end{array}$ & $\begin{array}{l}\text { Amount Active } \\
100 \text { Years }^{(8)}\end{array}$ \\
\hline & (Years) & (Curies) $^{(2)}$ & (Curies) $^{(2)}$ & $(\%)^{(2)}$ & (Curies) $^{(2)}$ \\
\hline $\mathrm{H}-3$ & 12.3 & 486.1 & 7,319 & 10.3 & 0 \\
\hline $\mathrm{Kr}-85$ & 10.7 & 85.9 & 86 & 0.1 & $<1$ \\
\hline Co- 60 & 5.3 & 67.8 & 54,495 & 76.6 & $<1$ \\
\hline C. 14 & 5,730 & 42.4 & 57 & 0.1 & 57 \\
\hline $\mathrm{Ni}-63$ & 100 & 10.7 & 9,044 & 12.7 & 4,522 \\
\hline Th-232 & $>10$ Billion & 10.5 & 11 & 0.0 & 0 \\
\hline Cs- 137 & 30.2 & 9.7 & 83 & 0.1 & 8 \\
\hline U-238 & $\sim 5$ Billion & 1.9 & 2 & 0.0 & 2 \\
\hline Tc-99 & 213,000 & 0.6 & 1 & 0.0 & $<1$ \\
\hline U-234 & 246,000 & 0.6 & 1 & 0.0 & $<1$ \\
\hline Pu-24l & 14.4 & 0.3 & 3 & 0.0 & $<1$ \\
\hline Sr-90 & 29 & - & 2 & 0.0 & $<1$ \\
\hline \multirow[t]{2}{*}{$\begin{array}{l}\text { Table } \\
\text { Sub-tot. }\end{array}$} & $\begin{array}{c}11 \text { Elements } \\
\text { in Table }\end{array}$ & 717 & 71,104 & 99.9 & 4,595 \\
\hline & $\begin{array}{l}\text { All material >5 } \\
\text { year half-life }\end{array}$ & 717 & 71,158 & 100.0 & 4,682 \\
\hline Total & $\begin{array}{r}\text { All Waste } \\
\text { Material } 1994\end{array}$ & $823^{(1)}$ & $140,934^{(c)}$ & $N A$ & $4,682^{(C)}$ \\
\hline
\end{tabular}
Notes (1) Part of total reflects percent of all radionuclides with half-life $>5$ years
(2) Numbers rounded for presentation
Sources (A) Table D-4. LLRWMB. January, 1996. 1994 Massachusetts Low-Level Radioactive Waste Survey Report.
(B) Table 21. Ibid
(C) Table 7. Ibid

Using 1994 as an example of annual loading at a potential facility, review of Table 2 shows that approximately three percent of the waste provided in 1994 would remain active in the 
year 2094. A majority of LLRW would be rendered benign within five years. One could infer that there would be a great degree of processing and handling of waste over the holding time as the large volume of waste that demonstrates decay to safe levels is processed for recycling, disposal and other types of special storage or disposal. An example of this latter case is materials determined to be hazardous due to characteristics other than radioactivity, such as corrosiveness, flammability, or dangerous genetic characteristics. Massachusetts law prevents land burial of this waste and requires that it must be accessible.

The tables do not depict volume and forms of wastes that are collected over longer periods. Nor do they demonstrate the degree to which materials of different half-life are intermingled. This is important because when a safe level of radioactive decay has occurred, material can be processed for removal from the facility without affecting other wastes that require further storage for decay. 


\section{Patterns / Trends in LLRW Production and Management}

\section{Trends and Changes in Massachusetts LLRW Production}

Based on the limited history of (longitudinal) data collected by the Management Board in the late 1980s and first half of the 1990s, it appears difficult to accurately predict changes in the volume and characteristics of the LLRW stream in Massachusetts. Generally, the Board estimates that the overall supply of LLRW will slowly decrease with time based on the assumption that the amount of sites required to undergo remediation or decommissioning will decrease with time. Noteworthy is that the Board often provides extensive information with little interpratation and commentary. Assumptions seem simplistic and incompletely documented, making it difficult to understand causality. Innes (1990) notes that such attributes make it difficult to understand policy and build on the statistical work.

Principally, the LLRWMB (1996: 25) discerns between 'routine' (process by-products) and 'non-routine' production of LLRW, with the latter being one-time (or point) clean-ups and decommissioning. By considering site clean-ups less frequent in the future, the LLRWMB (1996: 25-35) asserts that the volume of waste should become smaller because the major contamination has been eliminated in clean-ups made necessary by law and enforced as a government priority in the last decade. However, ability to predict the volume of remediation wastes requiring disposal seems limited because licensees do not report capital planning or detailed plans for clean-ups. 
Source reduction and minimization activities, both mandatory and voluntary, have resulted in less waste production from 1990 to 1994 (Ibid; GAO, 1996). The gist of efforts is to stimulate reductions in disposal volume by reusing waste, processing it differently, and adopting different applicable technology or practices that result in less waste per unit of production. Processing of waste on and off-site by licensees has been used to reduce volumes and minimize the hazardous characteristics of waste (LLRWMB, 1996: 14-15). One apparent problem identified in Chapter One is that source reduction on-site by the method known as 'storage by decay' may be occurring in less than ideal environments with inadequate safety and environmental controls.

\section{Predictions of Change in LLRW Production}

There are a number of factors which make it difficult to predict how demand for radiogenic waste storage will change. It would seem that if progressive restrictions in air and water discharge standards over the last quarter century are a good guide, that concentrations of radioactive materials emissions allowed to be discharged will become stricter in order to protect public and environmental health, and will result in a larger volume requiring storage. For example, incineration is often used prior to LLRW disposal, however, if incineration regulations become more stringent (such as to control mercury, dioxin, or fine particle emissions), this could mean that a much larger volume of waste would go directly to disposal. Conversely, advances in technology should make it easier to process waste as well as increase the efficiency of radiogenic material use. 
It is also unclear how economic growth and change will influence the overall demand for radiogenic materials. For example, there is great debate whether current levels of nuclear power production should be increased. Experts often relate electricity consumption to economic development.

If practices such as release to sewers, ambient air, or storage for decay are disallowed at current levels, there could be more waste that requires storage. For example, with contemporary concentration-based sewer discharge limits, the radioactive by-products that are freely released to the environment truly are low-level - the emissions are large volumes of very low concentrations of radioactivity. More strict regulations could result in much higher volumes of waste requiring processing. It is not possible to predict if such emissions standards will be more stringent. Current debates about risk from radioactive material are inconclusive and it would appear that these debates will continue into the near future.

It is also important to consider whether potential for environmental release of radioactive material from industry will be different than that demonstrated from the traditional sources -- the military and power industry. It seems that it may be more difficult to regulate private sectors of the economy because of the profit motive (Capra, 1983) and structure of regulations. In market capitalism it seems that a very common externality is for corporations that are not reaching necessary levels of profitability to put off proper waste 
disposal due to the high costs. Externalities that could occur are in the form of dangerous releases, illegal dumping, and other unlawful forms of use or disposal.

New technology could be produced that drastically alters demand for the services from a LLRW storage facility. There is a great history of society solving problems with knowledge and the application of technology.

It is useful to evaluate potential for the use of radioactive isotopes in industrial and medical sectors will change in the future. How will patterns of demand change? For example, if economic growth and development produce a larger high-order economy, will there also be more energy produced utilizing nuclear technology? And what is the likelihood that the volume of radiogenic materials used in commercial applications in medicine and industry will represent a larger proportion of the total amount of radiogenic materials used? In Massachusetts buoyant sectors of the economy seem to be high technology, biotechnology, and computer industry. Similarly, if public familiarity and acceptance of the use of radiogenic materials increases, would there be greater levels of nuclear waste production because there is less opposition and such technology becomes common on a larger scale? 


\section{Social and Economic Benefits Derived in the Production of LLRW}

One area of the economy where people commonly benefit from the use of materials that produce low-level radioactive waste is in the field of medicine. X-rays and laboratory tests are examples of applications that produce LLRW. Nuclear materials are also considered important to medical research which uses longer half-life isotopes such as tritium and Carbon-14 (Nuclear Energy Institute, March 1995). Academic and applied research is another area where LLRW is commonly produced. Examples of the common technical applications are carbon dating, tracing biological growth, and monitoring fluid movement in systems. Biomedical research is particularly dependent on long-lived isotopes (Ibid).

Areas that society benefits from the use of radioactive materials are:

$>$ From the results of research to aid the pursuit of knowledge and understanding;

$>$ National Defense (destructive armaments considered to deter hostility);

> Improved public health, such as from mediacal and high-tech applications;

$>$ New technologies, or more effective or efficient technologies; and

$>$ Realization of human needs such as job satisfaction, social interaction and learning.

These are examples of what Schwab (1993) classifies as benefits that are diffuse in society. The benefits of the technology are spread among many in society; however, siting the production capacity on land can produce negative impacts that are concentrated in a local region. To consider overall benefits to society seems important in order to evaluate the 
value of a land use activity and to enable consideration of whether, and how, a community should receive compensation for hosting an associated land use. 


\section{Conclusion}

Radioactivity presents potential to convey harm on living systems when it is improperly managed and when it is accidentally released to the environment. Much LLRW does not lose its hazardous characteristics except by natural decay, thus until safe levels are reached with time, LLRW presents some degree of potential for harm. Important to consider is what is the potential and what are urgent priorities?

Physical technologies, such as sophisticated containers, and social practices, such as detailed safety protocols, are developed to enable safe waste management. As shown in the tables, there is a small amount of quite hazardous material in the Massachusetts waste stream, and there are some materials with long half-lives. But a majority of the waste can be managed to prevent accidents and upon decay, dispose of it as normal refuse.

It is advisable to develop specific policies to rigorously manage the potentially problematic material, rather than attempt to manage the entire waste stream with more confidence and procedures. Separation of waste streams into components should occur early-on to ensure control over processing and safety. One reason this may be occurring is because there is a greater awareness of source reduction, recycling, and imposition of rules for life-cycle accounting for industrial materials. Encouraging separation also appear to be more costeffective than having to conduct remediation or stringent control over the entire load at a 
later stage. The economy will change and fluctuate in intensity, so separation of waste will enable management policies to be developed for components of the stream as these occur.

Most citizens are not familiar with nuclear science, types of accidental exposure, and ways to mitigate against problems. Rather, most people's knowledge of nuclear technology comes from a vague familiarity of nuclear weapons and nuclear power industry. Widely publicized accidents and events have resulted in a stigma regarding nuclear activity. Yet, there are many technologies, both management practices and physical devices, that enable LLRW exposure to be stringently controlled. These technologies can greatly reduce the potential for accidents to occur and should continue to be explained and publicized.

There is some uncertainty and unfamiliarity of dangers of nuclear exposure and appropriate management. Fear is a common aspect of societal use of radioactive material and it should not be down played. Due to incomplete knowledge, stringent safeguards are required for LLRW management.

Benefits of producing LLRW include:

* Hospitals using radioactive materials to carry-out medical procedures;

* Jobs and revenue generated in businesses and academia, such as in activities that involve carbon dating or food preservation using radiation (LLRWMB, 1995); and 
* Energy consumption produced for the high-order lifestyle of our society, with nuclear energy contributing a portion of the New England energy base.

In order for a LLRW facility siting to occur, public dialogue should occur to explicitly address people's fears and uncertainties about nuclear refuse, nuclear industry, and the procedures developed to enable high quality management. Risk communication is important to constructing an enlightened debate that is not constrained by avaoidable tension. This dialogue requires combining disciplines, such as social sciences and physical science, to develop ways to communicate effectively and to find new ways to safely manage nuclear materials use. Probability can be very useful to show people about how relative risks and unfounded fears arise. When people communicate effectively they are more likely to develop policy alternatives that are useful and accepted by a majority.

Continuous education should occur as to the purpose and meaning of regulations and management practices established to prevent exposure to radiation from LLRW disposal. Efforts should occur to discuss among stakeholders the types of harm that can occur from radwaste, likely sources of problems and accidents, methods designed to prevent accidents, the types of responses available in case of accidents and case studies from actual incidents that have occurred. 
Society should also strive to use appropriate scientific terminology, such as the metric system and the International System in discussions of LLRW management. To do so, more training of experts and laypersons is needed. In government processes involving LLRW land use regulation, there should also be efforts to provide clear and full explanations of when knowledge is limited and uncertain. 


\section{Chapter IV}

\section{Policy Making Criteria: Potential Economic Impacts of a LLRW Facility}

\section{Introduction: Economic Impact Criteria Definition}

Generally speaking, discussion of the economic impacts of a major land use decision involves debate about values (normative debate) in a deliberative process that is very political (Tauxe, 1995; Forrester, 1989). Focused analysis of policy impacts, such as the potential changes that development could cause on a community, involves using ad-hoc analytical techniques guided by general principles (Quade, 1989). This chapter presents examples of types of potential impacts of development. It also examines social indicators, criteria and methods that are useful in debate about the impacts of a LLRW facility. Particular attention is paid to community values, the social system, and prominent institutions in the locality (Pinel, 1992).

The following discussion demonstrates factors and types of information to consider in establishing boundaries of analysis and formulating alternatives to attain the optimum level of impacts for development. Criteria development is intended to aid the formulation of a systematic and comprehensive process to evaluate potential economic impacts. The analysis is concerned with a wide range of potential impacts, especially potential for externalities to occur if there is not action to prevent them or minimize potential adverse impacts. That social costs are not fully accounted for in traditional economic impact analysis is a main focus. Undertaking a broad review of potential criteria places an emphasis on total quality of life of the public interest (Ibid). Gramling and Freudenberg (1992) note that failing to deal with broad impacts has resulted in transferred risks and shifted burden. 


\section{Economic Impact Assessment Methodology and Tools}

When people think of economic impacts conveyed to a community from a project, it seems that they are likely to focus on the directly observable (primary) effects of development on revenue (Ibid). Yet, there is potential for long-term systematic effects to be set in motion as a result of major project development in a region (Finsterbusch, 1977). Carley and Bustelo (1984) review studies that identify 'secondary' impacts of energy and boomtown development on community relations, politics, and volunteer organizations. In characterizing social impact analysis, Gramling and Freudenberg (1992) note that analytical frameworks are needed to characterize impacts that occur over different time frames and across different systems of the human environment. They note:

"...[I]t is useful to recognize that certain categories of impacts are not a matter of substantial concern, particularly if it is possible to identify explicitly the reasoning behind the lack of concern." (Ibid: 217)

\section{A Tradition of Cost-Benefit Analysis}

Cost-benefit analysis (CBA), referred to by some as benefit-cost analysis, is a technique commonly used to deliberate about the economic impacts a project could convey in dollars, and to evaluate which alternative is the most economically efficient (Mishan, 1971). However, it is important to note that CBA is only one of many tools available to support decision making about what is a socially desirable policy (Quade, 1989; Duncan and Jones, 1976). Cost-benefit analysis requires a great deal of information about costs and benefits of choices. All methods are susceptible to user biases (Tietenberg, 1992). 
A problem with any method to evaluate economic impacts is how to place a monetary value on a potential impact. Another is how to objectively define evaluative criteria. Discussing this difficulty Quade (1989: 59) notes:

....[I]n many projects it is hard to classify every impact as a cost or a benefit, let alone find an acceptable way to express in dollars the benefits from such amenities as increased comfort...or the costs such as the need to destroy or move a historical monument. There are also other dimensions of interest to decision-makers for example, the costs may be paid and the benefits received by different sets of people. There is no foolproof way to bring these distributional impacts into the cost-benefit format.

This shows the limitation of using CBA analysis to evaluate potential effects of a project on a community. CBA methods demonstrate weakness in estimating distributive considerations and have inherent difficulty in estimating benefits of public goods (Ibid). There may be cases where a social goal may be desirable irrespective of the cost. Yet, debate about potential policy alternatives requires that criteria be established to estimate what economic effects could occur (Quade, 1989). As Lindsey, et al (1985 cited in Tietenberg) note, a strength of CBA is that it aids development of a rational decision-making process where factors are examined systematically to hypothesize different alternatives.

The following sections present criteria that could be used to estimate potential impacts of a policy. Some criteria presented could provide for 'real dollar' comparisons. Other criteria will aid analysis to consider changes in community that may convey more uncertain ffiscal 
effects. The sections below show broad areas to consider in establishing criteria. Criteria presented could be useful in applying impact evaluation and preference selection tools such as Delphi Methods (Kaplan, 1986; Linestone and Turoff, 1975) Sensitivity Analysis and Nominal Group Technique (Priestly and Cohen, 1995). Tietenberg (1992: 95) defines 'Impact Analysis' as techniques that are used to quantify consequences of various actions in absence of great detail as to potential costs.

\section{Categories / Typologies of Impacts: Time Frame and Physical vs. Social Effect}

Types of potential economic impacts from development of a LLRW facility are presented in a matrix with four main compartments. Two groups address the time-aspects of a potential impact: long range effects and short/medium range effects. This compares with Gramling and Freudenburg's (1992) categories: 1) 'Opportunity-Threat' impacts that occur as soon as an idea is public; 2) 'Development Stage' impacts during more active development and operation of a project; and 3) 'Longer Term' impacts where a community adapts to change, and the focus is potential for over-adaptation. Although long range effects are more uncertain and difficult to estimate, these are presented first because the long-range is necessarily a concern for a planner (Olshansky, 1996; Kent, 1964; So and Getzels, 1988).

The other classification is divided by whether an impact arises as a primarily physical or social effect. A similar dichotomy is used to define psychological sense of community where Lyon (1987) refers to a 'community of place' being related to a geographically defined territory 
compared with a 'community of interest' that is more 'aspatial' or extended such as a church, professional group or lifestyle. The two influence one another. Nasar and Julian (1995) note that criteria may be used to assess effects on community such as social support, fear, crime, and territoriality. Gramling and Freudenburg (1992) are more specific and consider six areas of the human environment: 1) biophysical and health systems; 2) cultural systems; 3) social systems; 4) political/legal subsystems; 5) economic; and 6) psychological systems.

Noteworthy is that there is not a consensus in the literature about what is a fiscal impact -the definition seems to vary by discipline. Descriptions in this paper follow a broad definition of 'economic impacts' that includes within economic considerations subject areas such as social impacts and environmental impacts. These criteria would seem to concern longer-term effects on the community, or its fiscal systems. Fiscal systems are important because they could affect social welfare. Thus, using a broad, socially oriented definition of economic impacts recognizes the interdisciplinary nature of the science.

Approximately twenty types of potential impacts are identified in the matrix that follows according to the major sub-categories:

1) Long-range Physical Economic Impacts;

2) Long-range Social-Environmental Economic Impacts;

3) Short-range Physical Economic Impacts; and

4) Short-range Social-Environmental Economic Impacts. 
Table 3

\section{Matrix of Types of Potential Economic Impacts Resulting from a LLRW Facility Development}

Long-Range Impacts

Social-Environmental Economic Impacts

- Change in Cultural Base/Mix

- Social-Psychological Welfare

- Unique Characteristics of Local Region

- Sense of Community

- Economic Base Development
Physical Economic Impact

- Impacts on Natural Resources

- Physical Health Effects

- Land Use Patterns and Infrastructure

- Economic Character/ Revenue Cycles

\section{Short-Range Impacts}

Social-Environmental Economic Impact

- Social-Psychological Welfare

- Stakeholders/Political Economy

- Equity/Discrimination

- Social Systems
Physical Economic Impact

- Emergency Planning \& Response

- Traffic and Construction Impacts

- Employment / Labor Market

- Public Admin./ Growth Management

- New Infrastructure Demand

All of the criteria identified in Table 3 are discussed below. Generally, it seems that impacts that involve management of nuclear materials, as opposed to development focused on the scale of the facility, are more unfamiliar, uncertain, and generally more controversial. Therefore, emphasis is placed on this subject in discussion. Identification of categories of potential impacts is derived primarily from literature on economic development, environmental and social planning, and urban and environmental economics. The next chapter 
provides examples of deliberations from cases which involve a siting process for a potentially hazardous, or locally unwanted land-use.

\section{Long-Range Economic Impacts and Short-Range Economic Impacts}

For the purpose of discussion, 'long-range economic impacts' occur over expansive periods, well after project implementation, such as four or more years in the future. 'Short-range economic impacts' are predicted to occur immediately, or soon after project implementation. Impacts begin as soon as there are noticeable changes in social conditions (Ibid: 217). To quantify impacts as 'direct' versus 'indirect' effects (Tietenberg, 1992), does not seem appropriate because a direct effect could occur which just takes longer to be manifested.

An example of short range effect is an immediate and demonstrable decline in land prices after a government announces a decision to evaluate a facility siting. A resolution to hire more public administrators, such as the assistance of a City Solicitor, or more Planning Department staff, is also a short term impact. Another short term impact, which might impact long term development of the local region and which has fiscal implications, is a policy that the city must practice a local hiring preference in selecting contractors, such as contractors, architects or engineers to perform project work.

Longer-term effects involve a longer frame of reference. They involve how a community adapts to change in the long term (Ibid). A policy to allocate public expenditure could 
demonstrate quite different effects on public debt depending on whether a loan is for a short or long period. An assumption that facility siting will attract other economic development, such as the location of other new businesses from certain industrial sectors, is a long-range impact. Another long term effect is slow, continual degradation of a commercial zone that has become isolated due to a LLRW facility development. Longer term effects could be:

- A chronic presence of noise, odor or smoke associated with industry;

- Change in employment levels among members of minority groups;

- Cost associated with elevated incidence of disease or death;

- Potential (fear) for adverse accidental effects, such as radioactive material release and costs of emergency evacuation or disrupted business;

- Changes in the community sense of well-being; or

- Changes in the level of tax revenue.

Generally, this paper typifies environmental and public health effects as far ranging impacts. It is more difficult to predict and guard against long-term chronic impacts than short term ones. One reason may be that people who undertake impact analysis are not trained to consider social change in a situation (Rohe, 1982 cited in Tietenberg, 1992). In discussing environmental economics, Tietenberg (1992: 44) defines an environmental problem as one where a future generation could be worse off because of decisions made in contemporary times. Long range effects seem to be more uncertain in source and effect, harder to predict and generally more intangible. 


\section{Physical and Social Economic Impacts}

To further aid discussion, time frames are divided by 'physical' and 'social' effects. This is a difficult ddistinction to make. Social impacts concern how people communicate and interact in groups. 'Physical Impacts' may convey social impacts, however, physical impacts are more directly related to a physical development of the landscape and space.

An example of a 'physical effect' is how infrastructure, such as a new roads, affect circulation of traffic, or friction. Another physical effect might be how new industry develops on the landscape. For example, would there be a chance that development of other potential 'nuisance' type industry might also occur? Alternatively, what other physical change might result if new industries, such as companies that do environmental monitoring, drilling, or waste transport locate in the region? A physical impact could affect natural resources or represent observable physical health-effects, such as cancer or physical injuries. Physical effects on natural resources might be restoration of a wetland, species extinction, or a pattern in a plume of facility air emissions.

Social effects concern human behavior and interaction. They are characterized by change in the community system of communication and influence. Social impacts may be intangible effects that are harder to measure and quantify, especially in fiscal terms. Examples are:

- Public fear from living near a potentially dangerous facility;

- Incidence of mental disease; 
- How people value a community characteristic;

- The way project development is estimated to effect aesthetics, such as a view;

- Estimates of how a project could affect the quality of life or community character;

- Whether a project will differently impact one social group than another; or

- Affects on community cohesion.

\section{Long Range Social Economic Impacts}

Socio-psychological factors have influence on public welfare. To paraphrase Duncan and Jones, (1976) a 'social impact' is a significant improvement or deterioration in people's wellbeing or significant change in an aspect of community concern. Social impact assessment sensitizes planning to what are important and prominent social values in the community, and helps identify important social behaviors and social systems (Pinel, 1992). To Carley and Bustelo (1984) it is focusing public debate on 'social consequences'.

\section{Cultural Base/ Change in the Cultural Mix}

This criteria involves whether and how culture and heritage of a region could be affected by development. It involves whether cultural transmission continues or is altered (Gramling and Freudenburg, 1992). For example, one Native American group experiencing the pressure of development from Phoenix used impact analysis techniques to consider how development would influence community integrity and its deep Indian culture (Stea and Buge, 1982 cited in Pinel, 1992). In Santa Fe, NM neighborhood residents used social impact assessment to 
demonstrate how economic development policy encouraged gentrification and housing displacement by favoring wealthy immigrants over long-time residents who are often members of disadvantaged groups (Pinel, 1992).

Numerous national policies ensure that groups are not discriminated against on the basis of cultural background, sex or race. Examples are programs to prevent discrimination in hiring or lending. Yet, Burchell and Listokin (1978) assert that differential impacts of policies on income groups or women is seldom addressed. Some social conditions that Blakely (1989) says must be characterized prior to evaluation of alternatives are:

- Levels of 'Community services' that provide for social, educational and recreational needs; and

- 'Area demographics' that describe the conditions in different social groups.

Examples of the latter might include the history of different cultures in a region and formulation of a variety of social and cultural indicators that describe the communities and change that is occurring within them.

\section{Unique Characteristics of the Local Region}

Just as there can be unique community values regarding preferred living practices and forms of social interaction, so can there be unique preferences about local aesthetics and quality of life. For example, people may differently value landmarks and characteristics of location. They may have different perceptions of what constitute icons that are unique and contribute 
to culture, a sense of history, a sense of place, or that are important to conventional social practices. Examples are:

- Views, prominent features or natural landmarks;

- Areas or districts of cultural importance;

- Manmade objects that have gained notoriety as cultural icons or landmarks; or

- Other patterns, such as the built environment, that represent unique images.

Design review is one method to quantify potential impacts of a project on cities to ensure that development will not detract from visual character. Vividness and coherence of environment are important aspects of use and enjoyment of urban areas (Lynch, 1960; 119). Luedtke (1985) advocates conducting community aesthetic evaluations to consider: visually-pleasing and displeasing characteristics. Criteria for evaluation include:

- Land use patterns;

- Streetscapes;

- Signage;

- Open space;

- Scale;

- Natural features, and

- Other environmental considerations. 
Taking this idea further, to what extent will change in city or regional environment affect whether and how people socialize, and does it ultimately affect well-being, particularly a human need for social interaction? The American Public Health Association lists social interaction as an essential element to attaining public welfare.

Tauxe (1995) shows how development alters local social traditions. In a public bureaucratic process implemented to ensure that a large scale energy facility siting was sensitive to a community environment, the process itself was a major force that prevented traditional community groups from articulating felt needs. This was because community norms of communication and influence were quite informal, therefore, by not being able to successfully operate in the legalistic process that stressed professional norms and terminology, popular community values that favored aspects of the agrarian social-economy were not expressed.

Blakely (1989) notes that an important effect on private sector investment is the quality of life, including attractiveness and amenity. Definitions of amenity can be highly variable and diverse. Consideration should also occur as to what new sorts of themes or characteristics could be created, and what might be the hypothesized effects.

\section{Sense of Community}

This subject refers to aspects of residential habitat such as neighborhood and home, especially social and psychological functions, outside of inconveniences of project implementation, such 
as noise (Finsterbusch, 1980) or neighborhood disruption. It is difficult to estimate how people will adjust to change. Homes and neighborhoods are objects of emotional attachment iinfluencing one's sense of belonging, rootedness and security (Ibid). The elderly are an especially vulnerable population.

It is noted that community and cohesion can have many different definitions, but important characteristics are solidarity, local service, collective action and social interrealtionship (Sutton and Munson cited in Finsterbusch, 1980). Measures are required to define the extent of contact as well as the range of contact and influence

Common aspects of neighborhood attachment are:

- Satisfaction with neighborhood;

- Neighborhood social ties; and

- Desire to stay or for conditions to remain the same (Ibid)

When attachment can not be measured directly, these authorities suggest using surrogates such as length of residency or duration of rental tenancy. Observation and interviews would also offer powerful tools.

\section{Economic Base / Development in Industrial Sectors}

To what extent will development proposed affect practices and institutions in the local fiscal system? It is difficult to estimate, but worthwhile to consider whether there will be an 
alteration in how money will circulate in the community. Will there be change in the cash based economy? For example:

- Will the informal economy be impacted (Ross and Usher, 1986);

- Will groups be differently affected by such development;

- Will local institutions be involved or have responsibility, such as to finance development; and

- How will links with the external economy be affected?

Income multipliers are tools to assess how money that is spent locally would be expected to cycle through the local fiscal system (Blakely, 1989). Gramling and Freudenberg (1992) note that anticipation of new development can spark other new development.

Discussing the long-range effects of a project upon the economic system, Gramling and Freudenburg (1992: 229) note that the economic system is particularly susceptible to 'overadaptation'. For example, could a local economy become reliant on a single, or volatile sector of the economy? Or is there potential for change to be smaller in magnitude or of a shorter duration than expected?

Blakely (1989) notes that economic change in a community is often subtle and difficult to detect, even with sophisticated analytical techniques. Two areas to monitor are:

1) Socio-economic base and 
2) Community development capacity.

Economic characteristics relating to 'social structure' such as character of the base, and its history, could demonstrate potential for change and vitality. Information on these subjects can help people evaluate:

- The economic development climate, including potential for change and linkage;

- Economic and political conditions, sometimes referred to as capacity; and

- Barriers to coordination (Ibid).

It is very important to consider whether a proposed development fits well with economic development plans that have been developed by the community. Blakely (1989) notes that enterprise targeted in economic development strategies should be selected on the basis of predefined community needs and resources. These needs will have both short and long range characteristics (Ibid: 48 ).

Thus, it is important to consider labor market conditions such as employment by social groups and industry. It is also important to characterize educational backgrounds and provide descriptions of common skills and job descriptions or histories of residents and groups. Levels of underemployment and unemployment are also relevant (Ibid). For example, if a rural community has a natural resource based economy, labor market mis-matches could arise if few residents have training sufficient to qualify them to work in roles in a high-tech facility. 
How will existing industry be affected by new industry? A common focus in economic development is how change in a local economic base will affect revenue cycles? Indigenous growth may help promote wealth retention at the local level because money cycles through the local system longer than if large 'off-shore' or out of town corporations control finances (OECD: 51 cited in Blakely, 1989). Blakely notes that projects can have an impact on the business climate and quality of life by providing long-term career choices.

Another concern may be that shifts will occur with one enterprise displacing another rather than providing for unfulfilled need. This is not win-win; one group would benefit while another loses. If such a shift does occur, it would not likely happen immediately, rather people's activity patterns would change over time, eventually resulting in one new institution being dominant over another. There are numerous criteria and scenarios to consider regarding how a local economy may change from a project going forward.

\section{Examples of Potential Long-Range 'Physical' Economic Impacts of a LLRW Facility} Long range impacts occur as a direct result of operating a facility, or indirectly as effects on community processes. Communities respond to impacts by change and adaptation; however, the way that it occurs and the degree of adaptation are important (Gramling and Freudenburg, 1992). Does the community adapt so readily to a new industry that important cultural traits or occupational skills unique to the community are lost? 
Physical effects from a LLRW disposal facility could emanate from nuclear or non-nuclear activity. For example, aesthetics, or a trend that demonstrates high incidence of an occupational disease (such as repetitive motion related), versus the presence of specific disease, specific monitoring requirements, or specific emergency response strategies and investment due to the presence of radioactivity or fear of high technology.

\section{Impacts on Natural Community/Natural Resources}

Miller (1985) defines the 'natural community' as the different plant and animal populations living and interacting in a given area at a given time and 'natural resources' as materials obtained from the environment that meet human needs. In economics, the environment and natural resources are assets for which we seek to prevent undue depreciation (Tietenberg, 1992: 19). Since ecosystems have limits of tolerance, introducing non-routine activity such as release of contaminants, could cause habitat destruction or species extinction. Such changes affect the health of the environment and capacity to sustain life.

Other examples of ecological problems that could occur as a result of human activity are:

- Domination by new species;

- Rapid change in the natural environment that results in an ecological imbalance or altogether different environmental conditions, or

- Ecosystem simplification (Ibid, 80-85). 
Efforts to maintain pristine natural environments typically involve water, air, and soil quality. A 'tragedy of the commons' to guard against is the occurrence of a synergy where many small economic externalities (such as cases of pollution or environmental harm) combine with the result of ecosystem degradation or collapse. Water pollution from contaminated stormwater run-off is such a problem. There are certainly instances where there are insufficient market mechanisms in place to prevent pollution, or where such preventative policy (risk avoiding policy) does not work as intended.

\section{Physical Health Effects on People}

Long term physical risks to human health related to a LLRW facility could concern:

- Potential effects upon the group of workers at the facility;

- Effects from release of dangerous levels of contaminants; or

- Potential effects on residents residing near a facility (LLRWMB, 1994: 16-3).

Benefit-cost analysis of exposure of a population to a hazardous air pollutant such as radionuclides (regulation of which was implemented in 1979) involves:

1) Estimating the amount of emissions and probable dispersion patterns;

2) Defining the number of people exposed to a risk and calculating degrees of risk;

3) Placing an actual dollar amount on the risk; and

4) Comparing costs of control(s) versus costs of problems (Tietenberg, 1992: 414). 
It is noted (lbid) that many policies to prevent environmental harm produce 'negative net benefits' -- they spin-off additional problems that are in excess of remedies and relief provided. For example, in many cases of air contaminant control policy, economists calculate the costs of control are more expensive (such as due to lost jobs or plant closings) than the cost of incremental injuries avoided or lives saved. Still, there are findings that assert that such costs are often overestimated (ibid).

Glickman and Gough (1990 cited in Tietenberg, 1992) note that health and safety policies of the last quarter century are heavy in content to promote 'risk aversion'. This implies that society values avoidance of risk. Publics usually seem to seek and benefit from a clean environment. A problem that has occurred is that policy to promote risk avoidance has been applied selectively in space. As a result, poor communities have often been recipients of adverse impacts. Facts to support this are the lower life expectancy of people of lower socioeconomic status and much higher proportions of hazardous waste sites being located in poor and ethnically diverse communities. Numerous studies point to spatial discrimination (environmental injustice) and the need to eliminate it in the development process (Bullard, 1990; Hamilton, 1993; Mohai and Bryant, 1992).

\section{Land Use Patterns and Infrastructure}

This category concerns how development of a LLRW site in a location could influence land use in the area immediately adjacent to the site, and in the community overall. One potential 
long-range effect could be opportunity forgone in the period that the site is unavailable for other development while it is used for disposal and undergoes a decommissioning period of approximately several hundred years (LLRWMB, 1994). It seems that in a rural area a few hundred acres would be a small portion of open space while in an urbanized location it might represent a majority of open space, or space available for development.

Another consideration is whether property values will change in the area. In Massachusetts, elaborate mechanisms are provided to guarantee compensation if a property value decline is demonstrated (LLRWMB, 1994, 17-1 to 18). Still, it is questionable whether such policy is adequate, if it will cover the entire region that could be potentially impacted, and if it is equitable? It seems that the existing program of property value guarantees does not provide relief or remedy to renters who may be dislocated as a result of site development. Rather, relief is provided primarily to property owners. Yet, if incentive is necessary to persuade residents to accept a potentially hazardous land use, a property value protection mechanism demonstrates utility.

Comprehensive plans and zoning codes are instruments that identify community preferences regarding areas of development. Another impact to consider is whether development of a site will conform with these legal instrument. For instance, a 'heavy industry' zoning code may demonstrate stringent performance requirements. Does proposed development conform with 
the land use classification and performance characteristics? Will variances be required and what other ways would neighbors be positively or adversely affected?

As discussed in a section below, how will development affect the level of property tax collected and operation of the tax system? Will site development require the community to provide infrastructure (such as roads or storm sewers) or services (water, extra security) for the site that will necessitateadditional public expenditure? And how does it relate to the municipal capital plan?

Haveman (1972) showed that when policy makers make predictions about the benefits that will occur as a result of public investment in water resource infrastructure, the predicted degree of investment returns were often overstated. This is important since not making investment could positively impact a city by not incurring debt or negatively impact it by not allowing investment in a more worthwhile alternative. If a project requires public financial investment, a common method to judge relative advantages and disadvantages of investment is to compare the expected benefits (returns) against the financial cost of borrowing money using a discount rate (Tietenberg, 1992; Blakely, 1989). If the costs of development are not captured in impact fees, potential exists for regressive taxation where residents do not experience benefits equal to the level of financial support provided. 


\section{Economic Mix/Character of the Local Economy}

It is difficult to predict how the make-up of business in the region adjacent to the site, or in the community, could change as a result of a LLRW facility development. Some broad areas to consider in assessing the socioeconomic base (Blakely, 1989) include 'physical/ locational conditions' involving features of the area such as:

- Common natural resources, and

- Land and transport availability. 


\section{Short and Medium Range Impacts}

This section considers more direct impacts that people could experience as a result of a major project being proposed. Construction, transporting waste to a site, government expenditures for legal advice, public fears, and how material is processed on-site all present examples of potential impacts to a community in the short range.

Citizens often ignore abstract plans for regions, such as a comprehensive plan, but respond to tangible developments in their neighborhoods, such as a plan for major local development (Olshansky, 1996). A dilemma is that a focus on the impacts of a major project, such as a NEPA or Califomia Environmental Quality Act (CEQA) review, can conflict with long-range public goals, such as when regulations force major projects to be examined incrementally, resulting in inadequate consideration of long-range needs of large regions (ibid).

\section{Short Range Social Impacts}

\section{Social-Psychological Welfare}

Although they may be difficult to estimate, what effects do fear, or optimism have on a community? Gramling and Fruedenburg (1992) assert that such affects are often immediate. They can influence social interaction as well as longer range interaction in the community. This is particularly the case of facilities that are large, controversial, risky or unique (Ibid). In the case of many LULUs, anxiety is expressed by citizens who fear that community character or public health will be negatively impacted. Can such social-psychology in turn 
impact the sense of community, sense of control, community character, or other economic development? To what extent does rapid change or development impact mental health?

Health effects that can be observed and measured include:

- Reductions in stress related to reemployment;

- Mental health problems, such as suicides or depression, or demand for specific services from social welfare agencies and health centers;

- Levels of self-confidence;

- Crime;

- Alcohol or drug abuse, such as demonstrated in Native American populations.

An example of potential for psychological and sociopsychological effect of development on people and community is available in the environs of the Seabrook Nuclear Power Plant. Emergency sirens are visible in many areas. Billboards that warn about the danger of an accident are a part of the community visual character. On the other hand, there may be substantial benefits to families who have household heads that are able to better provide for needs as a result of employment related to the plant.

\section{Stakeholders/ Political Economy}

These criteria concern how policy development relates to the local political economy. For example, how fairly are different political philosophies represented in decision making, and 
are critical concerns addressed? Tauxe (1996) notes that the very structure of public decision making, being bureaucratic, legalistic and scientific, tends to systematically exclude some of the very constituencies development policy was designed to represent. Tauxe found that farmers, who embody the local culture, were marginalized due to inability to effectively participate in the system characterized by the traits above.

Gramling and Freudenburg (1992: 221) note that there can be substantial change imparted on political and legal systems. Examples are:

- Numerous lawsuits and extensive litigation;

- Formation of new interest groups or new empowerment of stakeholders;

- Demands on individual's resources;

- Exceedence of institutional capacity; or

- Change in legal structure (such as new laws, policies, or administrative structure).

\section{Equity/ Discrimination}

A unique aspect of planning is consideration of potential for inequity and discrimination in space. Special attention should be made to evaluate if any groups may be adversely impacted that demonstrate low educational levels, incomes, or race. A major policy priority in the current EPA Five-Year Strategic Plan (1994) is environmental justice with a focus on environmental quality efforts benefiting all populations within a community equally. Examples of fairness considerations to consider are whether certain neighborhoods, labor 
groups, types of households, female populations, or populations of immigrants could be systematically excluded from realizing a benefit, or systematically experience an adverse effect, from a proposed development. Examples of factors to consider are

- Degree of accessibility to public decision making processes;

- Evaluation criteria definition (in terms of values, cultural importance, gender neutrality, etc.); or

- Recognition of, and preference for affirmative action.

\section{Social Systems}

More immediate impacts on social systems concern how people are affected in their ability to interact, and also their ability to communicate and even trust one another. The process of development may cause new groups to form or others to dissolve. For example, people may feel isolated or alienated from a decision making process that it appears they cannot influence.

\section{Short Range Physical Impacts}

\section{Emergency Planning \& Response}

Since 1986 The Emergency Planning and Community Right-to-Know Act requires communities and industrial facilities to undertake reporting of the levels of chemicals at sites, as well as to undertake planning for response to chemical accidents. For a potential LLRW facility host community, is there adequate capacity in the community to develop an adequate plan and allocate sufficient physical resources and staffing to ensure that it can be effectuated 
in the case of an accident? In particular, do tax mechanisms and program specific incentives provide sufficient fiscal resources and power to ensure equitable program development? This consideration should cover capital expenditure and the cost of financing development (interest or discount rate).

\section{Traffic Patterns and Construction Impacts}

Traffic impacts are often considered in traditional environmental impact analysis $>$ These are a major focus in a list of potential economic impacts in the Management Plan (LLRWMB, 1994: Chapter 16). Heilbrun (1987) notes that transportation planning is an area of economics that is closely related to land-use patterns and cost-benefit analysis is frequently used transportation system policy formulation. The author (Ibid) notes however, that it is difficult to measure and estimate the impact of a new facility on a transportation system.

It seems that traditional traffic analysis is the domain of engineers more than social scientists. In considering economic impacts, to what extent will there be increased traffic volume, noise, demands on public services and infrastructure from a facility? Additionally, will neighborhoods or certain groups be more likely to experience adverse impacts?

\section{Employment \& Labor Market}

How will a potential project affect rates of employment of community residents and the number of jobs within the community in the near term? What will be the effects of labor in- 
migration? In particular what short-term employment trends are underway in the community? For example, have there been layoffs or plant closings that require contingency planning (Blakely, 1989)? Such a closing might result in a large supply of particular skills or career backgrounds.

It would seem that any job creation is desirable, but it is possible that job skills of residents will not match the skills requirements of new potential jobs. There is also a potential problem if the jobs created do not offer a living' wage that will enable workers to meet basic needs or reside in the community. Blakely (Ibid) asserts that, in job creation, it is important to create the right jobs for those in need in the community. If retraining is required, this could establish demand for other public expenditure. Blakely (Ibid: 132) notes that to consider employment impacts, determine:

- How many jobs will be directly created in the new project?;

- What will be the wages of new jobs?;

- What industrial category will new jobs be in?

- Will unemployed people be able to occupy new jobs created? And

- Will there a resulting loss of jobs in other businesses?

Using other LLRW facilities as the basis for study, EG\&G (1994) estimated that approximately 65 jobs could be created in a small to medium size LLRW facility. This is 
exclusive of work generated constructing a facility. Some of the approximately 25 occupations with salary ranges from $\$ 15$ to $\$ 80,000$ per year are:

- Equipment operators;

- Security;

- Clerks;

- Inspectors;

- Operators;

- Technical personnel;

- Management;

- Environmental and laboratory staff; and

- Communication specialists.

For a LLRW disposal facility, it seems that the type of skills demanded would depend on the type of facility design selected. For example, a facility that actively processes waste would require different skills than one that just stores waste. Will waste be treated or will efforts occur to recover resources? Do other forms of hazards exist in the waste such as other hazardous materials or dangerous biological residues? What will be the overall size of the facility and how will the national supply of facilities affect the long term viability of the site being considered in the review? 


\section{Demands on Local Public Administration / Growth Management}

To what extent will a project require public sector review and local financial investment to go forward and will the expense of administration be recovered? One potential public sector resource may be staff time, particularly with a potential for litigation. In an era of downsizing in the public sector, will there be adequate staff and financial resources available to ensure that sufficient service is provided? The purpose of LLRWMB grants is to finance the process of evaluating economic impacts, however, a public concern raised is that the grants are not substantial enough to undertake a comprehensive analysis of the issue (Mckelway, 1995).

Tax revenue collected on a continual annual basis, one time impact payments, and community impact payments are examples of financial incentives that could be paid to a community as a result of hosting site development. The LLRWMB (1994) notes that the State will pay property taxes for a site. In one study that estimates community compensation and benefits from site development in Massachusetts, it is predicted that a minimum of $\$ 48$ Million will be paid for the first 40 years (EG\&G, 1994). A majority ( $\$ 36$ Million) would be from property tax alone. This may be a substantial sum to a community and is approximately ten percent of the total estimated project cost.

\section{Demand for New or Expanded Infrastructure}

Public expenditure that could contribute to a condition of urban fiscal distress may arise when a local government unit is forced to provide goods or services, but there is not sufficient 
revenue to pay for service delivery. Heilbrun (1987) notes that typical reasons for fiscal distress are change in the population or job base of a region. A problem to consider for a LLRW facility siting is whether new or expanded service delivery must occur as a result of a new facility development. In particular, while change is common, will there be any unique demands that a LLRW disposal facility could produce, such as:

- Special emergency response equipment;

- Expanded sewer service or water treatment, such as to serve the new facility or to serve new residents that migrate to the region in increasing rates corresponding with facility development; or

- New roads or major changes or improvements to the traffic and circulation system?

Such impacts are important to consider to ensure that tax policy enacted to pay for the services is equitable. Impact fees and user fees are common actions to recover costs. Additionally, in considering fiscal impacts on a community, will financing the development of a new or expanded service affect the long-term debt and liquidity of the local public sector? 


\section{Conclusion}

Some contemporary media stories describe communities that compete for local sitings of regional facilities such as federal and state correction facilities, in order to stimulate economic development. Other examples are power plants and incinerators. The public should understand that there is great uncertainty in the criteria and methods used in analysis of potential impacts; thus, there will also be uncertainty in the effects predicted to arise. Attempts should occur from early on to create public awareness of the role of values in decision making. The nature of information available and its reliability will also make a difference in the quality or analysis (Tietenberg, 1992: 96).

The array of criteria presented shows that a great deal of impacts can occur. Some will be much more prominent than others. The chance of some oooccurring will be quite remote. Even if an array of adverse social and economic impacts occur, by researching the probability of events and conducting consensus building, will identify opportunities to react to impacts or guide them so there is minimal effects. The socio-political process of exchanging values and opinions would seem to result in more awareness and democratic control at the community level over impacts that arise. The evaluation and assessment process can help build political networks anbolster the local public administration.

Nominal Group Technique, Decision Analysis, and Stakeholder Modeling are processes that rely on public involvement and convert typically non-quantifiable variables into objective ones 
that can be compared (Priestly and Cohen, 1995). Such models often involve systematic examinations of value trade-offs (Ibid). More often attempts to model 'what-if' scenarios are done utilizing geographic information systems (Ibid).

There should be explicit efforts to ensure that positive and negative impacts areequitably distributed - this is a unique role of planning. From an evaluation of the types of impacts that could arise from development of a facility to dispose of LLRW, questions arise:

$>$ Is it sensible for residents to accept incentive to host a facility, and if so what demands are reasonable?

$>$ What level, types, mix, and distribution of incentives is be adequate to compensate for development?

Will a change occur where communities start to realize that the benefits offered are recognized to outweigh the potential adverse impacts? More research is needed to quantify impacts and show how to specifically plan or control potential impacts. Houts, et al (1988) in an examination of Chernobyl show that predicted impacts were different than what was expected. Incentive helps a community protect against adverse impacts, provide substitutions to design programs to provide services that residents seek, and help ensure that exposure to risk associated with development is voluntary as much as reasonably possible. 
The are many cases where predictions of benefits and costs were inaccurate. In some instances facilities have little impact on community. In others there is inadequate impact planning with the result that sponsors realize many benefits, such as a corporation that profits from facility operation, while regressive public policy is enacted to support private industry or deal with problems that arise from development. The next chapter looks at cases and impacts experienced in new facility developments. A focus is on the processes used. 


\section{Chapter 5:}

\section{Case Studies / Examples}

\section{Introduction}

This chapter describes public processes, public opinions, and administrative structures from five cases that involve radioactive waste management or the siting of controversial land uses. The focus is how potential economic impacts are considered and managed at the community level in the siting process. A goal is to identify factors that influence policy design, especially that which is popularly accepted by stakeholders. As noted in other sections, public fear and distrust is a common theme in siting processes that involve potentially hazardous activities.

Five cases reviewed in this section are:

1. Barnwell, South Carolina - The Chem-Nuclear, Inc. LLRW Disposal Facility;

2. Baldwin, Florida - The Yellow Water Road Incinerator;

3. Yucca Mountain, Nevada - The Federal High Level Radioactive Waste Disposal Facility Siting Dilemma;

4. Clive, Utah - The Envirocare, Inc. LLRW Disposal Facility;

5. The Manitoba (Canada) Hazardous Waste Treatment Facility - A Success.

There are numerous examples of people collectively developing siting policies for Locally Unwanted Land-Uses (LULUs) that involve potentially hazardous activities. Similar 
examples also emanate from processes to develop plans to clean-up contaminated sites. There are also many examples of unexpected impacts from cases of accidents or site management problems. Some examples are:

- The Ventron Site in Beverly, MA that involves building demolition and remediation of nuclear materials produced in World War II;

- Corrections facilities sitings;

- Solid waste landfills and incinerators;

- An attempt by Clean Harbors, Inc. to site a hazardous materials incinerator in Braintree, MA;

- Love Canal (New York);

- Closure of the Yankee Rowe nuclear power plant in western Massachusetts;

- Operation of New England nuclear power plants such as Maine Yankee, Seabrook, NH, and reactors operated by Eastern Utilities; and

- Incidents at Chernobyl (U.S.S.R.) and Three Mile Island (Pennsylvania). 


\section{1.) Barnwell, South Carolina - The Chem-Nuclear, Inc. LLRW Disposal Facility}

The land-fill type facility in Barnwell, S.C. (hereafter Barnwell) is owned by the State and operated by the contractor Chem-Nuclear Systems, Inc. Currently it is the only U.S. facility certified to accept all forms of LLRW. Licensed in 1969 and 1971 for two different disposal operations, Barnwell was one of six U.S. sites established between 1962 and 1971 to accept LLRW produced in commercial sectors ruled ineligible for disposal in federal sites and which could no longer be disposed at sea (LLRWMB, 1994: 1-5). One noteworthy aspect of Barnwell is the relatively long period that the facility has been operational. It is located in the U.S. region that generates the most waste (Colgayer and English in Burns, 1988).

\section{Site/ Project Description}

Barnwell has a visible presence because it has a virtual monopoly as a disposal end point debates are often framed in terms of Barnwell. Many stakeholders are involved in site policy making including: State and Federal officials, lobbyists, trade organizations, producers of industrial effluent, local activists, environmental activists, scientists and engineers in service industries, and academicians. When disposal was terminated from Summer 1994 to Spring 1996 for material generated outside of South Carolina, this heightened debate in other states about an inadequate supply of disposal capacity (LLRWMB, 1996).

Barnwell consists of shallow-land burial and was designed with drainage and monitoring techniques (Ibid). Generally, controls practiced in the 1960s and 1970s were less restrictive 
than would be required today. Examples of problems in similar sites are disposal in packaging subject to decay (ie., cardboard), high volumes of mixed and poorly categorized waste and migration of contaminants (Ibid). Discussing problems with the early land disposal facilities the D.O.E. (Cited in LLRWMB, 1994) notes operational problems have included inadequate financial assurances and institutional controls.

A unique site feature is that it is close to the massive $(240,000$ acre) DOE Savanah River plutonium production plant which experienced extensive Atomic Energy Commission (AEC) investment in the 1940s and 50's, and federal investment since then for atomic weapons fuel production (Balogh, 1991: 96-99). Savanah River also has radioactive materials disposal sites for high and low-level material that is produced in the defense sector which is separately regulated. Some of these disposal sites have been operational since the Manhattan Project (Vari, et al, 1994). That site has gained national prominence for its role as one of few remaining Federal uranium materials processing facilities, the scale, and environmental contamination. In summer 1996 it was one of two sites to receive clean-up grants totaling more than $\$ 11$ Billion (Boston Globe, August 7, 1996), which is notable since the DOE budget has been threatened with dissolution and retrenchment.

\section{Public Processes Utilized in Site Design and Policy Development}

The Barnwell region demonstrates a history of economic activity involved with nuclear technology. This is characterized by a prominent role for federal government agencies, 
especially the military. Also active have been private industries supporting the DOD and DOE. A tradition of defense industry may have influenced a political economy that is characterized by deference to military authority. With the invocation of national objectives during Cold War tensions, the public may have come to accept the site as a national priority.

As noted in Chapter II, numerous Federal agencies are involved in site management and development. Key agencies include the: U.S. Department of Energy; U.S. Nuclear Regulatory Commission; the U.S. Department of Transportation; the U.S. Environmental Protection Agency; U.S. Geological Survey and the U.S. Department of Labor.

Barnwell is a State facility. Authority for facility operations comes through the Legislature. Another important legal stakeholder is the Southeast Interstate Compact Region that is composed of representatives from each state as well as two Commissioners. The Compact, with a two-thirds member approval, can certify policy for Barnwell to accept waste from other compacts and states. The Compact is in the process of developing a new regional LLRW disposal facility that has experienced delay in opening (slated for 1995 in S.C.). One study estimates the cost to develop the new site and begin operations at $\$ 152$ million.

It is noted that public participation in local governance is not a tradition in regions outside of New England where there is a history of town meetings and home rule (LLRWMB, 1994: 53). Yet, in descriptions located on Barnwell, it appears that public outreach has been 
extensive, with public education being a major sub-component. It is also possible that public participation has come in other legislative levels or in other forms. One alternative form of involvement could be through legal litigation, which there does appear to be a substantial amount for Barnwell. Legislative action could also have occurred at the State or county level.

\section{Public Opinions}

South Carolina officials have frequently stated that they believe it is unfair that the State is responsible for providing a disproportionate share of the disposal capacity for the nation (Peckinpaugh in Lewis, 1988; LLRWMB, 1994). Indications of a focus on safety are:

- Public decisions to decrease the volume of waste the site could accept;

- Restrictions imposed on receiving certain organic chemical hospital wastes;

- Action by the Governor (1979) to declare State unwillingness to bear the burden of LLRW disposal for the country; as well as

- Action by the State congressional delegation to establish policy to control how states were to be involved in managing and regulating disposal of effluent produced within the respective jurisdictions.

That disposal activities underway at Bamwell are controversial is demonstrated in a Southeast Compact Commission vote on whether to extend the contract to continue to accept Massachusetts effluent. A tie vote continued the contract (LLRWMB, 1994 15-2). This shows how political and contentious disposal is and how Massachusetts is obligated to pursue 
other management methods. Burns (1986) notes that in the 1980s the South Carolina governor cited public opinion as a reason why he enforced stringent requirements for generators to gain access to the site, as well as to deny site access.

\section{Administrative Structures/ Types and Forms of Incentive}

Compensation and impact payment at Barnwell are statutory (as opposed to discretionary). In Barnwell payments are not made to the site community or the abutting community (Ibid). Impact compensation consists of three main measures:

1. The facility operator buys locally and hires locally;

2. Payments to the County consist of $2.4 \%$ of gross operating revenues, with not greater than $\$ 440,000$ per year; and

3. State Payments are $\$ 4.00$ per cubic foot with surcharges of a portion of an approximately $\$ 220$ per cubic foot user fee (G. Larsen, 1989 cited in LLRWMB, 1994). Surcharges are levied in excess of operating fees charged by the site operator. $\$ 160$ of the $\$ 220$ fee is paid to the State as required by a Barnwell access law (LLRWMB, 1994: 15-2).

South Carolina is an 'Agreement Status State' which means that the state has assumed primacy in its programs of licensing local users of LLRW. For this program the State has utilized an administrative structure that attempts to recover a portion of the program cost directly from LLRW producers. By this method South Carolina is estimated to recover more 
than $\mathbf{7 5}$ percent of its program costs from fees. Other states attain cost recoveries ranging from 25 to 100 percent (U.S. N.R.C., 1989 cited in LLRWMB, 1994: 2-16). This policy is significant because it is progressive in structure.

\section{Summary}

No literature was located that directly discussed how social and environmental impacts were assessed for Barnwell. Nor were extensive explanations located on local community involvement in siting. But there does appear to be a political aspect of site operations. For one there are many federal officials, generator representatives, and other national level players who are stakeholders. Also because national attention is focused on the site, there has been a great deal of litigation. Because of publicity and the virtual monopoly over the market, it appears that the local community has been involved in a very sophisticated and detailed debate. The community seems to welcome the revenue the site brings to the region. 


\section{Baldwin, Florida - The Yellow Water Road Incinerator}

This Superfund site involving PCB contamination is an example of a siting process halted due to public opposition. It occurred over a decade ago and shows how opposition can remain strong despite efforts to undertake public education, risk communication and consensus building for a specific alternative. The problems encountered led EPA to improve its outreach and consensus building procedures. The descriptions of this siting are based on an EPA history (Thompson, 1985).

\section{Site/ Project Description}

This site is located just west of Jacksonville, Florida in a region (Jacksonville/Duval County) that contains three other Superfund sites. The population of the Jacksonville area is predominantly lower and middle income categories with an economy led by government employment. The population of the central city is nearly 200,000 with 25 percent AfricanAmericans. The site was in the suburban periphery just west of the city limits. A mobile incinerator was proposed to treat PCB contaminated liquid and soil.

\section{Public Processes/ Administrative Structures Used in Site Development}

A committee was formed to deliberate the intricacies of the site clean-up design. Although it is difficult to discern from the case history obtained, it seems that the committee, staffed by EPA officials, state environmental officials, and some local appointees, was viewed by the public as being composed of outsiders. A Regional Response Team resolved to use mobile 
incineration. This conclusion was based on an economic analysis showing this to be costbeneficial compared with alternatives. The Response Team hoped to obtain a variance for the activity since county ordinance prohibited burning hazardous waste. Specifically, a test burn would show the efficacy of the proposal and the community could select a citizen committee to monitor operations. Scientific evidence also showed that 99.9999 percent burn efficiencies would be obtained (considered by scientists to be high levels of destruction).

Public meetings were a form of outreach used in Baldwinville. Opposition to incineration coalesced at these meetings. Opposition occurred despite the use of communication and facilitation tactics such as:

- Door-to-door campaigns;

- Previous technical presentations and scientific reassurances; and

- Numerous other meetings used to brief stakeholders and build consensus.

\section{Public Opinion}

Public opposition to the siting was strong, particularly in a series of public meetings attended by 200 persons. Primarily, people feared the technology. They thought that it was not sufficiently proven and questioned what would be the consequences if technology did not perform as expected. Public fear resulted despite the fact that education and consensus building tactics occurred. 
The preferred alternative of outside experts was defeated. Although no further information has been located, it appears that the EPA has been required to go back to earlier stages and come up with new site remediation alternatives. Community stakeholders at Yellow River did not trust a high-tech approach to clean-up.

\section{Summary}

It does not appear that debate examined the economic pros and cons of hosting a site, rather the focus was the potential adverse effects of development. There did not appear to be a great deal of incentive offered to proceed with development of the incinerator. One implied benefit would be the site clean-up subsidized by the federal government in order to promote public health protection. It may be that the community sought the clean-up, but without the incineration technology that was perceived as risky. This may be a case where it could have been advatageous to examine the levels of financial savings of one clean-up technology over another, and develop policies to share a portion of the expected savings with the community in order to achieve consensus to use the innovative technology. 


\section{Clive, Utah - The Envirocare, Inc LLRW Disposal Facility}

Clive, Utah is the only privately owned and operated U.S. LLRW disposal facility. Opened in 1988 by Envirocare of Utah, Inc. (Envirocare), it was to accept only naturally-occurring radioactive material (NORM). Yet, through private lobbying and state legislative action the facility is now permitted to receive LLRW obtained in the remediation and decommissioning of sites that provide large volumes of waste with relatively low contamination concentrations (LLRWMB, 1994: 1A-10 to 12). Because the site was permitted in the last five years it is seldom discussed in the literature.

\section{Site/ Project Description}

Envirocare is over 30 miles from residential development or farming and is three miles from the interstate highway. It has rail access one mile from the site. Climactic conditions are such that rainfall is more than ten times less than the average the rate of evaporation, known as evapotranspiration (Ibid).

Shallow land burial is practiced at the site which is approximately one square mile in size. It is designed to withstand erosion and flood for 1,000 years. The federal government has required that the site be zoned 'Heavy Manufacturing/ Hazardous Materials'. Other physical controls are special burial procedures, drainage ditches and fences. 


\section{Public Processes Utilized in Site Design and Policy Development}

Most information located on public deliberation involves action by Federal government agencies to ensure that operation conforms to rules. Many of the other actions involve maintaining agreement state status and compliance with state regulations (Ibid).

\section{Public Opinions}

Most debate about Clive appears to occur between the Northwest LLRW Compact, Federal officials, the State, and Envirocare. It seems that disposal is a concern of the Compact because it may influence regional disposal patterns and affect implementation of Federal legislation. Discussion often concerns regulatory authority and policy definitions (Judd, March 1995; Sinclair, 1995). In 1995 an annual conference of LLRW producers was held in Park City, Utah to showcase the site that was heralded as a success.

\section{Administrative Structures}

The site is located in a county. Envirocare gained a State exemption to conduct disposal on land not owned by the state or federal government. The resolution was based on an NRC opinion that all appropriate authority had been granted upon a license award.

For control Envirocare is required to provide engineering drawings twice per year. Legislative audits, NRC program reviews, and public comments on the license request are other examples of controls on the facility license (Judd, 1995). Envirocare is responsible for 
the site through the period of institutional control. The state of Utah controls a trust fund to ensure that this objective is completed (Ibid).

\section{Summary}

It does not appear that there were many stakeholders involved in economic impact assessment and planning at the local level. The region is sparsely populated and does not seem to have a developed local economy. There probably were not a lot of economic impacts that would be expected to occur in the short term. It may be the case that with low population density, per capita benefits to those likely to be impacted were substantial. The remote site may also have presented a buffer zone sufficient that people felt that they would not be adversely impacted in case of an acute accident. 


\section{Yucca Mountain, Nevada - The Federal High Level Radioactive Waste Disposal Facility Siting Dilemma}

Yucca Mountain is a visible and contentious hazardous facility siting debate underway in the western U.S. It concerns development of a temporary high-level radioactive waste disposal facility. While LLRW management technology is thought to be highly researched and present high margins of safety, high-level radioactive (HLRW) waste disposal technology must have more safety mechanisms because that material is extremely hazardous. HLRW has high concentrations of long-lived isotopes and conveys a greater risk in the case of an accident.

Some assert that there is insufficient knowledge about accident scenarios and probabilities and that the stakes are high for this case. But there are many who assert that engineering science can be used to achieve a safe and effective site. This case is relevant to discussion because it shows how people's conceptions of scientific uncertainty influence debate and policy making. It has not been possible to build consensus. It shows how incomplete knowledge limits debate. For this case, there were not discussions in the literature located on how extensively participatory action research has been employed. This may be a case where it is not feasible to use incentive to leverage public opinion in favor of a siting. The political opposition is strong and does not appear willing to be persuaded with compensation. A problem is that there is no equal alternative disposal site developed in the nation in terms of 
state of the art technology. Management of high-level radioactive waste without this site may be in less than optimal conditions.

Opinion is split between scientists and federal officials who are proponents versus scientists, citizens and public officials in opposition. Congress is very active debating site policy and budgeting (Monitor Radio, July 1996). There is little settlement in the desert region bordering the thirty square mile test range that would host the site that was selected in a National process.

\section{Site/ Project Description}

While states must develop outlets for LLRW, high-level radioactive material (HLRW) is the responsibility of the federal government. Yucca Mountain is the site selected to host undergo deep underground disposal. HLRW has a long disposal time and is generally more hazardous than LLRW. There is some scientific debate about the efficacy of underground disposal.

Disposal will occur thirty miles from weapons testing. Site management systems proposed demonstrate sophisticated high technology and human controls. A 'Monitored Retrieval Storage (MRS)' has been selected for the site (LLRWMB: 1994) with deep underground disposal proposed to occur in salt caves. The site was selected in 1987 based on geological features which include a high degree of estimated physical stability and a water table level that 
is more than one thousand feet below the level set for disposal (1987). Extensive literature exists on the site and HLRW siting that is engineering and physical science oriented.

Yucca was selected as an alternative to a Kansas site in the mid-1970s. The selection process for a high level radwaste site had begun in 1957 when the National Academy of Sciences recommended bedded salt deposit disposal (Tang and Saling, 1987). Yucca is currently the only site in the U.S. being reviewed for temporary storage of HLRW. The concern of opponents, such as the Governor, is that the site will become a long-range disposal site.

Site management systems are characterized by the overlay of many safety strategies and controls designed to collectively present a low probability of accidents, especially ones critical in nature. For example disposal modules are engineered with extensive specifications to ensure safety in case of an accident. There are also redundant policies (layers of protective procedures or failsafes) designed to ensure protection in case the first level of protection fails.

\section{Public Processes Utilized in Site Design and Policy Development}

As a federal facility the siting processes are very bureaucratic, similar to Superfund actions and DOE clean-ups. N.E.P.A. analysis is required as it would be for an federal facility. There are extensive guarantees for citizen involvement in site policy development and implementation. The siting debate is quite visible nationally, both in the media and literature. There is also extensive involvement of the scientific community, such as the National 
Academy of Science; environmental protection advocates, such as Greenpeace; and professional organizations, such as the American Society of Mechanical Engineers.

\section{Public Opinions}

It is proposed to use complex and extensively planned strategies in a sophisticated site management system. While there are some uncertainties that have been pointed to as requiring more examination, many scientists do not believe all of the technologies combined present physical-scientific limitations to the site, rather friction is centered in socio-political factors. For example, in describing development at the site, Moeler (1992) believed that all obstacles were political in nature, resulting from government policy that allows a minority to prevent development from moving forward. Evidence that debates about the facility are uncertain, even in scientific communities, is the explosion theory postulated by Federal officials (Eisner, 1995). While subordination of science to politics is cited in the debate, there is indication among scientists that the issue should be addressed in further detail (Ibid).

Opposition is centered in regional groups of citizens. The most visible and powerful opponents are state elected officials, such as the U.S. Congressional delegates. Other opponents are Native Americans, State and Federal bureaucrats who have the responsibility to ensure that comprehensive impact evaluation and mitigation occurs, and national and regional environmental organizations. The opposition is stiff despite the fact the site is remote 
with few local inhabitants. One fear of opponents is that while the site is being permitted as a temporary disposal site, the site could become the permanent disposal site by default.

\section{Administrative Structures/Incentive}

The siting is facilitated by the Federal Government since the site is on Federal lands. It is typified as being formal, heavy in scientific debate, and bureaucratic. Extensive litigation is apparent and there is no sign of it easing. The Governor threatens more litigation if the siting goes forward (Ibid) with indication that it will.

\section{Summary}

The impasse demonstrated in this case is noteworthy. Tactics used to successfully site potentially hazardous facilities in other cases do not appear to have not worked here. Also common to many siting debates is the fear and distrust of high-technology.

In a skeptical economic assessment of global warming, Beckerman (Cited in Helm, 1991) discusses uncertainty and choice in policy making, the case of catastrophe, and discounting the future. Many of his points are comparable to the Yucca siting where people are fixated on the long-term nature of the issue and the potential for catastrophe. Rather than advocating for policy that can be extremely costly to society in the short-term to prevent adverse effects of global warming, he recommends taking additional time to analyze costs and benefits of alternative policies. The objective is to gain a more comprehensive understanding 
of alternatives. This will allow stakeholders to identify 'no regret policies' (win-win policies), such as eliminating market imperfections, that do not carry potential to adversely impact society.

Beckerman (Tbid) also discusses discounting the potential for future problems to some extent because technological innovation will occur with time and allow greater benefits. If decisions are implemented, systems theory would indicate that examination will continue and flexible changes can occur in the future. In the case of Yucca, with a retrievable system, there is flexibility to modify technology as long as there is not a catostrophic accident such as a mine shaft collapse.

Finally, Beckerman (Ibid) recognizes a tendency to promote risk aversion at any cost. He notes that this occurs especially when there is no statistical basis for associating probabilities with outcomes. His conclusion is that costs and benefits can be greatly exaggerated and highly politicized. Focusing on low probability events can also present costs in that more probable events and activities in society which could be controlled, are not. 


\section{The Manitoba (Canada) Hazardous Waste Treatment Facility - A Success}

This siting for a Canadian facility to dispose of hazardous industrial waste is unique because of the limited public opposition encountered during site development. It is characterized by the ability to build support with time. Success occurred creating a public dialogue that resulted in a majority of local citizens and regional stakeholders supporting a siting. This case in Manitoba for a hazardous waste treatment facility appears similar to the Canadian model for siting LLRW disposal facilities which Brown and Pollack (1993) describe as "...community-based, cooperative, and consultative". Castle's 1993 study is the basis for the descriptions provided below.

\section{Site/ Project Description}

This Manitoba Hazardous Waste Treatment Facility (MHWTF) is located in a Canadian province with an agricultural economy that produces small quantities of hazardous waste. When the legislature identified a lack of local storage capacity to treat, store and dispose of 'indigenous' hazardous effluent, the Manitoba Hazardous Waste Management Corporation (Corporation) was established by a special act. The Corporation mission was to establish, operate and maintain a regional hazardous waste management system.

Site selection in Manitoba involved two stages:

1. A broad process to publicize commencement of a siting initiative. This stage provided general information on the goals, objectives, and basic strategies for siting, with an 
objective to identify (using opinions from questionnaires) localities where there was strong public support for learning more about the siting. It is characterized by formulation of a plan with central goals and some supporting objectives. Extensive rules and procedures were not established beforehand ; and

2. Detailed evaluation of compatibility of a community with the proposed use, with approval of a siting and development of detailed site procedures in later stages.

The host community finally selected is rural with 1,600 residents centered in three villages, having an agriculture-based economy. At the point of site selection, Montcalm was in the midst of a long economic slump with population declines. Interest in siting was initiated by a committee established to promote economic activity in the municipal region.

\section{Public Processes Utilized in Site Design and Policy Development}

The siting process in Manitoba focused on procedure. Directing officials believed that failed sitings usually occurred because of procedural (socio-political) problems rather that technical (physical science) ones. No effort was made to select a specific site beforehand. Rather, a detailed facility plan devised at the outset showed market characteristics, described the types of activity that would occur at the plant, provided basic and generic site specifications, and general operating specifications. For technical siting evaluation criteria the Corporation created exclusionary and inclusionary criteria. 
Analysis of regions for compatibility with siting objectives were made only in response to invitations from communities. Preliminary evaluations were suspended in locations where proposals failed to maintain acceptable levels of support, such as when there was early and strong opposition. The 'volunteer method' was utilized previously in a similar siting in Alberta that resulted in three communities bidding for location of a plant. For the Manitoba siting there were 60 declarations of interest, primarily from municipal councils.

Individual concerns about the siting were addressed in small groups and by person-to-person contact. A reason for using one-on-one type communication format was belief (by the MHWTF officials and advisors) that people did not want to raise personal concerns in large, public groups and meetings because of being shy or fear of appearing silly. Therefore, a 'town meeting' approach was avoided. In the Alberta siting process, large forums were not considered useful environments for communicating details of a complex facility proposal. Castle notes that officials believed town meeting processes allowed complex proposals to be oversimplified and served as forums for opposition formation.

In place of large open public meetings the siting process centered on 'open houses'. Many such meetings were held and provided citizens with opportunities to discuss the project with proponents and provincial environmental officers. Some 24 communities had open houses. Questionnaires were used there as well as in later stages as an survey instrument. 
Referenda were held in communities were there appeared to be substantial and sustained support. The purpose was to determine if more detailed public deliberation should occur about a siting. In communities with favorable referendum outcomes Community Advisory Committees (CACs) were formed to conduct further research and planning.

One unique characteristic of decision-making in Manitoba was that staffing for the local CACs was voluntary. CAC meetings were publicly advertised and people were allowed to volunteer time serving on the committee without any need for appointment or approval.

Among the tools used by the CAC to study the siting were meetings, presentations by technical experts, and trips to view similar projects in other locations. To resolve the major technical concern that arose of threat to the facility from being in a flood plain, the CAC resolved to erect a dike around the site. A Terms and Conditions Negotiating Committee and an Environmental Impact Committee were formed in later stages of site planning. Important developments regarding economic performance of the site was that land the facility would be placed on was always the responsibility of the Province.

\section{Public Opinions}

Castle notes that a key element of the Manitoba siting approach was not to identify an ideal physical site, but rather find a willing community - much of the early siting work involved building popular support for a facility in a host community. Corporation members felt that 
broad community support was required. By addressing political opposition the Corporation sought to directly address a common reason for defeat of what Castle (Ibid) defines as "...technically adequate facility proposals."

In Montcalm the informal social networks, such as ones that were used to gossip, appeared quite active and useful. Public officials used what they learned to shape decisions and they also used the networks to build support. The role of public opinion seems particularly important in the later phase. At one point opposition arose, but it was demonstrated that it was a minority, and officials actively addressed opposition concerns.

The role and stature of local government officials also played a significant role in decisionmaking. Particularly important is the visibility, prestige, and leadership provided by officials, such as mayors, select persons, and municipal finance officers.

\section{Regionwide (Provincial) Siting}

Castle notes that major environmental organizations in the province supported the project. In addition, the corporation attempted to recruit provincial environment staff and some representatives from environmental organizations to participate in the process. The author notes that it was difficult to get them to participate, but helpful to have them on hand. 
In the preliminary stage, questionnaires were administered at open houses with 68 percent of survey respondents favoring further investigations in the community. Castle considers this 'relatively enthusiastic'. Five communities that were selected to further investigate siting demonstrated strong support, with ranges of 62 to 90 percent approval.

One of localities receiving further study had an existing government atomic research facility. Castle speculates that high proportions of nuclear scientists contributed to public support. The author notes that other research 0 shows that publics familiar with the operation of 'riskladen' facilities are less fearful than the general public.

Two communities that showed strong initial support for undertaking further planning defeated continuation of siting in referenda. Officials interviewed cited reasons for defeat as:

1. Change in the political affiliation of elected officials or change in the make-up of elected bodies, and

2. Inadequate time (less than 18 months), particularly votes taken too soon, with insufficient time to work within the community to build support.

Castle notes that in cases where the public corporation did not proceed with siting, the reason was strong opposition from residents in areas immediately adjacent to proposed site locations. Another common problem was the occurrence of disputes between members on local advisory 
committees that resulted in protracted decisions and delay. Finally, lobbying by political officials could also result in delay that resulted in a local siting process to be halted altogether

\section{Montcalm Siting}

A local referendum was used to ensure that there was support to go through with the project. In Montcalm a yes vote of 76 percent in favor of siting was considered strong support for the project. The Montcalm the siting may have benefited from the rural characteristics of:

- A rather homogeneous population (a French speaking enclave) characterized by agrarian occupational base, relative isolation, and a dominant religious or historical culture; and

- A community where personal interaction was often typified by many more 'personal' relationships as opposed 'status' relationships such as would be encountered in a typical business transaction. The former enables more personal contact, personal discussion, and persuasion (Bierstedt, 1974).

In Montcalm personal relationships were so developed that when a petition was circulated, based on rumors and gossip, local officials discounted its validity. This decision was based on resident's comments that they signed the petition out of peer pressure and to avoid on the spot personal confrontations, rather than real support for the petition. 
Castle notes that the Chief Executive of Montcalm was a strong proponent of the facility. The executive was a well educated technocrat who had served in the Canadian Foreign Service, was very popular, practically a local celebrity. It appears that a strong and visible opinion leader was useful in helping galvanize public opinion in favor of the siting. Besides having the official authority of office, a leader may demonstrate status, competence, and leadership skills (Bierstedt, 1974) that equate into power and lend credibility to a process.

\section{Administrative Structure/ Types of Economic Impacts}

Based on Castle's review, discussion of economic impacts focused on incentive to site the facility. The committee considered the main incentives to be $35-45$ jobs and $\$ 250,000$ in annual tax assessments. A survey conducted of residents showed strong belief that there would be positive economic developments as a result of the site. Castle notes that with a small population of 1,600 the economic benefits per capita would be high.

\section{Summary}

This case resulted in a community accepting the a hazardous waste treatment facility siting with a majority supporting the project. A cooperative siting approach helped build political support and galvinized opinion in favor of a siting. It was characterized by a lot of personal one-on-one communication and informal persuasion (versus more strict administrative/ legal actions). The positve economic impacts were perceived by residents to be substantial even though this siting involved a land use activity that typically incites strong opposition. 


\section{Conclusion}

The concluding chapter synthesizes the study findings, but some common attributes of these case of hazardous facility sitings are provided here. Open public proces are commonly used to provide access to government decision making and enable involvement in policy making. A consultative/collaborative approach which is perceived by stakeholders as legitimate, and limited in formality, may help avoid legal action by building inclusion and avoiding potentially unpopular policy -- it permits understanding of opposition at an early stage and provides for addressing issues with negotiation. There are many cases where efforts to build consensus and obtain stakeholder involvement fail. This shows the importance of continually monitoring opinions and constantly building consensus and inclusion where feasible.

One theme in the limited set of cases reviewed was potential to change administrative structures and policy concerning land uses. Opposition may fear that policy will not be effectuated as developed. They suspect that rules or agreements will not be followed with the effect that stakeholders will experience adverse impacts. Conversely, as conservative facility designs are demonstrated to work with many net benefits, there have been cases where permit conditions or operating conditions are modified without community opposition.

Analysis of fiscal impacts of development, such as detailed examinations of economics involved in alternative policies does not seem to be common to the cases reviewed. Making economic and fiscal analysis a more central part of the process may help clarify the role for 
incentive. Values must also be discussed within economic analysis. Education can help identify types of economic impacts -- both positive and negative that are probable. Findings of economic impacts can also be used to better rank alternatives. Education also promotes examining the relationships between economic theory and social values. The cases show that there is not a great deal of economic information on the costs and benefits involved with risky land uses and long term decision making. 


\section{Chapter 6}

\section{Recommendations on Assessing the Economic Impacts of a LLRW Facility and Attaining Equitable Siting Arrangements}

\section{Introduction}

Success in LLRW facilities sitings depends on a commitment to a social planning context -it requires realization that political issues are prominent. Many studies examine national and international difficulties that surround sitings of radioactive waste disposal facilities. For LLRW disposal particularly, a common focus in the last decade is problems encountered in the political and institutional processes to site facilities. This contrasts with the technical (physical science and engineering) issues that were a focus in the 1960s and 70s (Castle, 1993; Kasperson, et al, 1983). Attempting to outwardly address the social and political nature of sitings concerns:

- Roles and requirements for technical expertise;

- Recognition of local values and culture;

- The affect of stakeholder's values, definitions and assumptions on decision-making;

- How to deal with fear of technology and accidents; and

- Debate that is emotionally and politically charged (Houts, et al, 1988).

Synthesized below are recommendations on how to structure analysis of the social and economic impacts of sitings. The objective is to promote policies that minimize the adverse impacts involved in sitings. A major assumption in this study is that economic impacts can not be examined independent of a larger, and more comprehensive analysis of potential social 
impacts of development. Thus, to promote a positive analysis of potential economic impacts that will result in some municipalities seeking to host a site, it is a recommendation of the author to consider social and economic impacts as early and as comprehensively as possible.

There are not straightforward patterns of recommendations in the literature on how to structure and administer the socio-political process of evaluating and managing the social impacts of siting potentially hazardous facilities. However, regulatory performance deadlines are approaching in the U.S. (although many have been overlooked in the past), combined with stockpiling refuse that require disposal outlets, which are causing the issue to be prominent. This debate is influencing new paradigms to take shape.

Discussion of how to evaluate and plan the social and economic impacts of a LLRW facility siting occurs in four parts:

1. Presentation of factors that influence economic impact planning;

2. General discussion of issues, analytical techniques, and paradigms;

3. Explicit discussion of equity issues -- a prominent topic in contemporary planning; and

4. Potential modifications to public administration and policy to attain successful sitings. 


\section{Presentation of Factors That Influence Economic Impact Planning}

In order to realize a successful siting, effort is required to evaluate different alternatives.

Obtaining consensus on how to proceed with development requires planning on how to promote positive impacts and minimize adverse impacts. Figure 1 presents eight factors that

Figure 1

\section{Factors Influencing Successful Sitings And Planned Impacts}

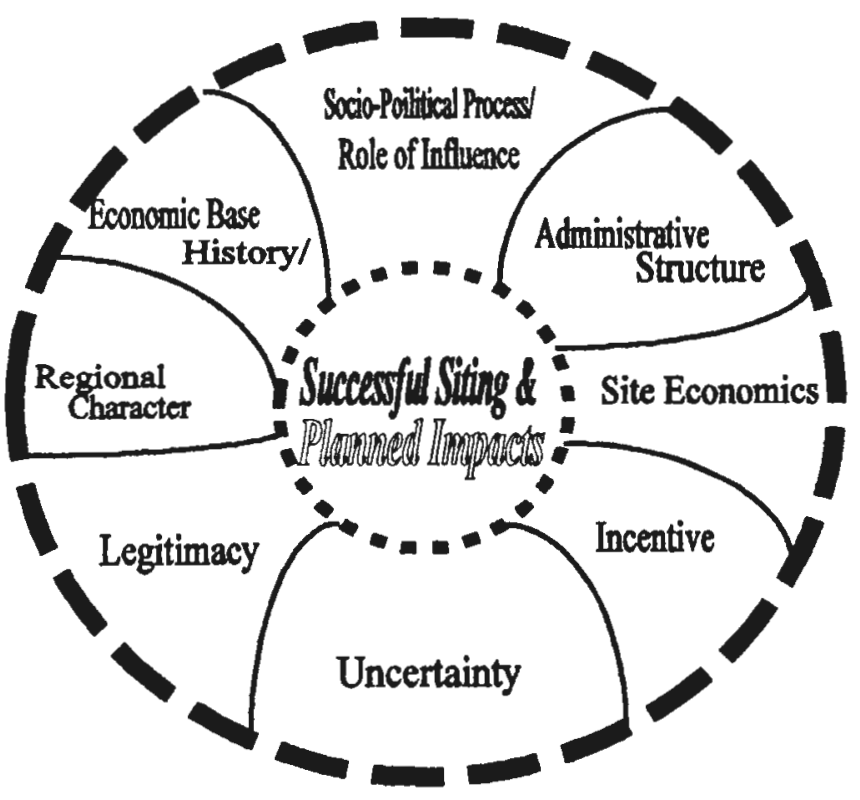

influence the formulation of a political/administrative process to evaluate potential economic impacts of a potentially hazardous facility. These factors relate to how impacts arise. There is not definitive mix and relationship between factors -- the diagram attempts to show the 
amorphous or overlapping nature of factor relationships. It is not a complete matrix, but it is useful to assess factors in relation to one another on a continuing basis. Factors are explained briefly to foster further discussion and should be considered in relation to the types of possible impacts presented in Table 3 (Page 82).

\section{Socio-Political Process and Role of Influence}

Efforts to build networks of support and consensus are political and involve group interaction. People have different values and group behavior is highly complex. This factor concerns how power and influence are manifested in people's interactions and deliberations.

\section{Uncertainty}

Incomplete information is a fact of life. For a LLRW facility siting stakeholders may not know how effective is technology. What is the probability of accidents? What issues and events may occur that will influence debate? What level of uncertainty is acceptable? How will people act on and value uncertain information?

\section{Regional Character/ Location}

This concerns the population density and demography of a community and region considering hosting a site. It concerns how people interact in groups and operate social networks in an area. It may relate to distance between people, or the frequency of communication personally 
or using technology. Location also related to the linkages to the economy outside the community. Many human and ecological systems are evident in a location.

\section{Economic Base/ History}

This concerns how the history, social and economic structures that people are accustomed to relates to proposed development. What economic trends have been manifested? What are physical and social characteristics of the local economy?

\section{Legitimacy}

Legitimacy concerns the extent people are willing to accept or defer to authority. It concerns the fair design of public policy. For example, do community residents feel that imposition of impacts will be voluntary? People are more likely to view a process as legitimate if they benefit from development or understand the collective meaning.

\section{Incentive}

Incentive concerns attempts to modify behavior with rewards. may be used to make exposure voluntary and build consensus. Defining how to distribute incentive, such as in an equitable basis, depends on values. 


\section{Site Economics}

Financial aspects of a site are relative to the economy in which it is involved. Some portion of utility will be locally based and another portion based on factors outside the region. In this study other relationships discussed are public-private sector links and fiscal relationships in time and space. What aspect of costs and benefits are noteworthy? What is the effect of market supply and demand on a site and when is market intervention appropriate?

\section{Administrative Structure}

How are rules codified and procedures selectively applied to influence and guide group behavior? This concerns potential for litigation, fair representation, and appropriate scale. It also involves site management and operating policy. How are accountability and oversight of technology and operating practices used to conduct LLRW disposal/ management? 


\section{General Discussion of Issues, Analytical Techniques, and Paradigms}

This section examines broad substantive issues that influence LLRW management policy formulation. Discussion is intended to promote awareness of how these factors influence debate. It also examines potential to facilitate successful LLRW facility sitings by publicizing these issues and actively attempting to influence the outcomes.

\section{Systems Analysis is Useful}

Systems analysis is complementary to economic impacts analysis and the use of compensation and incentive in LLRW disposal facility sitings. In systems analysis future action is determined by continually examining objectives and alternative policies, comparing where possible economic costs, effectiveness and risks (Quade, 1964 cited in Fisher, 1971). Systems analysis is amenable to siting land uses involving radioactive material because the issue is broad in substance, contains uncertainties, and is long-range in nature. A problem is that the method requires extensive staffing, but government cutback is often the rule.

\section{Leave Technology Selection For Later Stages}

In summarizing how to evaluate cost (disutility) considerations in systems analysis, Fisher (1971) emphasizes avoidance of heavy emphasis on mathematical modeling and computing. He recommends postponing evaluation of detail until later stages. This advice does not seem to be heeded in many LLRW facility sitings. Stakeholders charged with siting seem too often 
to focus on details of site management technology, or are extensively concerned with physical site selection procedures. More important is cultivating widespread support and favorable public opinion regarding the subject.

Technology in the form of either management practices or equipment does not seem to be a major limiting factor -- whatever site is selected will be highly engineered. There will be a great deal of scientific theory underlying it and there will be many redundant procedures to ensure that the site is safe. Rather, the Canadian model focuses on socio-political considerations involved in picking a site. The belief is that with satisfaction of a few broad physical site selection criteria, such as not being in a flood plain, and acceptable soils, other impediments to physical site design can be addressed with engineering science.

It is the opinion of the author that uncertainty or technology should not be a limiting factor in site development. But since people may associate uncertainty with adverse economic impacts, such as potential for accidents, it makes sense for important uncertainties to be addressed by subcommittees as early as possible. This prevents potential impediments to siting from being put off and presenting potential to hold-up the siting process at later stages. For example, studies should be made as to how to isolate highly toxic waste, long lived isotopes, or concentrated wastes as early as possible. 
One area to address this issue is in problem formulation. Well thought-out policy statements about the role of engineering science and high-technology in site design can explain the confidence that experts have in existing technology. Endorsements or statements by environmental advocacy groups or other stakeholders such as political leaders can help promote detailed analysis of management and control technology in later stages.

\section{Defining Economic/ Social Impacts}

Seldom in the plans and policies of the Massachusetts LLRWMB is there discussion of what constitutes an economic impact. Nor is there discussion of potential for differential impacts on social groups. As Pinel (1994) notes in discussion of 'social impact' assessment, the definition is not concrete, varying by profession and subject under review. Definition of a fiscal impact to economists, often does not account for social costs or hard to measure social impacts such as externalities and spin-offs. Conversely, in sociology there is more likely to be a comprehensive focus on the effects of development upon group behavior. Since there seems to be increasing awareness that human impacts on the environment can be profound and complex, it seems that research is needed on how to unify the theories of these seemingly distinct fields.

Descriptions in this paper follow a broad definition of 'economic impact' that includes within economic considerations subject areas such as social impacts and environmental impacts. 
These criteria would seem to concern longer-term effects on the community, including effects on social welfare. Using a broad, socially oriented definition of economic impacts recognizes the interdisciplinary nature of the science. It also points to a need to build links between arts and sciences that are now held to be somewhat distinct.

\section{Recognize Difference Between High and Low-Level Radioactive Waste}

A major difference between high and low-level nuclear refuse is that the latter does not usually contain the high concentrations of hazardous radioactive isotopes. LLRW is generally thought to be manageable with existing technologies and practices. Conversely, for high-level radioactive waste there is more debate as to what practices are optimal and safe. Any effort to manage LLRW should explain the differences between the two waste streams. There should also be efforts to deal with inconsistencies and overlaps between the two categories. For example, a small portion of LLRW appears to demonstrate high toxicities, and efforts should occur to manage this material separately and as high level waste.

\section{Promote Public Debate and Promote Familiarity and Learning of the Subject}

Saving extensive analysis of detail until later stages will also serve the process by providing sufficient time to educate the public about nuclear technology, the history of nuclear waste management, and nuclear policies. Time is needed to gain familiarity of the subject and develop educated opinions about nuclear materials management. Citizens are often not 
routinely familiar with this subject and are fearful of technology which they do not understand. Much of the ensuing discussion examines how to build capacity to promote understanding and build consensus on acceptable policy.

\section{Promote Leadership and Authority}

A characteristic of many potentially hazardous facility sitings is public distrust for authorities responsible for siting land uses that convey a broad public good, but which may convey adverse impacts to the local area. Providing leadership training to elected officials, community members, and citizens to help them communicate effectively and maneuver successfully in political negotiations can promote clear communication and policy development. A question is to what extent should this occur in any one location? Building leadership skills can help:

- Ensure that consistent messages are provided by leaders;

- Avoid contradictions that are not value based and which could cause confusion;

- Ensure that leaders are familiar with communication skills, as well as scientific information, findings, and comparable cases; and

- Prevent differential access to information. 


\section{Reconcile the Opinions of Citizens and Experts}

Another focus is how stakeholders formulate consensus by the exchange of observations, scientific information, and beliefs about how the economy and social fabric will be effected by development. How can laypersons and scientists resolve discrepancies about expected development impacts? Contemporary approaches that could help achieve consensus are:

- Design/ policy charettes that introduce stakeholders to one another and which promote detailed examination of issues and formulation of policy alternatives;

- Negotiations facilitated by trained neutral mediators, where stakeholders are forced to resolve issues. In these formats, outcomes are often viewed as fair and legitimate;

- Directly undertaking hazard/ risk communication using multimedia tools such as videos, posters, and hand-out literature to clearly explain issues, uncertainties and the state of the art;

- Constantly monitoring public opinion;

- Use of consensus building techniques such as new delphi methods, Nominal Group Technique, Stakeholder Modeling, and Decision Analysis. These methods help define alternatives and rank them according to stakeholders preferences using statistical methods (priestly and Cohen, 1995);

- Use of visioning and descriptive technologies such as Geographical Information Systems (GIS), Computer Aided Design (CAD), and visual scenario building to show what a built-out alternative could look like in physical space. 
- Using cases, storytelling, and site visits to demonstrate actual experiences and review applied plans and policies.

\section{Recognize Limits to Technological Optimism}

A technologically optimistic paradigm where engineers or scientists assert that they can control and manage adverse impacts does have limits. There is often not clear recognition of uncertainty. Another problem is that small impacts could accumulate over time to convey a substantial adverse impact. Experts may be overly influenced by values common to the profession, neglecting values important to society, or to other professions. This implies that there is utility in using an interdisciplinary approach early on, such as seeking the opinions of residents or consulting professional disciplines commonly excluded from decision making.

'Lay' citizen fears may be legitimate because residents are aware of specific attributes of local areas. Citizens may know of inter-relationships between different factors in the community, such as topography, history and neighborhood culture. Thus, it is sensible to heed their ability to predict that a traffic circulation pattern will change, or that a neighborhood or stream ecology will change because of development. Stakeholders involved with local areas, or issues, for extended periods may possess unique observations about local character. 
Unless compensation or mitigation measures that are perceived to be equitable are designed into development proposals, projects have potential to be unpopular with many in the community. Opposition may be expected if public approval is not cultivated. It may also be unlikely that citizen exposure to adverse impacts will be voluntary, or that they expect positive impacts. Thus, public processes should remain in place to minimize adverse impacts. Examining potential impacts and compensation is sensible to include as early as possible to build approval.

Engineers and scientist can benefit from training on how to negotiate win-win alternatives that dually achieve project objectives and reduce adverse impacts through creativity and clear communication. Engineers and design professionals should be aware of how to define impacts, how impacts arise, how to mitigate them, and the successful use of compensation to reduce residents' opposition to development. Community resources are often common property, so mitigation and compensation offered by development sponsors should be directed to the improvement of common community resources, such as schools, parks or public investment funds with benevolent objectives.

\section{Deal Directly with Citizen Fears and Potentially Irrational Behavior}

Likewise, there is evidence that citizens can be irrational, particularly with events or scenarios they are unfamiliar with. Clear research and definitions of different types and levels of 
impacts that may be conveyed to a community promote clear discussions of how to control development and minimize adverse risk. Cultivating voluntary inclusion in site development appears to be the best way to build citizen awareness of projects and build acceptance for development alternatives.

\section{Importance of Addressing Fear and Uncertainty}

Addressing citizens concerns is important because this indicates uncertainty and the need for research into why there are real, or perceived issues. Identification of controversies may point to subjects that require the formulation of planned response. In a real event, such as an accident, if issues have not been addressed, contingencies evaluated, and response plans generated, then it is not possible to know how people will react, and there could be adverse results. For example, during recent coastal flooding, when evacuation plans were implemented along the New England Atlantic Coast, evacuation proceeded smoothly in the area where civil defense officials had trained citizens in emergency response in case of an accident at the Seabrook nuclear power plant (Boston Globe, October 1996).

In the case of the Three Mile Island (TMI) incident, retrospective research (Houts, 1986) indicates that there was little physical harm to residents, or the environment, as a result of the actual accident at the nuclear reactor. However there were social impacts, such as disruptions in work and school, and psychological stress that did impact the economy. While Houts 
(Ibid) defines the social effects of TMI to be limited, and near the event in time, a slightly different scenario could have caused far greater adverse impacts, both economic and social. Thus, it seems important to rigorously evaluate potential accident scenarios and develop contingency plans to address them. For a community hosting a LLRW disposal facility, what patterns are present that may create a significant potential for problems?

Noteworthy is that the scientific community and the public often perceive and value risks differently (Louisiana Department of Environmental Quality, 1995). For example, while the public ranks location near a hazardous waste site as highly problematic, the EPA considers other factors to be more dangerous to public health, such as health effects that occur from general urban air pollution and radon in homes (EPA, 1994). This points to the need to reconcile perceptions of risk between experts and citizens.

In many situations that involve predicting how to minimize risks from hazards, models contain assumptions and calculations that present complex situations in simplified patterns of probability for use in comparisons. A key topic in risk assessment is how to perfect modeling, so that error does not arise, or be transferred through mathematical models of risk to the extent that these are questionable. Building strong linkages between scientists that make calculations and policy analysts that apply such information to formulate alternatives is also 
necessary. A result will be that systems analysts will be better informed as to what is important scientific uncertainty versus that which is not central to policy analysis at hand.

Suggestions to improve risk communication and policy analysis using risk assessment are:

- Making greater efforts to identify where there is uncertainty;

- Making explicit descriptions of to what extent health and safety policy is based on uncertain information;

- Attempting to define what are assumptions versus widely accepted scientific fact;

- Discussing what value to place on uncertainty;

- Requiring elaborate efforts to address uncertainty, describe the reasons it is believed to exist, and how it was dealt with in models;

- Encouraging more scenario building and evaluation of more policy alternatives; and

- Explain how to obtain needed information.

\section{Establishing a Role for Personal Communication in the Design of Alternatives}

Case studies show that it is often important to cultivate socio-political support for a siting within a region early on rather than choose an actual site or a technology to be utilized (Castle, 1993; EPA, 1989; Kasperson, et al 1983). This socio-political support seems necessary to enable further debate that is sophisticated and detail oriented. 
The public depends on experts and government officials for processed information and education. People seek to understand how experts place value on information and reach decisions (Houts, et al, 1988). Often planners use story telling to establish meaning, help groups assess values, and define social goals and alternatives. Based on cases reviewed, people may feel alienated from decision-making processes that are exclusive. It is worthwhile to use techniques to encourage small group and one-on-one participation in decision making. With awareness that the subject of nuclear disposal facility siting presents potential to convey pshycological stress on communities, clearly attempting to address such fears, such as providing funding for extensive emergency response procedures, may prevent attitudes from forming that there is not a commitment to safety. Demonstrating flexibility can show that designs are not final. And personal communication and small group discussion can define crucial issues and design alternatives that are meaningful and acceptable to stakeholders.

\section{How Should Cumulative Adverse Impacts Be Controlled?}

Small impacts that are inherently difficult to account for and mitigate at a projects inception, or ones which combine with impacts from other projects over a long period of time to demonstrate a noticeable impact are not often addressed in traditional environmental impact analysis (Olshansky, 1996). Examples of cumulative development impacts are poor regional air quality or species decline though habitat loss. 
It is planners that can promote the review of competing paradigms so that meaningful alternatives are designed which consider future scenarios and the effects of development on community character in the long-range. A planner is a particular professional who has the responsibility to promote awareness of community character, the local social fabric, and the systems that affect it in the future. Planners are specifically trained to be aware of social and economic mechanisms used to identify potential effects, predict their prevalence, and help identify alternatives that may present less overall impact. Having long range development plans in place, such as progressive zoning ordinances, master plans, and community comprehensive plans can ensure that there are performance standards established with which to benchmark potential impacts of development.

This discussion also points to a need of global standards for public health protection. Many human behaviors are affecting time-space relationships on a global scare, and doing so with impacts that are immense. Environmental health standards that are promulgated by international organizations, such as the World Health Organization (W.H.O.), do promote awareness of the ecological affects of development on a global scale. Such an organizarion also provides a forum to address international global problems. It seems that a necessary ingredient of local control over evaluations of impacts should be use and recognition of global standards such as are promoted by the WHO or the International Union of Concerned Scientists. 


\section{Addressing Equity Issues in LLRW Management}

A review of 'Locally Unwanted Land Uses' shows that there have been many instances where areas of low political resistance, such as areas of low socio-economic status, have been targeted for site development with the effect that local residents directly experienced adverse effects of development. More recently there seems to be commitment by governments to avoid such 'environmental injustice' and promote compensation for sitings. There is more awareness of this problem, and sophisticated tactics have evolved for responding to it.

In communities that have experienced adverse effects of development there is often a local capacity to oppose development (Hamilton, 1989). For example, with support of regional ecological advocacy groups, a community can build an effective opposition network. If a community wants to halt a local siting, it appears that they can often do so with intense political opposition. There is often need for more for diplomacy rather than creating impasse. Lawsuits and hostility should not be the only option available to block development.

In order to address prominent social and institutional problems in a LLRW land use siting Kasperson (1983: 332), advocates for "explicit consideration of equity issues" with a goal to define an equitable and socially acceptable waste management system. The author notes (Ibid) that besides defining benefits and costs, effected populations, and postulating impacts of alternatives, moral analysis can be used for technological choice by establishing 
".... a set of standards or principles by which the equity or 'fairness' of particular distributions may be judged and by which the social preferability of one distribution over another may be judged" (Ibid).

Kasperson (Ibid) notes that what is highly contestable and debatable is what equity principles to use in such analysis. Some of the examples of equity principles are:

- Utilitarianism;

- Parieto Optimality;

- Equality;

- Freedom of Choice; and

- Rawlsian Procedures of Justice.

Three principles that have wide acceptance in society are that:

1. Beneficiaries (LLRW producers/users) should bear burdens for cost of disposal;

2. Risk should be shared; and

3. Imposition of harm should be made as voluntary as possible through informed consent (Ibid).

To build on Kasperson's recommendations, one objective in Massachusetts should be to encourage examination of equity issues in early stages of site identification and site assessment. This could include capacity building among State or community stakeholders or the use of consultants to aid such an endeavor. 
While responsibility for direct disposal costs (such as operating costs) are charged to users, it is not apparent whether LLRW producers have typically borne the full range of costs of management. Great public expense can be incurred to respond to externalities (adverse social impacts) or protect against potential accidents (Ibid). An examination of equity issues should concern distributional impacts of policy.

Practices to ensure that equity issues are addressed, and benefits enjoyed by all in sitings are:

- Continued responsibility for siting centered in the public domain. Many experts note that this is more inefficient than private responsibility for waste and siting, but helps improve accountability (Kasperson, et al, 1983; Vari, et al, 1994);

- Recognize alternative paradigms, such as the 'Limits to Growth Debate' (Hamilton, 1992), which encourages incorporating sustainable development practices into development. Recognizing alternative values and cultures can ensure that community preferences are not ignored. It also ensures that the design of incentive and compensation is directed towards popular (also fair) values and social goals;

- Assign another government body, a sort of ombudsman, responsibility to monitor and oversee the central authority (Vari, 19). Checks and balances add legitimacy to a process. Legitimacy is a characteristic that many quasi-public authorities and administrative law judges do not seem to have; 
- Grant regional advisory groups (such as unions, charities, or environmental groups) involvement in site and method selection;

- Allow and encourage voluntary participation in siting administration at the local level. For example, in the Canadian CAC models, anyone wishing to participate was given an opportunity to serve on committees. Advantages are:

- People are less likely to legitimately claim being left out of decision-making;

- The public will not view authorities as imposing decisions on locations;

- The process is not susceptible to public discontent regarding assignment of representatives to administrative bodies by elected officials (Castle, 1989);

- Ensure that outreach efforts are extensive. Focus a portion of public outreach on obtaining participation of typically disadvantaged groups and regions;

- Commit to meeting schedules and forms of participation that are inclusive and are not likely to exclude members of frequently disadvantaged groups. For example: hold meetings on a diverse schedule of times and days; conduct canvassing equally in all neighborhoods; and do not rely on only phone solicitation; or provide special stipend grants to enable low income persons to be involved in public processes.

- Kasperson et al (1983) recommend using lottery techniques to select among sites. Perhaps this is a fair way to select among communities that seek to host a facility. 


\section{Limitations to a Focus on Values/ Preference}

Even with an emphasis on attaining equity, problems are likely to remain such as:

- Valuing criteria;

- Establishing eligibility criteria (such as who is entitled to property value protection);

- Defining types of compensation; and

- Defining methods for distributing compensation (Ibid).

In a comparison of issues definition and policy preferences across a set of facility sitings, (Minton, 1996; Priestly and Cohen, 1995) found that many similar trends occur in how stakeholders value different alternatives and rank preferences. And collaboration between interest groups, especially when facilitated by experts, can reduce contention and produce outcomes widely perceived as legitimate (ibid). A shortcoming of a reliance on stated values of stakeholders is that they may overemphasize preferences (Houts, et al, 1988). It is recommended that research be conducted to examine when people are prone to exaggerate, and why. Similarly, when discussing alternatives and social conditions, effort should be taken to identify and eliminate bias, such as when there are problems with a particular survey method employed, or there is a potential for bias from a sub-group of respondents. 


\section{Modifications to Public Administration and Policy to Encourage Successful Sitings.}

\section{Coherent and Consistent Government Policy Aids Sitings}

In comparing practices that influence international success in LLRW sitings, Vari, et al (1994) note that there is typically more coherent state nuclear policy in foreign countries. For example, Sweden identifies waste management as integral to a national energy policy that has involved nuclear power (Ibid). The advantage is that the public better understands the context of planing decisions (such as a determination to develop a LLRW facility). The public also understands benefits derived from nuclear industry and nuclear materials such as in nuclear medicine. Explicit expressions that a government seeks to safely manage radioactive waste remind the public of the commitment and becomes part of the mind set of both officials effectuating policy as well as the public (Ibid). This helps promote needs of the large region so that local demands do not become too powerful.

In the U.S. there does not seem to be planned development of a national energy policy. Compared with other countries energy is inexpensive. Agencies involved in energy policy such as the Department of Energy, and other nuclear energy stakeholders, such as the Atomic Energy Commission, Nuclear Regulatory Commission, or the Department of Defense do not traditionally have visible public roles, especially outside of Washington and regions with federal installations. The public is more likely to consider their role as concerned with defense. One reason may be that these agencies have a history of being staffed by experts and 
working in isolation (during the cold war era), or with industry, rather than with the public (Balogh, 1991). In a similar way, it seems that the public does not perceive the EPA to have a role in energy policy. In the last five years, DOE policy has changed to include as major objectives 1) being visible and accessible where a Federal issues may impact communities, and 2) addressing environmental hazards at federal facilities. However, federal budget downsizing has prevented these issues from being fully implemented.

In foreign countries there is more consistency in providing clarity in stated goals of sitings as well as concrete definitions of waste sources and volumes (Ibid). This translates into higher levels of support (Vari, 1994). Clear goals, and clearly articulated underlying assumptions help control rumors. These can also help prevent being bogged down in statistical discrepancies and uncertainties that are not important to the main problem and do not effect the orientation of the analysis system (Fisher, 1971). Massachusetts would benefit from more concise summaries of predicted nuclear materials loadings, and more explicit policy statements. Political posturing and an unclear agenda convey a sense of secrecy or an unclear mission.

\section{Developing a System of Social and Scientific Indicators Will Aid LLRW Management} Innes (1990) discusses the process of formulating social indicators and using them in policy development and politics. Institutionalizing indicators is important, but takes a long time (Ibid). Massachusetts does not have well processed statistics. Nor does the Board provide 
discussion of statistics in the context of problems and objectives. Doing so in an unbiased fashion would aid debate and should involve social scientists.

\section{Role of Legislature/ Governor}

Heavy legislative involvement, such as by a state congress, is interpreted to help build public support and legitimacy for decisions; however, such involvement can result in the processes becoming less goal centered and time consuming (Vari et al, 1994). In Massachusetts, it is unclear whether the legislative helps or hinder the process. Currently the LLRWMB budget and bond issue approval are authorized by this branch of government. Involving the legislature could help build links to municipalities and promote local leadership.

\section{Compensation to Other Municipalities in the Region}

Vari (1994) considers it important to develop compensation and incentives packages that not only are supported by and benefit the host community, but which also are considered acceptable to more distant communities. Building regional cooperation will help avoid impasse. It would seem that a special regional planning authority, such as a CSC with a mission of focusing on fairness and equity issues in a concentric region around proposed communities, could better facilitate the design of popular alternatives than one based in a single city or town. 
Krumholtz (1988) discusses how equity was addressed by a Cleveland area regional transportation board. The Massachusetts Water Resources Authority (MWRA) is a regional authority. A similar quasi-independent authority may be useful for pursuing development objectives that cannot by law be carried out by the LLRWMB. While the MWRA is often cited as wasteful, it receives attention in the literature for extensive efforts at impact mitigation and consensus building. Its compensation and impact payments are also noteworthy (Gregory and Kunreuther, 1990).

\section{Why Extensive Rule Codification May be Problematic}

In the U.S., difficulties in siting often occur due to stakeholder belief that there is little opportunity to participate meaningfully in decision making (Vari, et al, 1994). In Massachusetts many policies that involve compensation and impact payments are already codified in law. For example, there are extensive screening procedures to establish what communities can consider hosting a site, according to factors such as population density or susceptibility to flooding. Rather than develop extensive screening procedures for site selection, communities should be encouraged to develop the screening criteria independently. A role of the State to provide guidance and facilitation could be accomplished without the extensive rules and procedures.

Another problem could be present if extensive and detailed plans and procedures are formulated to provide for public access and input, but are not followed. In meetings of the 
LLRWMB, efforts are always made to open the floor to comments. This is commendable. In controversial debates, or at points of action by the board, such as votes, the public appears to always have opportunity for comment. A strong commitment to public participation publicly viewed as legitimate, would appear to aid decision making and should continue. The LLRWMB should avoid developing regulations and programs that do not have a funding source established.

\section{Methods for Municipal Financial Impact Assessment}

Discussion shows that long-range planning techniques, such as comprehensive plan formulation and social science evaluation methodologies, can help predict how a major project may impact local social systems and public finance. One important item is to understand linkages and interconnections in the economy in order to estimate effects on area and regional fiscal systems when considering LLRW facility siting. As they exist, Massachusetts regulations do not provide other communities in surrounding regions opportunities to review impacts and possibly receive compensation. Negotiation should occur early on to explore suitable agreements that could otherwise hamper siting.

It seems that many municipal government finance professionals are concerned with strict financial accounting, rather than economic evaluation that is qualitative in nature. Sophisticated techniques are required to show how financial costs are incurred on governments and groups of people as a result of major projects. While planners seem to carry 
out this role, it may be that the discipline does not often employ tools for economic analysis that other public officials or the public are familiar with. One recommendation may be to provide the public and local officials with training in such techniques to enable more sophisticated analysis and clear communication.

Defining criteria and measuring outputs of a public agency, including the utilization of methods to determine unit costs, are examples of skills required to improve decision making and which may aid evaluation about relationships between the size of jurisdictions and efficiency (Heilbrun, 1986:427-428). While the philosophy of planning is not specifically concerned with efficiency, per se, it is an important comparative criterion, if for no other reason than it is a dominant paradigm and equity discussion can be built on it.

\section{A Demonstrated Importance for Economic Development Planning}

In order for economic impact evaluation to occur, it is highly beneficial for a community to already have in place a comprehensive economic planning strategy and function that is based on an analysis of the characteristics and qualities of the community, as well as an inventory and evaluation of needs. This relates directly to social values and public goods. The problem at hand demonstrates the value of performing such analysis. Benefits of performing economic planning are increased understanding of the local economy and overall social system, and 
better public understanding and commitment to planned economic development strategy. In discussing the economic development profession, Blakely (1989: 290) notes:

"The total community or area circumstances must be taken into consideration in assessing the economic development need as well as in determining the priorities for action. The atmosphere in which the change is to be made is as important as the change itself. As a result, the Economic Development [ED] specialist must reach well beyond technical know-how to help the community see itself as a social and physical entity...In addition to getting the economic geography right, the ED specialist must also assist the community in getting the problem right.

As Blakely (Ibid) suggests, a community that has already performed economic analysis and planning will be in a better position to react to developments in the marketplace.

\section{Appropriate Level of Subsidy/ Incentive?}

It would seem that for facility siting, when no communities express interest in a siting, as has often been the case for LLRW facility siting in the U.S., that market economics dictate that the level of incentives should be incrementally increased until communities express interest in hosting a site. The alternative of realizing a siting soon because the incentive is sufficient to stimulate interest in development is for costs to continue to be accrued to operate bureaucracy to deal with the interim.

State and regional governments should assume a role coordinating facility siting and funding. These bodies can regulate to ensure that facilities are not disproportionately grouped in 
regions where communities lack resources to block sitings. Such governments could also use policy to ensure that municipalities that routinely avoid local sitings of regional facilities, are required to subsidize such development in other regions.

\section{LLRW Producers Should Fund Facility Development}

The LLRW Management Fund is established specifically to fund the LLRW Management Plan implementation. The fund is supported by annual assessments to entities licensed to process radioactive material in Massachusetts. A potential problem is that the total amount assessed in one year may not exceed $\$ 500,000$. This figure seems arbitrary. Funds are to be used to cover facility operating costs, but it is not clear what is the relationship between the fees collected and costs to manage waste produced. Studies are needed to determine if LLRW generators should be assessed more taxes to cover program costs. Schedules of surcharges may be developed and State bonds have also been authorized to fund development, finance for which will be paid by producers.

Placing the financial responsibility for radioactive waste management with direct users would appear to be the scenario with the least regressive fiscal implications. Taxation encourages LLRW generators to innovate and adopt more beneficial waste management practices. Placing financial responsibility on producers eliminates politically connected organizations from influencing policy to the advantage of those entities. It is important to reduce regressive 
taxation where all citizens assume the burden of funding facility development, unless it makes sense to subsidize the market to keep it active. Financially powerful and sophisticated organizations, such as multinational corporations and prestigious hospitals and universities, have used extensive lobbying apparatuses to influence development of poor public policy and deflect responsibilities of LLRW producers.

LLRW generators could claim that policies place exorbitant expense on doing business; they may threaten moving an enterprise, or future endeavors, out of State to avoid such expense. Yet, in many economic development negotiations involving public subsidy to attract development, public officials act irrationally. They grant concessions and make poor estimates of corporate negotiating positions that result in public agencies providing subsidy that is not required to attract development. If the Federal LLRW management system works correctly, costs of management should occur uniformly across all states. Here is a case, similar to debates concerning public subsidy of sports stadiums development, where policy should be developed to dissuade competition at the expense of other regions.

\section{Enforcement}

If the LLRWMB finds that licensees are not complying with regulations, it may leverage civil penalties to ensure that non-compliance is more expensive than compliance. The state should enforce rules to promote compliance. Sometimes the relationship between the fine leveraged 
and the crime committed is unclear. It also seems that many regulations are selectively enforced. While initiatives to promote source reduction and voluntary compliance are beneficial, there must be enforcement for these programs to succeed because officials will experience pressure to innovate.

\section{Promote the Use of Standard Scientific Terminology}

Based on research conducted during this project, it is the opinion of the author that experts and lay people seldom communicate about issues of LLRW management using the established scientific terminology of dose, exposure, and technical management. There should be explicit efforts to do so because it promotes ranking of risks and the evaluation of policy according to accepted standards and practices. Promoting understanding of the technical terminology and encouraging its use prevents speculation that is not crucial or central to policy debates. 


\section{Conclusion}

In the 1980s the Commonwealth embarked on an ambitious program to effectuate low-level radioactive waste management. Since siting a facility was a major objective, a process was formulated to include potential communities in the site selection process and offer incentive to host a site. Since then, more research has occurred on successful siting, the results of which should be incorporated into the program to ensure success. Important is an awareness of how to develop policy in a collaborative/ iterative fashion to ensure that stakeholders are educated about issues -- and that they feel a stake in the outcome. This should ensure that fears and uncertainty are adequately addressed and will identify methods to mitigate unwanted effects. To succeed with a collaborative approach, it is important for government officals to be consistent in following-up on the policies collectively developed.

Right now there is little support from any stakeholders to site an in-state facility. Some resistance to siting may be due to inconsistency or lack of commitment to the process by the executive branch. There is not a clear State nuclear policy. Public knowledge must be promoted regarding the likelihood that LLRW can be managed safely with given technology and the state of the art of many disciplines that would be involved with facility siting and management. Leadership in defining whether there is adequate in-state demand for a facility, and commitment to a system to address the local and regional aspects of the siting problem, can help set-up an environment conducive to a siting. There is a need for consistency from 
State Government, including clear interpretations of the meanings of regulations and how policy will be enforced.

Building cooperation with local residents to reduce community opposition to a siting may cause other stakeholders to enter negotiations on behalf of actually implementing a siting. This would be because a major source of opposition to siting would be eliminated and groups opposed to a siting, such as environmentalists, corporations and institutions, would be forced to re-evaluate the degree of political leverage they possess.

A great deal of incentive seems available to a community to host a facility should site selection get to that stage. Outside of complete control which is not possible, the process does promote public awareness and planned impacts. It seems that with the level of incentive offered, and a commitment to faimess, that adverse impacts on community will be more than offset by the positive impacts will occur, and to some extent can be planned. A no action alternative is risky at the state level due to potential for accident and occupational exposure. In addition, inaction in developing a state of the art facility to manage LLRW may result in the continued use of other technologies which convey equal amounts of risk and adverse impacts to society. 


\section{References}

Air and Radiation Division. August, 1994. Radioactive Waste Disposal: An Environmental Perspective. Washington, D. C. United States Environmental Protection Agency.

American Planning Association. 1985. Use of Compensation and Incentives in Siting Low-Level Radioactive Waste Disposal Facilities. DOE?LLW-42T. U.S. Dept. of Energy, National Low-Level Radioactive Waste Management Program. Idaho Falls, Idaho. April, 1985.

Amick, Carol. 1994. Personal Telephone Interview with LLRWMB Executive Director. Boston. November 12.

Amick, Carol C. March 27, 1996. Staff Discussion Draft: Options to Consider in Reviewing The Level of Management Board Siting Activities. Low-Level Radioactive Waste Management Board: Boston.

Armour, A., Bowran, E., Miller, E., et al. 1977. A Framework for Community Impact Assessment. In K. Finsterbusch and C.P. ed. Methodology of Social Impact Assessment. New York: McGraw-Hill.

Bierstedt, Robert. 1974. The Social Order, 4th Ed. New York: McGraw-Hill.

Blakely, Edward. 1989. Planning Local Economic Development. Newbury Park, CA: Sage Publications.

Bolagh, Brian. 1991. Chain Reaction: Expert debate and Public participation in American Commercial Nuclear Power. New York: Cambridge University press.

Brown, P.A. and Pollack, R.W. 1993. Low-Level radioactive Waste Management in Canada. In Low-Level Radioactive Waste Environmental Remidiation and Environmental Management Issues, Vol. 3. New York: American Society of Mechanical Engineers.

Bullard, Robert D. 1990. Dumping in Dixie. Boulder, Co.: Westview Press, Inc.

Bullard, Robert D. 1992. In Our Backyards. EPA Journal, Vol. 18, Nu. 1 March/April. Washington, D.C.: U.S. E.P.A.

Burns, Michael E. 1988. LLRW Regulation: Science Politics and Fear. Chelsea, Michigan: Lewis Publishers. 
Cadmus Group. April 18, 1996. Environmental Risk Management Trends. Presented to Associated Industries of Massachusetts. Westboro.

Capra, Fritjof. 1982, The Turning point: Science, Society, and the Rising Culture. New York: Bantam Books.

Carley, M.J. and Bustelo, E.S. 1984. Social Impact Assessment and monitoring. Boulder and London: Westview Press.

Castle, Geoffrey. 1993. Hazardous Waste Facility Siting in Manitoba: Case Study of a Success. Air \& Waste, Vol. 43, July 1993, 963-969.

Cochrun, Steven. 1994. Defining, Understanding, and Enhancing Sense of Community in Neighborhoods. Journal of Planning Literature 9,1: 92-9.

Commonwealth of Massachusetts. 1987. The Low-Level Radioactive Waste Management Plan (345 CMR 1.00). Boston

Covello, V. T. and Slovic. 1988. Risk Communication, Risk Statistics, and Risk Comparisons: A Manual for Plant Managers. Chemical Manufacturer's Association. Washington.

Daniels, B. and C. Tilly. 1985. Community economic Development: Seven guiding Principles. Resources 3(11). Washington D. C. Congress for Community Economic Development.

Department of Environmental Health. 1991. Kinwait Oil Fires Conference. Harvard University School of Public Health. June. Cambridge, Ma: Two day conference at the American Academy of Arts and Science on health effects of the Gulf War.

Dorfman, Robert, ed. 1965. Measuring Benefits of Government Investments. Washington, D. C. : Brookings Institution.

Duncan and Jones. 1976. Methodology and Guidelines for Assessing Social Impacts of Development. Berkeley: Duncan and Jones, Inc.

EG\&G Idaho. February 1994. Estimating Costs of Low-Level Radioactive Waste Disposal Alternatives for the Commonwealth of Massachusetts. Idaho Falls, Idaho: U.S. DOE National Low-level Waste Management 
Emaleh, David S. March, 1995. Personal Interview with Massachusetts General Hospital Associate Professor. Boston, MA.

Emaleh, David S. December, 1994. Personal Interview with Massachusetts General Hospital Associate Professor. Boston, MA.

Exchange Monitor Publications, Inc. 1996. Cost, Lack of Disposal Capacity Cuts Beneficial use of Radioisotopes. Radioactive Waste Exchange. Washington D.C , January 26.

Executive Office of Environmental Affairs. March, 1996. Boston.

Finsterbusch, K., and Wolf. 1977. Methodology of Social Impacts Assessment. Stroudsburg, PA: Dowden, Hutchinson, and Ross.

Finsterbusch, K. 1980. Understanding Social Impacts: Assessing the Effects of Public Projects. Beverly Hills and London: Sage Publications.

Fischoff, B. 1977. Cost-Benefit Analysis and the Art of Motorcycle Maintenance. Policy Sciences 8, 177-202.

Fisher, G. H., ed. 1971. Cost Considerations in Systems Analysis. New York: Elsevier.

Friesma, H. Paul, and Paul J. Culhane. 1976. Social Impacts, Politics and the Environmental Impact Statement. Natural resources Journal 16,2: 339-56.

Forester, John. 1989. Planning in the Face of Power. Berkeley: University of California Press.

Glynn, Thomas J. 1981. Phychological Sense of Community: Measurement and Application. Human relations 34,7:789-818.

Gramling, Robert and William R. Freudenburg. 1992. Opportunity-threat, Development, and Adaptation: Toward a Comprehensive Framework for Social Impact Assessment. Rural Socialogy 57(2), 216-234.

Gruber, W. 1992. Community Incentives. EI Digest. New York: Environmental Information, Ltd. February. 
Hamilton, Cynthia. 1993. Confronting Environmental Racism. Cited in Bullard, Robert, Editor.

Hance, et al, 1990

Havel, Vaclav. 1991. Open Letters: Selected Writings 1965 - 1990. New York. Alfred A. Knoph.

Haveman, Robert H. 1972. The Economic Performance of Public Investments: An Ex Post Evaluation of Water Resources Investments. Baltimore: John Hopkins University Press.

Helm, Dieter, Ed. 1991. Economic Policy Towards the Environment. Cambridge, MA: Blackwell Publishers.

Helminski, Edward L., Editor. March 17, 1996. The Radioactive Exchange. Washington, D.C.: Exchange Publications.

Hennekens, Charles H. and Buring, Julie E. 1987. Epidemiology in Medicine. Boston; Little Brown and $\mathrm{Co}$.

Houts, Peter S., et al,. 1988 The Three Mile Island Crisis: Psychological, Social and Economic Impacts on the Surrounding Population. University Park: The Pennsylvania State University press.

Howard, R.A. 1980. An Assessment of Decision Analysis. Operations Research 28(1), 4-24.

Hustedde, R., Shaffer, R., and G. Pulver. 1988. Community Economic Analysis: A How To Manual. Ames, Iowa: Iowa State University North Central Regional Center for Rural Development.

Innnes, Judith. 1990. Knowledge and Public Policy: the search for meaningful indicators, 2nd Ed. New Brunswick, New Jersey: Transaction Publishers.

Johnson, Beverly. June 16, 1995. Telephone Personal Interview with LLRWMB Staffperson. Boston.

Kaplan, T. J. 1986. The narrative Structure of Policy Analysis. Journal of Policy Analysis and Management 5(4), 761-778. 
Kasperson and Stallen, 1991

Kasperson, Roger E., Editor. 1983. Equity Issues In radioactive Waste Management. Cambridge, MA: Oelgeshlager, Gunn \& Hain, Publishers, Inc.

Kent, T.J., Jr. 1964. The Urban General Plan. Chicago: APA Press.

Kidd, Keith. 1995. Personal Interview with Tufts University Environmental Health and Safety Officer. Boston: August 1995.

Krumholtz, Norman and Forester, John. 1990. Making Equity Planning Work. Philadelphia: Temple University Press.

Luedtke, Gerald. Winter, 1995. How to Conduct a Community Aesthetics Evaluation. Michigan Chapter of APA.

Linestone, H. A., and Turoff, M., eds. 1975. The Delphi Method: Technioques and Applications. Reading, MA: Addison-Wesley.

Lippman, Morton and Schlesinger, Richard B. 1979. Chemical Contamination in the Human Environment. New York: Oxford University Press.

Lynch, Kevin. 1960. The Image of the City. Bostom: The M.I.T. Press.

Lyon, Larry. 1987. The Commuity in Urban Society. Chicago: Dorsey press.

Luedtke, Gerald. 1985. How to Conduct a Community Aesthetics Evaluation. Michigan Planner, Winter. Ann Arbor: Michigan American Planning Association.

Madansky, Albert. 1968. Uncertainty, in Systems Analysis and Policy Planning (E.S. Quade and W. Boucher, eds.). New York: Elsevier, pp. 81-96.

Massachusetts Department of Public Health. 1987. Chapter 111H. Massachusetts LowLevel Radioactive Waste Management Act. Boston.

Massachusetts Department of Public Health. July 13-14, 1995. Improving Risk Communication Through Community Involvement. Boston.

Massachusetts Low-Level Radioactive Waste Management Board. Winter, 1996. LLRW Up-Front. Volume 5, Number 1. Boston. 
Massachusetts Low-Level Radioactive Waste Management Board. March 27, 1996. Management Board Monthly Meeting. Boston.

Massachusetts Low-Level Radioactive Waste Management Board. December, 1993. Management Board Monthly Meeting Minutes. Boston.

Massachusetts Low-Level Radioactive Waste Management Board. February 16, 1994. Management Board Monthly Meeting Minutes. Boston.

Massachusetts Low-Level Radioactive Waste Management Board. April 4, 1995. Proposed Additional Revisions to 345 CMR 1.00. Boston.

Massachusetts Low-Level Radioactive Waste Management Board. November 1994. 1993 Massachusetts Low-Level Radioactive Waste Survey Report. Boston.

Massachusetts Low-Level Radioactive Waste Management Board. January 1996. 1994 Massachusetts Low-Level Radioactive Waste Survey Report. Boston.

Massachusetts Low-Level Radioactive Waste Management Board. December, 1993. Management Board Monthly Meeting Minutes. Boston.

Massachusetts Low-Level Radioactive Waste Management Board. January, 1994. LowLevel Radioactive Waste Management Plan, Volume II. Boston.

Massachusetts Low-Level Radioactive Waste Management Board. April 12,1995. Site Selection. Boston.

Massachusetts Low-Level Radioactive Waste Management Board. April 12, 1995. Monthly Management Board Meeting and Public Hearing. Boston.

Massachusetts Low-Level Radioactive Waste Management Board. January, 1994. LowLevel Radioactive Waste Management Plan, Volume I. Boston.

McKean, Roland N. 1967. Cost and Benefits from Different Viewpoints, in Planning, Programming, Budgeting (F.J. Lyden and Ernest G. Miller, eds.). Chicago: Marcam, pp. 199-220.

Mckelway, Ben. 1996. Telephone Interview with the Massachusetts Low-Level Radioactive Waste Management Board Public information Officer. February. Boston. 
McMillan, David W., and D.M. Chavis. 1986. Sense of Community: A Theory and Definition. American Journal of Community Psychology 14,1:6-23.

Miller, G. Tyler, Jr. 1985. Living in the Environment, 4th Edition. Belmont, CA: Wadsworth Publishing Co.

Mishan, E.J. 1971. Cost Benefit Analysis. New York: Praeger.

Moeller, Dade W. 1992. Yucca Mountain High-Level Radioactive Waste Disposal Site. Boston: Harvard School of Public Health, Department of Environmental Health Lunchtime Speaker Series.

Mohai, Paul and Bunyan, Bryant. 1992. Race, Poverty and the Environment. EPA Journal, Vol. 18, Nu. 1 March/April. Washington, D.C.: U.S. E.P.A.

Nagel, T. (1993, Summer) Equal Treatment and Compensatory Discrimination. Philosophy and Public Affairs 2, 348-363.

Nasar, Jack L. and Julian, David A. 1995. The Psychological Sense of Community in the Neighborhood. Journal of the American Planning Association, Sping 1995, Vol 61, No. 2.

National Public Radio. March, 1996. News Story on Issues and Political Status on Barnstable, North Carolina Low-Level Radioactive Waste Disposal Facility. Washington, D. C.

Nuclear Energy Institute. Seeking Solution. March, 1995. Washington, D.C. PotoMac Communications Group, Inc.

Office of Environmental Management. November, 1994. Public Participation Starter Kit. United States Department of Energy. Washington, D. C.

Office of Emergency and Remedial Response. January, 1992. Community relations in Superfund: A Handbook. United States Environmental Protection Agency. Washington D. C.

Office of Environmental Management. 1995. The DOE Clean Sites Program. U.S. Department of Energy. Washington D. C.

Olshansky, Robert P. 1996. The California Environmental Quality Act and Local Planning. Journal of the American Planning Association, Vol. 62 (3) 313-330. 
Peele, Elizabeth. 1974. Social Effects of Nuclear Power Plants. In Social Impact Assessment, Charles Wolf, ed. Environmental Design research Center. 113-20.

Pendall, Rolf. 1996. Environmental Impact Assessment: the state of the states, and some issues for local government. Environmental Planning Quarterly, Vol 13, No. 3. Chicago: American Planning Association.

Pinel, Sandra Lee. 1992. Draft, Social Impact Assessment Sensitizes Planning. In Agenda for America's Communities. Chicago: American Planning Association.

Priestley, Thomas and Cohen, Daniel. 1995. The Public and Electric Facility Siting. Environmental Planning Quarterly Vol. 12, No. 2 Spring 1995. Indianapolis, IN: Center for Urban Policy and the Environment.

Quade, E.S. 1989. Analysis for Public Decisions, 3rd Ed. Englewood Cliffs, New Jersey. Prentice-Hall, Inc.

Rawls, J. 1971. A theory of Justice. Cambridge, MA The Belknap Press of Harvard University Press.

Resources, Community, and Economic Development Division. January, 1996. Environmental management: An Integrated Approach Could Reduce Pollution and increase Regulatory Efficiency. Washington: U.S. General Accounting Office.

Ross, David P. and Peter J. Usher. 1986. From the Roots Up: Economic Development as if Community Mattered. Croton-on-Hudson, New York: The Bootstrap Press.

Sackman, H. 1975. Delphi Critique: Expert Opinion, Forecasting, and Group Process. Lexington: Heath.

Schon, Donald. 1983. The Reflective Practitioner. Basic Books.

Schwab, Jim. 1993. Environmental LULUs: Is There an Equitable Solution? Chicago: American Planning Association, APA Urban Agenda Policy Statement.

Selieg, Stephen, Esq. 1995. Overview of Risk Communication Principles. Presented at Massachusetts Department of Public Health, Bureau of Environmental Health seminar, Improving Risk Communication Through Community Involvement. July 13-14. Boston.

Shimizu, Y., Kato, H., and Schull, W.J. 1990. Studies of the Mortality of A-bomb 
Survivors: Report 9: Mortality, 1950-1985. Radiation Reseach. 1990: 121:120141.

Shlay, A. B. and Holupka, C. S. 1993. Political Economy and Urban Development. In R. D. Bingham, et al (eds.) Economic Development in the United States: Towards a theoretical perspective. Newbury Park, CA: Sage.

Sigmon, E. 1987. Achieving a Compensated Agreement in Siting: The MRS Case. Journal of Policy Analysis and Management. No. 6. New York: Association for Public Policy Analysis and Management.

So, Frank and Getzels, Judith, eds. 1988. The Practice of Local Government Planning, 2nd Edition. Washington: internation City Management Association.

Stea. D. and C. Buge. 1982. Southern Pauite People: SIA Responses to Energy proposals. In Geisler, Green, Usner and West, eds.

Struhs, David B., Commissioner. April 16, 1996. Memorandum and Attachments on DEP Implementation of Governor Weld's Executive Order to Reduce Unnecessary Regulatory Burden. Boston: Executive Office of Environmental Affairs.

Sugden, R. and Williams, A. 1978. The Principles of Practical Cost-Benefit Analysis. Oxford: Oxford University Press.

Susskind, Lawrence and Cruikshank, Jeffrey. December, 1987. Breaking the Impasse: Consensual Approaches to Resolving Public Disputes. Basic Books, 1987.

Tang, Y.S. and Saling, J.H. 1988. Radioactive Waste Management. New York:

Tauxe, Caroline S. 1995. Marginalizing Public Participation in Local Planning. Journal of the American planning Association 61,4: 471-481.

Thompson, Hagan. december, 1985. Community Says No to Incinerator. EPA Journal. Vol. 11, No. 10. Washington, D.C.: E.P.A. Office of Public Affairs.

Throgmorton, J.A. Fall 1992. Planning as Persuasive Storytelling about the Future: Negotiating an electric power rate settlement in Chicago. Journal of Planning Education and Research 12(1), 17-31.

Tietenberg, Tom. 1992. Environmental and Natural Resource Economics, 3rd Edition. New York: Harpers Collins Publishers. 
U.S. Committee for energy Awareness. 1984. Nuclear Energy; Moving Ahead. Washington, D. C.

U.S. Congress. 1980. The Comprehensive Environmental Response, Compensation, and Liability Act. Washington, D. C.

U.S. Congress. 1986. The Superfund Amendments and Reauthorization Act. Washington, D.C.

U.S. Congress. 19xx. The Emergency Planning and Community Right to Know Act. Washington D. C.

U.S. Congress. 1980. Low-Level Radioactive Waste Policy Act. Public law 96-573 42 U.S.C. section 2021 (b) - (d). Washington.

U.S. Congress. 1980. Low-Level Radioactive Waste Policy Act. Public law 96-573 42 U.S.C. section 2021 (b) - (d). Washington.

U.S. Congress. 1980. Low-Level Radioactive Waste Policy Act. Public law 96-573 42 U.S.C. section 2021 (b) - (d). Washington.

U.S. Congress. 1980. Low-Level Radioactive Waste Policy Amendments Act. Public law 99-240 42 U.S.C. section 2021 (b) et seq. Washington.

U.S. Congress. 1980. Low-Level Radioactive Waste Policy Amendments Act. Public law 99-240 42 U.S.C. section 2021 (b) et seq. Washington.

U.S. General Accounting Office. January, 1996. Environmental Management. GAO/RCED-96-41. Washington, D.C.

United Nations Educational, Scientific and Cultural Organization. Socio-economic Indications for Planning: Methodological Aspects and Selected Examples, No. 2. Paris: UNESCO.

United Curch of christ Commission for racial Justice. 1987. Toxic Wastes and Race in the United States: A National report on the racial and Socio-Economic Characteristics of Communities with Hazardous Waste Sites. New York: United Church of Christ Commission for Racial Justice.

Wabba, Daniel. 1995. Interview with DuPont Medical Products Employee. Boston: January. 
World Resources Institute. 1992. Environmental Almanac. Boston: Houghton and Mifflin Co. 